\title{
$5-2016$
}

\section{Exchange patterns and relations in collaborative governance.}

\author{
Charles Wharton Kaye-Essien \\ University of Louisville
}

Follow this and additional works at: https://ir.library.louisville.edu/etd

Part of the American Politics Commons, Behavioral Economics Commons, Comparative Politics Commons, Economic Policy Commons, Economic Theory Commons, Education Policy Commons, Emergency and Disaster Management Commons, Energy Policy Commons, Environmental Policy Commons, Environmental Studies Commons, Growth and Development Commons, Human Geography Commons, Income Distribution Commons, Industrial and Organizational Psychology Commons, Infrastructure Commons, Leadership Studies Commons, Organization Development Commons, Other Public Affairs, Public Policy and Public Administration Commons, Other Social and Behavioral Sciences Commons, Policy Design, Analysis, and Evaluation Commons, Political Economy Commons, Public Administration Commons, Public Affairs Commons, Public Economics Commons, Public Policy Commons, Regional Economics Commons, Social Policy Commons, Social Welfare Commons, Transportation Commons, Urban Studies Commons, and the Urban Studies and Planning Commons

\section{Recommended Citation}

Kaye-Essien, Charles Wharton, "Exchange patterns and relations in collaborative governance." (2016). Electronic Theses and Dissertations. Paper 2470.

https://doi.org/10.18297/etd/2470

This Doctoral Dissertation is brought to you for free and open access by ThinkIR: The University of Louisville's Institutional Repository. It has been accepted for inclusion in Electronic Theses and Dissertations by an authorized administrator of ThinkIR: The University of Louisville's Institutional Repository. This title appears here courtesy of the author, who has retained all other copyrights. For more information, please contact thinkir@louisville.edu. 


\title{
EXCHANGE PATTERNS AND RELATIONS IN COLLABORATIVE GOVERNANCE
}

\author{
by \\ Charles Wharton Kaye-Essien \\ B.Sc., Kwame Nkrumah University of Science \& Technology, 2005 \\ M.A., Ruhr University of Bochum, Germany, 2009 \\ MPA., University of the Western Cape, 2010
}

\begin{abstract}
A Dissertation
Submitted to the Faculty of the

College of Arts and Sciences of the University of Louisville

in Partial Fulfillment of the Requirements

for the Degree of
\end{abstract}

\author{
Doctor of Philosophy \\ in Urban and Public Affairs \\ Department of Urban and Public Affairs \\ University of Louisville \\ Louisville, Kentucky
}

May, 2016 
Copyright 2016 by Charles Wharton Kaye-Essien

All rights reserved 



\title{
EXCHANGE PATTERNS AND RELATIONSHIPS IN COLLABORATIVE GOVERNANCE
}

\author{
by \\ Charles Wharton Kaye-Essien \\ B.Sc., Kwame Nkrumah University of Science \& Technology, 2005 \\ M.A., Ruhr University of Bochum, Germany, 2009 \\ MPA., University of the Western Cape, 2010
}

A Dissertation Approved on

March, 29, 2016

by the following Dissertation Committee:

Janet Kelly, PhD (Dissertation Director)

Steve Koven, $\mathrm{PhD}$

Aaron Rollins, $\mathrm{PhD}$

Mathew Ruther, PhD

David Buckley, PhD 
In Loving Memory of my Dad

Edwin Annan Kaye-Essien

(1933-2013) 


\section{ACKNOWLEDGEMENT}

I first of all want to thank the almighty God for giving me the wisdom and inner strength to carry out this study from inception to completion. My sincerest gratitude also goes to my dissertation chair, Dr. Janet M. Kelly, whose mentorship, guidance and unflinching support throughout the stages of this research have contributed to this meaningful and scientifically substantiated paper.

I could not have put it all together without the solid backing of my dissertation committee members. That is why I also thank Dr. Steven G. Koven, Dr Aaron Rollins, Dr. Mathew Ruther and Dr. David Buckley for their guidance throughout the research

process. A special acknowledgement is given to Dr. Aaron Rollins in particular for his encouragement and unyielding support.

To all the staff at the School of Urban \& Public Affairs, particularly Dr. David Simpson, Dr. David Imbroscio, Juli Wagner and Patty Sally I say thank you for your administrative support. I cannot conclude without thanking Yanni Vozos whose reply to my first enquiry in 2012 led me to this PhD program. Thanks Yanni.

To my mum and siblings, I say thank you for your constant prayers. Finally, I could not have put all this together without the unflinching love and support of my wife Joko. I sincerely appreciate your decision to put your dreams on hold for mine.

God Bless You All!!! 


\title{
ABSTRACT
}

\section{EXCHANGE PATTERNS AND RELATIONS IN COLLABORATIVE GOVERNANCE}

\author{
Charles Wharton Kaye-Essien
}

May 13, 2016

Collaborative governance has received considerable attention in recent years. From environmental resource management to public safety, collaborative governance continues to play a vital role in regional problem solving. In spite of this increasing popularity previous attempts to model the political, economic, and demographic determinants of collaboration have in most cases produced inconsistent results, thereby undermining the ability to generalize from such findings. Additionally, our understanding of the relational patterns that emanate from collaborative agreements remains fairly rudimentary.

The main objective of this research is to address some of the gaps in the literature and improve our understanding of collaborative governance by examining existing patterns of collaboration in the Commonwealth of Kentucky. Using transaction cost economics theory and the concept of network embeddedness as theoretical lenses, the study examines collaborative governance by going beyond what already exists in current literature - determinants of collaboration - to explore what has barely been addressed patterns of collaboration. This research includes which services are the strongest candidates for collaboration, which levels of government are the best candidates for 
partnerships (vertical or horizontal) and what number of partners are appropriate for collaborative arrangements (bilateral or multilateral).

The units of analysis for this study are 'home rule' cities in Kentucky with populations above 230 people. A city-by-service cross-sectional pooled data was derived from existing agreements signed between years 2000 and 2013 to test the research hypotheses. Descriptive statistics were used to measure the relation between transaction characteristics and the pattern of collaboration while binary logistic regression models were used to test the relation between network embeddedness and the pattern of collaboration.

The findings of the study showed that compared to other public services, economic development services have a greater association with vertical collaboration whilst public safety services have a greater association with horizontal collaboration. Similarly, infrastructure services have a greater association with bilateral collaboration whilst public safety services have a greater association with multilateral collaboration. The study also corroborated previous findings that asset specificity and service measurability have strong influence on the likelihood of collaboration. With respect to the pattern of collaboration, the study indicated that compared to other transaction characteristics, services that have high levels of asset specificity but easily measurable have greater associations with vertical and bilateral collaborations. Similarly, services that have high levels of asset specificity and measurement difficulty have greater associations with horizontal and multilateral collaborations. With respect to network embededdness, the study established that repeated interaction in the past has the most significant influence on decisions to collaborate. 


\section{TABLE OF CONTENTS}

ACKNOWLEDGEMENT ............................................................................ iv

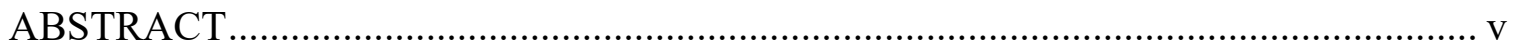

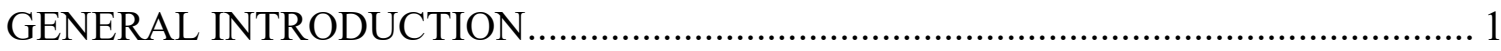

An Emerging Governance Model .................................................................... 1

Toward a Working Definition of Collaborative Governance..................................... 3

United yet Divided: America's Fragmented State .................................................... 5

A Case for Transactive Collaborative Governance ............................................... 7

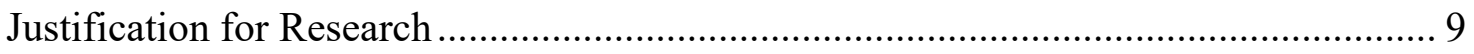

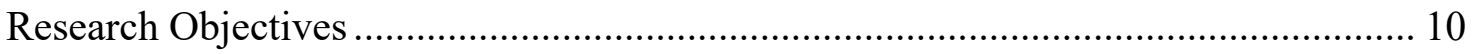

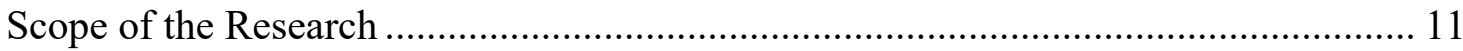

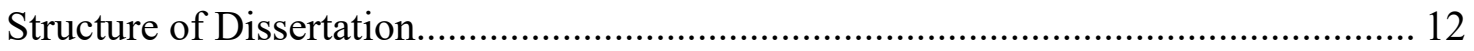

THEORETICAL AND EMPIRICAL BACKROUND TO COLLABORATIVE

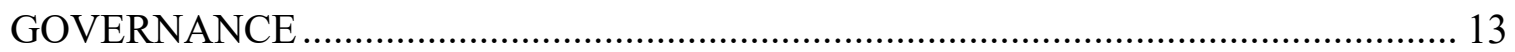

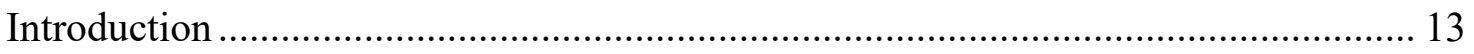

To Produce or To Provide - A Local Government Dilemma ..................................... 13

Modes of Exchange in Collaborative Governance.................................................. 16

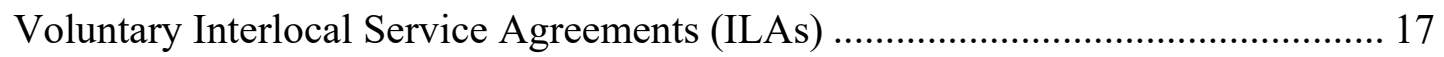

Restrictive vs. Nonrestrictive Interlocal Agreements (ILAs) .................................. 21

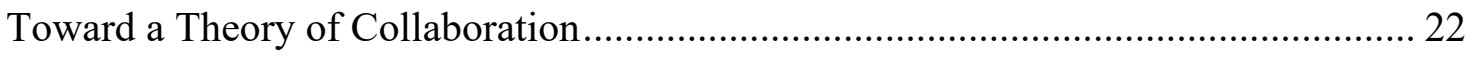

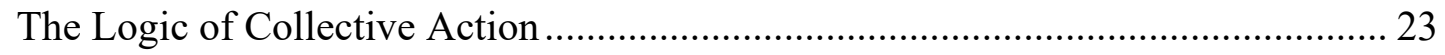

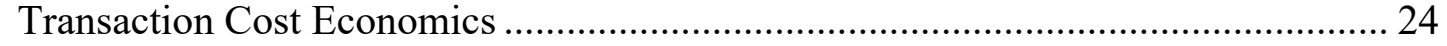

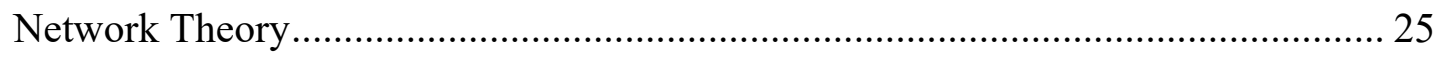

Theorizing Interlocal Collaboration .................................................................... 26

Microanalytics of Transaction Costs in Collaborative Governance ......................... 28

Network Embeddedness - How Well Do You Know Your Partner?........................ 31

Towards A New Model of Interlocal Collaboration.............................................. 33 
Determinants of Interlocal Collaboration: Empirical Background ........................... 39

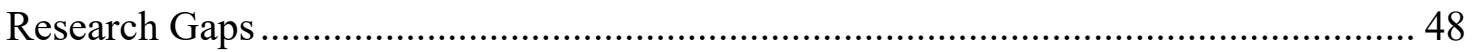

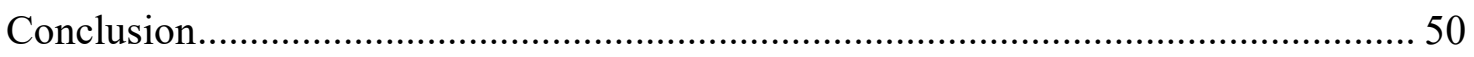

RESEARCH QUESTIONS, HYPOTHESES AND METHODOLOGY ....................... 51

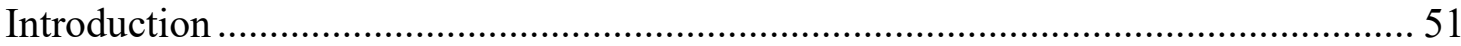

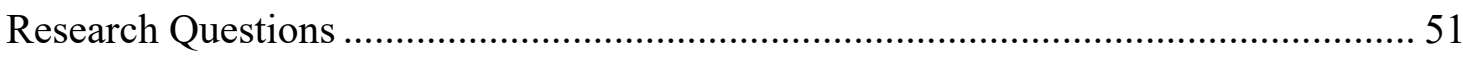

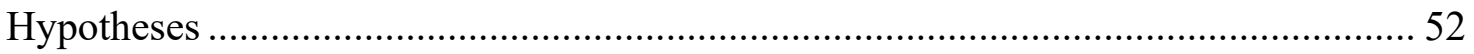

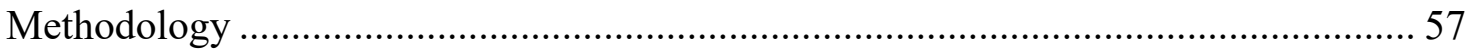

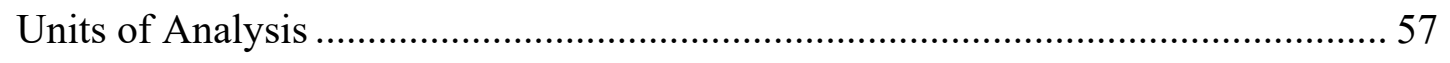

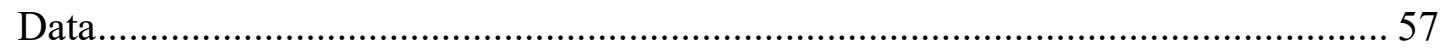

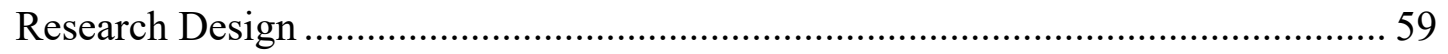

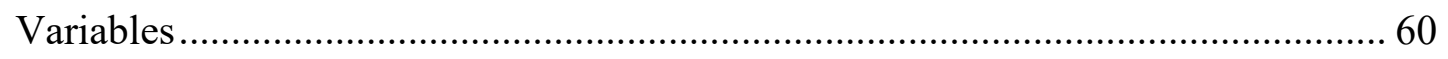

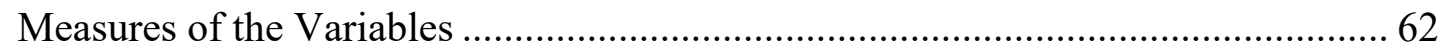

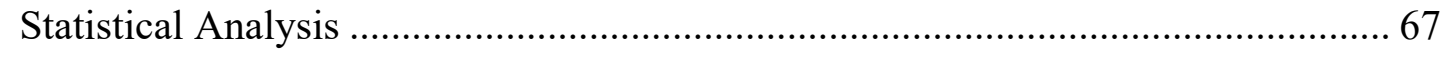

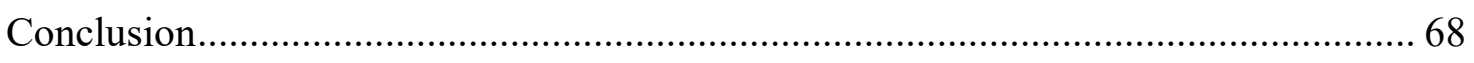

PATTERNS OF INTERLOCAL COLLABORATION: ANALYSES OF DATA.......... 70

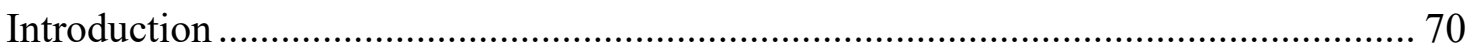

Overview of Local Governance in Kentucky....................................................... 70

General Overview of Interlocal Agreements in Kentucky .................................... 71

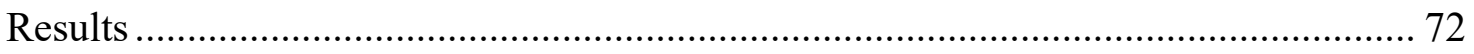

Descriptive Statistics for Dependent Variables .................................................... 72

Descriptive Statistics for Predictor and Control Variables.................................... 75

Regression Models on the Direction of Collaboration ........................................... 76

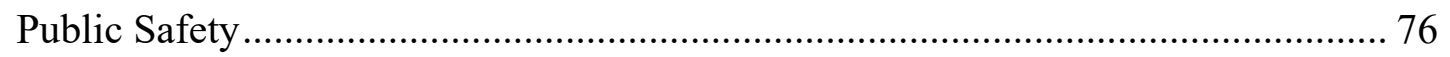

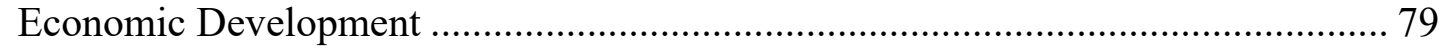

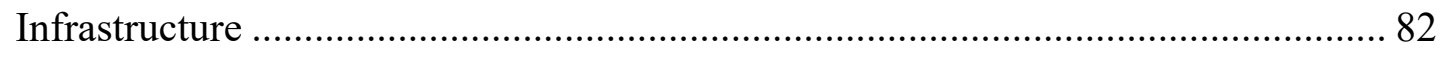

Regressions Models on the Number of Collaborators ............................................ 85

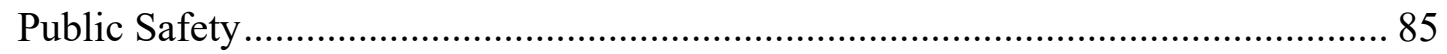

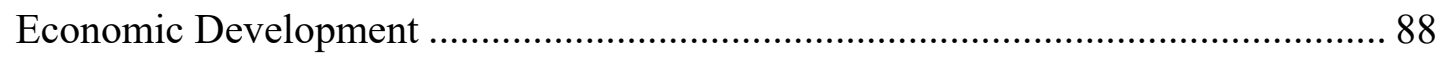

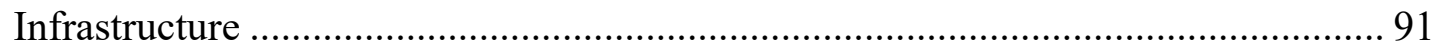

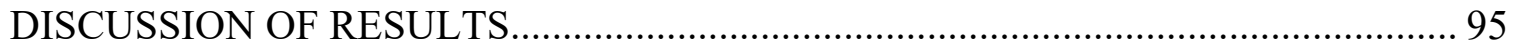




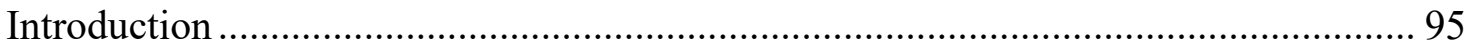

Characteristics of Services and the Pattern of Collaboration ........................................ 95

Network Embeddedness and the Pattern of Collaboration............................................. 98

Fiscal Capacity and the Pattern of Collaboration ....................................................... 101

County Density and the Pattern of Collaboration..................................................... 102

City Population and the Pattern of Collaboration.................................................... 103

Median Household Income and the Direction of Collaboration............................... 104

County Seat and the Direction of Collaboration ..................................................... 106

Form of Government and the Direction of Collaboration ......................................... 107

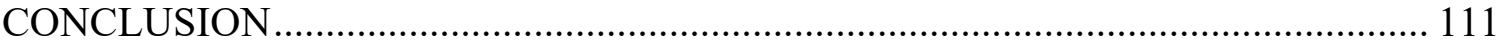

Determinants of Vertical, Horizontal, Multilateral and Bilateral Collaboration......... 112

Implications of Study: Main Contributions to Scholarship........................................ 113

Limitations of This Study.................................................................................. 114

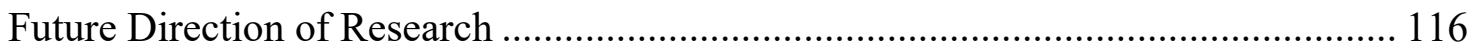

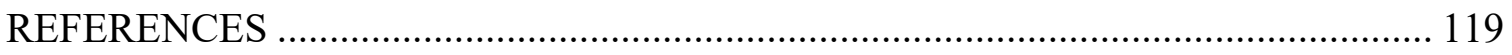

APPENDIX 1: Municipal Service Classification by Asset Specificity and Service

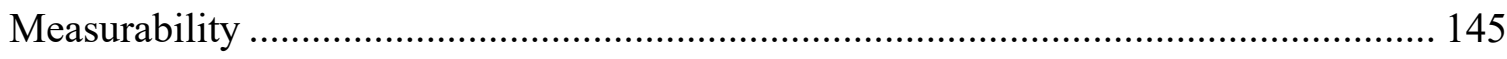

CURRICULUM VITA …………………………………................................... 146 


\section{LIST OF TABLES}

TABLE

PAGES

3.1 Characteristics of Services and Direction of Hypothesis 56

3.2 Summary of Variables $\quad 62$

4.1 Descriptive Statistics for Dependent Variables 73

4.2 Descriptive Statistics for Dependent Variables based on Transaction Characteristics

4.4 Binary Logistic Regression Models Predicting the Likelihood of Vertical Collaboration in Public Safety

4.5 Binary Logistic Regression Models Predicting the Likelihood of Horizontal Collaboration in Public Safety

4.6 Binary Logistic Regression Models Predicting the Likelihood of Vertical Collaboration in Economic Development

4.7 Binary Logistic Regression Models Predicting the Likelihood of Horizontal Collaboration in Economic Development

4.8 Binary Logistic Regression Models Predicting the Likelihood of Vertical Collaboration in Infrastructure

4.9 Binary Logistic Regression Models Predicting the Likelihood of Horizontal Collaboration in Infrastructure

4.10 Binary Logistic Regression Models Predicting the Likelihood of Bilateral Collaboration in Public Safety 
4.11 Binary Logistic Regression Models Predicting the Likelihood of Multilateral Collaboration in Public Safety

4.12 Binary Logistic Regression Models Predicting the Likelihood of Bilateral Collaboration in Economic Development

4.13 Binary Logistic Regression Models Predicting the Likelihood of Multilateral Collaboration in Economic Development

4.14 Binary Logistic Regression Models Predicting the Likelihood of Bilateral Collaboration in Infrastructure

4.15 Binary Logistic Regression Models Predicting the Likelihood of Multilateral Collaboration in Infrastructure

5.1 Summary of Significant Variables

5.2 Results of Test of Hypotheses 


\section{CHAPTER I}

\section{GENERAL INTRODUCTION}

\section{An Emerging Governance Model}

Collaborative governance and its variants - administrative conjunction (Fredrickson, 1999), cross-sector collaboration (Bryson et al., 2006; Simo \& Bies, 2007), collaborative planning (Healey, 2003; Innes \& Booher, 1999; Selin \& Chevez, 1995; Tewdwr-Jones \& Allmendinger, 1998) and collaborative public management (Agranoff, 2006; Agranoff \& McGuire, 2003; Cooper et al., 2006; Leach, 2006) - have received considerable attention in urban affairs, public management and environmental management research over the past few decades (cf. Donahue \& Zeckhauser, 2011; Gerlak et al., 2013; Goldsmith \& Eggers, 2004; Heikkila \& Gerlak, 2005; Kettl, 2000; O'Toole, 1997; Salamon, 2002; Weber et al., 2005). From infrastructure and housing development to education and health care delivery, collaborative governance has emerged as an essential institutional arrangement for providing public goods and services (Tang \& Mazmanian, 2010).

Similar to the emergence of hierarchies in the agricultural age and bureaucracies during the industrial age (McGuire, 2006), collaborative governance has emerged as a new management paradigm, one “... that defines its task more broadly than do previous paradigms and achieves many of its purposes through a dynamic of network governance" (Stoker, 2006, p. 43). Scholars of collaborative government have reiterated that vertical 
hierarchies of command and control no longer possess the solutions to the complex problems of the $21^{\text {st }}$ century (Goldsmith \& Eggers, 2004; O'Toole, 1997). Rather, collaborative webs of multiple government and nongovernmental institutions operating at different scales and across different jurisdictions offer more inclusive and adaptable solutions to the persistent contemporary problems of poverty, fiscal distress and natural disasters (Alter \& Hage, 1993; McGuire, 2006).

In public management, collaborative governance is the process of “...facilitating and operating in multi-organizational arrangements to solve problems that cannot be solved, or easily solved, by single organizations" (Agranoff \& McGuire, 2003, p. 4). In urban affairs, collaborative governance is largely regarded as a mode of "governance without government" (Savitch \& Vogel, 2000). In the field of environmental resource management collaborative governance is a process of pooling together institutional resources to plan and manage cross-jurisdictional environmental problems (Bentrup, 2001; Gerlak \& Heikkila, 2006; Innes \& Booher, 1999; Selin \& Chevez, 1995). Although scholars approach the concept from different perspectives, the fundamental principle of agreement is the notion of constructive engagement - open and inclusive communication and the representation of diverse interests. As Bressers, O’Toole, and Richardson (1995) observe:

"No organization of government possesses sufficient authority, resources, and knowledge to effect the enactment and achievement of policy intentions. Instead, policies require the concerted efforts of multiple actors, all possessing significant capabilities but each dependent on multiple others to solidify policy intention and convert 
it into action. Indeed, it is often difficult for any one actor, or group

of actors, to manage, or manipulate, the flow of problems and solutions onto the political agenda in the first place." (p. 4)

\section{Toward a Working Definition of Collaborative Governance}

The concept of 'governance' is generally understood as the act of steering “...the process that influences decisions and actions within the private, public, and civic sectors" (O'Leary et al., 2006, p. 7). The term 'collaborative' on the other hand denotes colaboring and cooperating across boundaries in multi-sector relationships to achieve common goals (O'Leary et al., 2009, p. 3). Put together, collaborative governance conveys the notion that existing institutions across localities can be harnessed in a cooperative, reciprocal, fluid and voluntary manner (Savitch \& Vogel, 2000) to provide public services (Parks \& Oakerson, 1989). The definition of collaborative governance adopted for this research is that of Tang and Mazmanian (2010, p. 4):

“...the process of establishing, steering, facilitating, operating, and monitoring cross-sectoral organizational arrangements to address public policy problems that cannot be easily addressed by a single organization or the public sector alone. These arrangements are characterized by joint efforts, reciprocal expectations, and voluntary participation among formally autonomous entities, from two or more sectors - public, for profit, and nonprofits -in order to leverage (build on) the unique attributes and resources of each." 
This definition of collaborative governance extends beyond the conventional focus on the public manager (Agranoff \& McGuire, 2003, p. 4) or the public - private partnership (Donahue \& Zeckhauser, 2011, p. x). Unlike these conventional definitions, the Tang and Mazmanian (2010, p. 4) definition is broader, encompassing partnerships among local governments, the private sector, civil society, and non-profits. Most importantly, the Tang and Mazmanian (2010, p. 4) definition regards collaborative governance as a process and not just an institutional arrangement.

Two forms of collaborative governance can be identified from the extant literature. These are transactive collaborative governance (TCG) and institutionalized collaborative governance (ICG). I refer to TCG in this study as a collaborative arrangement formed voluntarily between municipalities, for profit institutions, non-profit institutions and special districts for the purposes of ensuring the supply of public goods and services to citizens. Feiock (2004, p. 6) observes that "local governments can act collectively to create a civil society that integrates a region across multiple jurisdictions through a web of voluntary agreements and associations and collective choices by citizens." An ICG on the other hand refers to a cross-jurisdictional institution that has been established by statutory mandates to undertake specific tasks. The main structural difference between the two forms of collaboration is that TCGs operate as economic exchange arrangements while ICGs operate as typical bureaucracies led by a board of directors that includes elected city officials and department heads.

TCGs include typical interlocal service exchanges like pay-for-service agreements, joint service agreements and mutual aid arrangements. ICGs are often more formalized and include area development districts (ADDs) and regional organizations 
that unite stakeholders on broader planning and development issues. The Commonwealth of Kentucky has fifteen (15) ADDs that serve as a connection between local officials, the Governor's office, state and federal agencies, and private organizations (Kentucky League of Cities, 2012). The twenty eight (28) National Estuary Programs (NEPs) established under Section 320 of the 1987 Clean Water Act (CWA) to protect and restore estuaries of national significance are also examples of ICGs. This study focuses on transactive forms of collaborative governance.

\section{United yet Divided: America's Fragmented State}

America's local government remains highly fragmented. The 2012 Census of Governments reports a total number of 90,056 local governments of which 38,910 (44 percent) are general-purpose and 51,146 (56 percent) are special-purpose governments. For those who embrace fragmentation having many local governments means residents can have unlimited access to a variety of urban services (Liesbet \& Gary, 2003; McGinnis \& Ostrom, 2012; V. Ostrom et al., 1961). In his magnum opus, A Pure Theory of Local Government Expenditure, Charles Tiebout (1956), a renowned public theorist, opined that having many local governments within metropolitan regions promotes economic efficiency through competition. Tiebout stressed that fragmentation allows residents who are not satisfied with a particular set of services within a particular locality to vote with their feet by moving to new jurisdictions. The public choice view has been critiqued on a number of grounds. First public choice assumes that just like consumers in a private market, residents and jurisdictions have full knowledge on the variety and quality of services produced by different jurisdictions. In actuality people are bounded 
rational when it comes to residential mobility. Public choice also assumes that all public services are excludable and so can be sold on the private market. However, the difficulty of excluding residents from most public services encourage free riding which hinder the private sale of these services (Shrestha, 2005).

While public choice theorists tout America's fragmented local government system as responsive and efficient, there are others who condemn its relative inefficiencies inequality and environmental spillover (c.f ACIR, 1985, 1987; Downs, 1994; Miller, Miranda, Roque, \& Wilf, 1995; Nice, 1987; Oakerson, 1999; Parks \& Oakerson, 1989, 1993). Frederickson (1999, p. 702) opined that fragmentation in any form - jurisdictional or institutional - constitutes a "disarticulation of the state" which is the greatest challenge to an effective system of metropolitan governance.

Chief amongst those who oppose the public choice view are the consolidationists who embrace the idea of having a unified metropolitan government. From the earlier writings of Maxey (1922) and Reed (1949) to more recent scholarship from Cisneros (1993), Downs (1994) and Rusk (2013), the main arguments cited in favor of metropolitan government have been motivated by what these authors perceived as inefficiencies and inequalities associated with local government fragmentation. To consolidationists, too many local governments means duplication of services, inequality and inner city decline. Some have observed that the fragmented system of local governments does not provide the "...political leadership, sensitive to the well being and interests of [an] the entire region, responsive to socioeconomic problems and planning for the future" (Stephens \& Wikstrom, 2000, p. 48). Rather, fragmentation inhibits policies that address issues of metropolitan scale including economic inequality, inner-city 
decline, traffic congestion, air and water pollution (Downs, 1994; Peirce, 1993; Rusk, 2013). To consolidationists the solution to these inefficiencies lies with a one-size-fits all metropolitan government. They perceive that by bringing interjurisdictional activities under one government complex issues can be effectively coordinated and dealt with in an efficient manner.

Despite these seemingly positive remarks evidence suggests very few attempts at consolidation have been successful (c.f Blomquist \& Parks, 1995; A. Brierly, 2004; Carr \& Feiock, 1999; Feiock et al., 2006; Kelly \& Adhikari, 2013; Rosentraub, 2000; Savitch et al., 2009) One reason for this lack of success is that consolidation as a form of territorial rescaling removes all jurisdictional autonomy, a condition most independent cities reject. Additionally, having a unified government has been linked to principal-agent and internal coordination problems (Chubb, 1985; Nicholson-Crotty, 2004).

\section{A Case for Transactive Collaborative Governance}

From the arguments leveled so far against public choice and consolidation it stands to reason that for efficiency gains local governments that value their autonomy must turn to interlocal collaboration as the next best solution (Rothenberg, 1970; Shrestha, 2005). In line with this thought, new regional scholars have propounded the idea of metropolitan governance without government. At the backdrop of their proposition were empirical findings that the fates of central cities and suburbs in the post industrial era were tied to each other (c.f Adams \& Savitch, 1997; Downs, 1994; Hill et al., 1995; Ledebur \& Barnes, 1992, 1993; Rusk, 2003, 2013; Savitch \& Collins, 1992; Savitch et al., 1993; Swanstrom, 1996; Voith, 1998; Wikstrom, 2002). New regionalists 
hold the view that the solutions to today's public issues require multijurisdictional rather than individual efforts. They contend that fragmented forms of local government are not efficient in dealing with complex problems of equity, environment, and economy that transcend local government boundaries. Instead, intergovernmental networks and horizontal linkages offer prospective pathway for solving regional problems including fiscal stress, segregation, and central city decline (Downs, 1994; Lowery, 2000; Savitch \& Vogel, 2000).

As globalization and information technology continue to alter the meaning of physical space, voluntary collaboration and networking, as opposed to traditional instruments of power and control are seen as the solutions to problems of the disarticulated state (Frederickson, 1999). In their paper, Paths to New Regionalism, Savitch and Vogel (2000) highlighted three metropolitan governance frameworks within the American local government system. These frameworks, namely multi-tiered, linked functions (functional consolidation) and complex networks (overlapping interlocal agreements) represent hybrid forms of governance based on collaborative efforts. In the view of Savitch and Vogel (2000) the "complex networks" approach is the perfect form of metropolitan governance without government. It is a governance structure that allows several local governments to collaborate voluntarily through overlapping webs of interlocal agreements without sacrificing their autonomy (Adhikari, 2015; Feiock, 2009; Feiock et al., 2004; Oakerson, 2004; Parks \& Oakerson, 1989; Savitch \& Vogel, 2000).

Collaboration is however not a substitute for competition. While jurisdictions may compete for residents and businesses, the process of attracting these residents and businesses need not necessarily be competitive (Adhikari, 2015; Howell-Moroney, 2008). 
Even in highly fragmented regions where competition is rife, governance without government and competition can still coexist (Adhikari, 2015; V. Ostrom et al., 1961; Parks \& Oakerson, 2000).

\section{Justification for Research}

In spite of its increasing popularity our understanding of the determinants, patterns and relations in collaborative governance remains fairly rudimentary. Previous attempts to model the political, economic, and demographic determinants of collaboration have in most cases produced inconsistent results, thereby undermining the ability to generalize from such findings (Carr et al., 2007; Krueger \& McGuire, 2005; Leroux, 2006; Post, 2002; Rawlings, 2003; Wood, 2004; Zeemering, 2007).

Perhaps one reason for the lack of consensus in past studies is that most researchers relied on the US Census of Government Finance which has not provided dyadic information between transacting cities since 2007. Additionally, while most past studies have tried to explain collaboration from a purely economic point of view, it is becoming clearer in recent studies that local governments pursue different types of collaboration for different reasons (Carr et al., 2007). The growing popularity of collaborative governance provides a unique opportunity for urban and public management scholars to begin to address critical exchange pattern questions that focus on the direction (vertical or horizontal collaboration) and number of collaborating partners (bilateral or multilateral collaboration) in an agreement. Horizontal collaboration here refers to collaborative arrangements involving similar cohorts of local government (Carr et al, 2009). Examples include municipalities collaborating with other municipalities, 
special districts or non-profits on services such as law enforcement, parking and street sweeping. Conversely, vertical collaboration refers to collaboration between different cohorts of local government. Examples include cities collaborating with counties on infrastructure, economic development, emergency planning, animal control, and environmental initiatives. A bilateral agreement in this study is one that has only two partners of which one is a municipality. It could either be an agreement between two municipalities, between a municipality and a county or between a special district and a municipality. A multilateral agreement is one that has three or more partners of which at least one is a municipality.

\section{Research Objectives}

The main objective of this research is to address gaps in the literature and improve our understanding of collaborative governance by examining existing patterns of collaboration in the Commonwealth of Kentucky. Using Williamson's (1971) transaction cost economics theory and the concept of network embeddedness (Uzzi, 1996) as theoretical lenses, I examine collaborative governance by going beyond what already exists in current literature - determinants of collaboration- to explore what has barely been addressed - patterns if collaboration. This research includes which services are the strongest candidates for collaboration, which levels of government are the best candidates for partnerships (vertical or horizontal) and what number of partners are appropriate for collaborative arrangements (bilateral or multilateral).

The novelty of this research is both conceptual and spatial. At the conceptual level, the research attempts to complement the existing theory of collaborative 
governance by addressing two (2) main exchange questions - direction and number of partners - that have not been thoroughly addressed in previous studies. Spatially, the research contributes to the existing practice of regionalism by providing in-depth explanation to the structure and nature of exchange patterns in collaborative governance networks.

\section{Scope of the Research}

The units of analysis for this study are 'home rule' cities in the Commonwealth of Kentucky with populations above 230 people. The choice of home rule cities in Kentucky was made on the basis of data availability and convenience. The Kentucky Department of Local Government maintains an online database which unlike the Census of Governments provides information on dyadic relations between collaborating municipalities. This information was useful for analyzing vertical and horizontal as well as bilateral and multilateral exchanges. The study uses existing data on all interlocal agreements signed between years 2000 and 2013 from. A city-by-service cross-sectional pooled data was derived from existing agreements signed between years 2000 and 2013 to test the hypotheses developed in Chapter III. Besides data availability, convenience was a key factor in study. The proximity of the selected cities to the University of Louisville enabled quick and easier access to city officials in situations where clarification of data was required. 


\section{Structure of Dissertation}

The remainder of this dissertation is organized as follows. In Chapter II, I review the existing theoretical and empirical literature related to collaborative governance and highlight the research gaps. I place particular emphasis on three theoretical foundations Mancur Olsen's (1965) logic of collective action, Williamson's (1971) transaction cost theory and the extant literature on network theory to explicate the relational patterns of collaborative governance. Next in Chapter III, I outline the research questions and propose six research hypotheses for further enquiry. Additionally I describe in detail the research design, dataset and methodology for testing the hypotheses. In chapter IV I report in detail the descriptive statistics and binary regression models on the patterns and relationships of interlocal collaboration in Kentucky. Next in Chapter V I summarize and discuss the main findings of the study and test the research hypothesis in the light of the extant theoretical and empirical research. I conclude in chapter VI by discussing the limitations as well as the academic and policy implications of this research. 
CHAPTER II

\section{THEORETICAL AND EMPIRICAL BACKROUND TO COLLABORATIVE GOVERNANCE}

\section{Introduction}

In the literature review that follows I explore both the theoretical and empirical contexts of collaborative governance. I first identify the theoretical foundations of the concept and their connection to the broader public administration and urban affairs literature. The theoretical context is drawn from three grounded theories - the logic of collective action, transaction cost economics and network theory. The empirical context of collaborative governance on the other hand is drawn from the extant literature on public management, metropolitan governance and new regionalism.

\section{To Produce or To Provide - A Local Government Dilemma}

The decision to make, buy or collaborate does not only apply to the firm (Coase, 1937; Geyskens et al., 2006; Gulati et al., 2005; Williamson, 1975). It also serves as one of the major administrative dilemmas facing local governments. First envisaged by Ostrom, Tiebout and Warren (1961), the idea of a production-provision dichotomy - the separation of public service provision from production - helps to redefine economic functions in a public service economy. Production requires local communities to go into the business of producing local goods and services themselves, while provision includes mechanisms such as "contractual arrangements with private firms — or with other public 
agencies" (V. Ostrom et al., 1961, p. 834). Drawing on V. Ostrom et al's productionprovision logic, Parks and Oakerson (1989) have propounded what they perceive as a system of governance without government in metropolitan regions constituted by local 'public economies'. Indeed, Ostrom et al (1961) and Parks and Oakerson (1989) agree that by choosing service provision over production local government leaders perform the roles of decision makers and service coordinators.

Based on voter preferences, local governments are charged with the responsibility of deciding between what combination of goods and services to produce in-house and what to provide through other exchange mechanisms. It is the mission of every local government to provide services to its citizens by using available information and resources in a very productive and legitimate manner (Donahue \& Zeckhauser, 2011). As demonstrated in Figure 1, a rational local government could realize that acting independently it may not be able to deliver a particular public service efficiently. Thus it would be better off shifting its focus from in-house production to provision. Such provision of service could be in the form of collaboration with other jurisdictions or contracting out to private institutions. If a local government chooses to collaborate with other jurisdictions on services it still has to decide the direction of collaboration as well as the number of partners it wants to maintain in an agreement. 
Figure 1

The Public Service Delivery Dilema
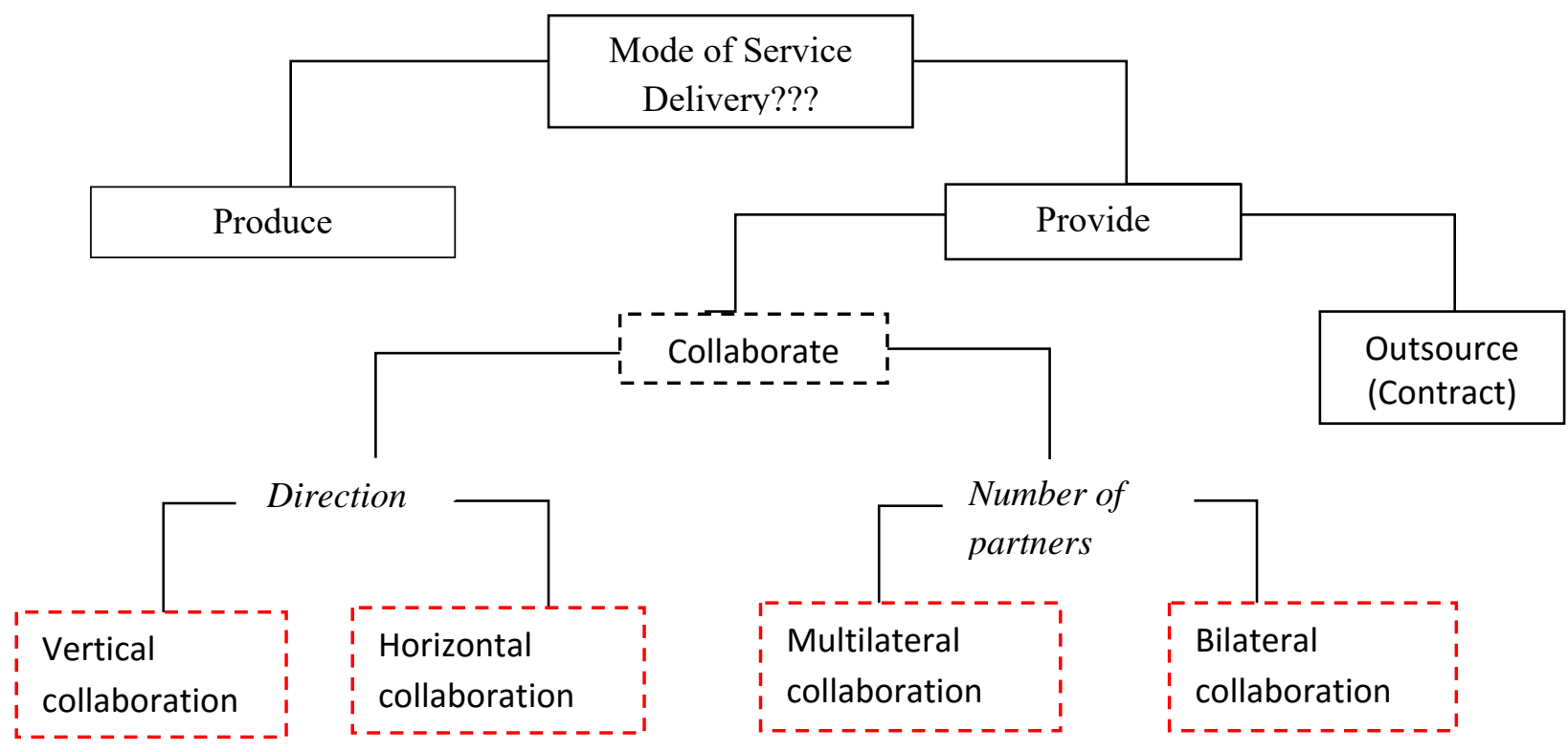

Direction

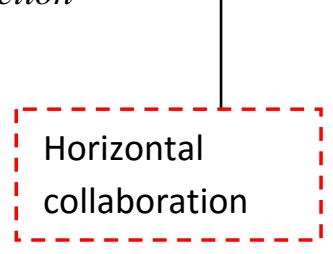

Number of partners

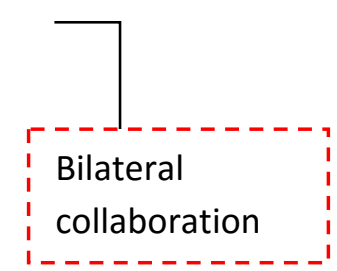

Source: Author's Construct based on V. Ostrom et al. (1961), Parks and Oakerson (1989), Williamson (1971)

In terms of direction a municipality can choose to collaborate vertically, where different levels of government collaborate or horizontal, where the players are local and represent multiple interests within a particular region Agranoff and McGuire (2003). Beyond bilateral and multilateral arrangements, collaborations can be either bilateral where agreements exists between two local governments - or multilateral - where agreements exists between more than two local governments. The freedom to rely on these combinations of service delivery arrangements allows local governments to maximize efficiency by arriving at the optimal combination of in-house production, contracting, and collaborations that provide the optimal satisfaction to citizens. 


\section{Modes of Exchange in Collaborative Governance}

The different modes of service delivery within the US local government are akin to Williamson's (1991) model of market-hybrid-hierarchy trichotomy. As depicted in Figure 2, on one extreme is a typical market economy that operates on arms-length contracts. Cities that operate this market form of government provide services to residents through either direct purchase from a private producer or through franchise authorizing a private producer to operate a service and charge fees (Shrestha, 2008). On another extreme is a hierarchy (consolidated government) that undertakes in-house production within a unified governmental structure. Consolidation is a form of territorial rescaling, where local governments forgo their individual autonomies in pursuit of common regional government agenda (as was the case of the Louisville/Jefferson County Metro Government). Nevertheless, evidence suggests that consolidation as a mode of government is more popular in theory than in practice. There are few consolidated governments in the US today because local governments resist losing their autonomy (Brierly, 2004; Carr \& Feiock, 2004).

Between private markets and hierarchies is the domain of collaborative governance. Collaborative mechanisms applied here may include pay-for-service agreements, mutual aid agreements, joint agreements, voluntary special districts and regional partnerships (Shrestha, 2008). The underlying difference in these exchange mechanisms is the obvious increase in autonomy as a municipality shifts from market forms of exchange to hierarchies. 
Figure 2

Forms of Exchange Mechanisms

\section{Markets}

0
Hybrids

\section{Hierarchies}

Source: Author's Construct based on Williamson (1991) and Shrestha (2008)

Special districts and regional partnerships are institutionalized forms of collaborative governance which are in most cases created through statutory mandates (Leroux, 2006). Because these forms of exchange mechanisms are not voluntary, participating municipalities have very limited autonomy in decision making (Feiock \& Scholz, 2010; Gerber \& Gibson, 2005). The analyses in this dissertation did not include these two forms of collaboration.

\section{Voluntary Interlocal Service Agreements (ILAs)}

Voluntary Interlocal Agreements (ILAs) have been widely researched by different disciplines in the past decades (c.f. Andrew, 2009; Andrew \& Hawkins, 2012; Andrew et al., 2015; Carr et al., 2009; Chen \& Thurmaier, 2009; Collins, 2006; Feiock, 2007, 2009; Frug, 2002; Gillette, 2001, 2005; LeRoux \& Carr, 2007; MacManus \& Caruson, 2008; Reynolds, 2003; Taylor \& Bassett, 2007; Wood, 2006; Zeemering, 2008a). Zeemering 
(2008a, p. 731) describes ILAs as crucial "features of contemporary local government management." In its basic form, a voluntary ILA is an arrangement established voluntarily between local governments for the purposes of producing or providing public services across interjurisdictional boundaries. From this logic any ILAs that are crafted in response to state mandates and funding requirements are not classified as voluntary and therefore not covered under this study. They may either be formal, where contracts are signed or informal where agreements are based on trust and a simple handshake (Andrew 2009a; Atkins 1997).

Pay-for-service agreements, joint service agreements and mutual aid agreements collectively constitute the main voluntary interlocal service agreements adopted by the majority of cities and counties in the United States (Advisory Council on Intergovernmental Relations, 1985; Friesema, 1971; ICMA, 1997; Thurmaier \& Wood, 2002; Zimmerman, 1973). They may exist between only two localities or crafted among multiple agencies and local governments (Andrew \& Hawkins, 2012).

A pay-for-service contract comes into effect when a buyer municipality enters into a legally binding agreement with a producer municipality such that the buyer municipality pays for the delivery of a particular service produced by the producer municipality. What differentiates pay-for-service contracts from private contracting is the element of integration. Integration refers to the achievement of collaboration between organizations. It encompasses not only cooperation (alignment of interest) but also coordination (alignment of actions) (Camerer \& Knez, 1996, 1997; Foss, 2001; Heath \& Staudenmayer, 2000). Because private contracting typically involves arm's length bidding processes the interests and actions of the buyer municipality and the private 
contractor may not necessarily be aligned. Shrestha (2008) has noted that owing to their relatively longer life spans, pay-for-service contracts enable buyer and producer municipalities to protect their interests from short term political and administrative changes. This is in contrast to private markets where buyer municipalities protect their interests by entering into short-term deals so as to take advantage of better future deals in the market (Shrestha, 2008).

A joint service agreement (JSA) is a form of collaboration that allows two or more units of government to jointly plan, finance and deliver a service to citizens (Leroux, 2006; Shrestha, 2008). They may include agreement options such as joint service provision, sharing of equipment or facilities, joint planning, tax revenues sharing and coordination of land-decisions (Advisory Council on Intergovernmental Relations, 1985; Nunn \& Rosentraub, 1997; Zeemering, 2008b). A JSA enables individual municipalities to contribute to each other's welfare by contributing resources into a generalized pool from which all municipalities obtain benefits. Through a JSA, collaborating municipalities are able to cut costs and take advantage of economies of scale in the production and provision of public services (Advisory Council on Intergovernmental Relations, 1985; Collins, 2006; Morgan \& Hirlinger, 1991; Morton et al., 2008). The difference between a JSA and a pay-for-service contract is that in a JSA each participant in an agreement is actively involved in the production of the service, whereas in a pay-for-service contract jurisdiction A produces the service with its own resources and supplies it to jurisdiction B at a purchase price. The structure of JSAs varies in terms of primary tasks, mutual responsibilities and liabilities of collaborating parties. Compared to pay-for-service contracts, JSAs are the preferred mode of delivery 
for most cities and counties in the nation (The Advisory Council on Intergovernmental Relations, 1985)

Mutual aid agreements are service arrangements devised by two or more jurisdictions in which each jurisdiction agrees to provide a service to the other at the provider's expense whenever the need arises (Friesema, 1971; Lynn, 2005; Nicholson, 2007). They form the majority of informal (undocumented) forms of agreements available to local governments in the United States. Informal mutual aid agreements generally occur as handshake deals among governing officials, verbal confirmations, implicit understandings and mutual adjustments - where a city takes into account programs of neighboring cities as part of its planning process (Friesema, 1971). Because the responsibilities created by mutual aids are established on good faith, they “...are operative only when certain conditions come into existence and they remain in operation only so long as these conditions are present" (Bollens \& Schmandt, 1965, p. 77).

In a typical mutual aid agreement, jurisdiction $\mathrm{A}$ is under no legal obligation to provide assistance to jurisdiction B when the need arises especially if providing such aid would be injurious to jurisdiction A's personnel or would reduce jurisdiction A's capacity to provide the service to their own residents (Shrestha, 2008). Friesema (1971) noted that although these informal forms of exchange cannot be easily quantified their knowledge helps to understand a broader perspective on collaborations in general. The Advisory Council on Intergovernmental Relations (1985) has observed that documented contracts are more popular amongst cities and counties with larger populations whilst undocumented contracts are more common in cities and counties with populations under 
2,500. In this study, a collaborating local government is one that uses any one or more of these three types of ILAs.

\section{Restrictive vs. Nonrestrictive Interlocal Agreements (ILAs)}

Based on the nature of enforcement mechanisms that go along with an agreement two types of ILAs can be identified - restrictive and nonrestrictive. Restrictive ILAs are agreements that are generally safeguarded by a binding formal contract to offset opportunistic behavior (Andrew \& Hawkins, 2012; Gillette, 2001). The contents of an ILA may range from simple task descriptions to full details of the nature and scope of individual responsibilities. Andrew et al. (2015, p. 403) have suggested that for a restrictive ILA to be more effective it must be supported by “...(1) specific state statutes or (2) legal or economically defensible local ordinances."

There are several advantages of having a restrictive ILA. First a legally binding agreement ensures that efforts of all parties are coordinated in a stable and decisive manner (Hawkins \& Andrew, 2011; Kettl, 2013; Lynn, 2005). Also, by clearly specifying the outcomes, rules and regulations of a contract before its inception, ex-post monitoring costs are ultimately minimized. Most states (including Kentucky) have statutory procedures that help to streamline interlocal collaborative activities of local governments. These interlocal collaboration statutes provide information and expectations necessary for local governments to make strategic choices (Advisory Council on Intergovernmental Relations, 1985; Andrew, 2010).

Nonrestrictive ILAs are those agreements that are enforced through standards of professional norms (Frederickson et al., 2004; Wukich, 2014). Local governments, 
especially those that belong to a common county, council of government or area development district are in constant interaction. Such proximity and regular communications help generate trust among partnering local government officials, which, in turn, reduces the need for formal control mechanisms (Shrestha \& Feiock, 2009; Wukich, 2014). Although certain contracting clauses are important to ensure contract performance and to hold contracting partners accountable, local governments generally have similar goals in the provision of quality urban services. This engenders confidence that a contracting partner will not act contrary to expectations or to the detriment of another jurisdiction. Another reason why local governments may be motivated to opt for nonrestrictive agreements is the cost element associated with restrictive ILAs. Evidently, monitoring restrictive ILAs involves enforcement costs. Thus having a flexible less restrictive arrangement allows partnering local governments to adapt to local circumstances at less to no cost. The disadvantages however lie in the fact that nonrestrictive ILAs may lead to "standard principal-agent dilemmas" (Andrew et al., 2015, p. 403).

For the purposes of this study I will concentrate solely on restrictive ILAs available from the Kentucky Department of Local Government database.

\section{Toward a Theory of Collaboration}

As a concept, collaborative governance draws from several grounded theories including group theory (Bentley, 1949), logic of collective action (Olsen 1965), prisoner's dilemma/game theory (Axelrod, 1984; Dawes, 1973), the commons research (E. Ostrom, 1990) and transaction cost economics (Williamson, 1971). For the purposes 
of this study I will restrict the review of concepts to the logic of collective action, transaction cost economics and network theory.

\section{The Logic of Collective Action}

Collective action as defined by Mancur Olson (1965) in his book, The Logic of Collective Action: Public Good and the Theory of Groups, is an action undertaken by a group of individuals to provide a good/service for the benefit of everyone in that group. The novelty of Olsen's logic is the revelation that just because all individuals in a group would gain from a collective action does not necessarily mean they would act in agreement to achieve that objective (Olson, 1965, p. 2). Rational self-interested tendencies of humans mean that individuals will often abstain from expending personal resources to ameliorate social problems, assuming that someone else will bear the burden. This inclination to "free ride" on the actions of others is the essence of the collective action problem. In order for individuals to voluntarily contribute resources of time, effort, or money to a particular cause, they must hold the perception that the personal benefits of doing so will outweigh the costs. The solution, Olson concludes, is small group size, coercion or the institution of some other special incentives to make individuals act in their common interest.

Based on Olson's theory different schools of thought have posited their own interpretation of what constitutes collective action. Public choice theorists (e.g., V. Ostrom et al., 1961) have opined that individuals have greater voluntary incentives to support collective action within smaller homogenous local government jurisdictions than within metropolitan governments. This view is different from that of scholars within the 
metropolitan governance and new regionalism camps (Downs, 1994; Feiock, 2004, 2005; Rusk, 2013). Feiock (2004, p. 6) has argued that "local governments can act collectively to create a civil society that integrates regions across multiple jurisdictions through a web of voluntary agreements and associations and collective choices by citizens". Instead of competition as the public choice theorists suggest, Feoick contends that local governments can simultaneously engage in competitive and cooperative interactions in a system of decentralized governance.

\section{Transaction Cost Economics}

Collaboration in any form and at every level involves transactions. For every transaction undertaken by individuals, private organizations or public organizations (including cities) there are associated costs that differ depending on "...the nature of the transaction and on the way that it is organized" (Milgrom \& Roberts, 1992, p. 28).

Transaction costs can take many forms including search costs, measurement costs, administrative costs, information processing costs and maladaptation costs (Williamson, 2010). These costs emanate from two intrinsic problems - coordination and motivation (Milgrom \& Roberts, 1992). The coordination problem is mainly a communication problem. It occurs when there is difficulty in transmitting information across various layers of authority. It may also occur when decision makers have insufficient or inaccurate information to make the most cost effective decisions. The motivation problem on the other hand results from imperfect commitment from participants in an agreement. In situations where it is difficult to motivate partners the prospects of exchange are low. It 
stands to reason that for efficiency gains, it is best to adopt the exchange arrangement that minimizes coordination and motivation problems.

Ultimately, whether a firm (government) operates as a hierarchy, market or hybrid form of institutional structure is largely determined by five related characteristics:

1. the specificity of investments required to conduct transactions

2. the difficulty of measuring performance in the transaction

3. the frequency with which similar transactions occur and the duration or period of time over which they are repeated

4. the complexity of transactions and the uncertainty about what performance will be required

5. the connectedness of the transaction to other transactions (Milgrom \& Roberts, 1992)

\section{Network Theory}

Network theory provides another analytical lens for understanding the American administrative state. In the field of public administration for example, network analyses have often been used to examine (1) the role of public managers (Agranoff \& McGuire, 2001; Mandell \& Keast, 2007); (2) decision making and policy outcomes (Agranoff \& McGuire, 2003; Mandell \& Keast, 2007; Provan \& Milward, 2001) and (3) systems of public service delivery (O'Toole, 1997; Provan \& Milward, 2001).

In network analyses, collaborative governance may be conceptualized as a system of actors (nodes) and relationships (ties) (c.f. Borgatti et al., 2013; Carrington et al., 2005; De Nooy et al., 2011; Kadushin, 2012; Newman, 2010; Robins, 2015; Scott, 2012; Scott 
\& Carrington, 2011; Valente, 2010; Wasserman \& Faust, 1994). Actors are disjoint entities such as individuals within a group, departments within a municipality, cities within a county or counties within a state (Leroux, 2006; Wasserman \& Faust, 1994). Relational ties on the other hand are conduits for the flow of material (e.g; funds, equipment or personnel) and non-material (e.g; information) resources between actors (Leroux, 2006; Hanneman \& Riddle, 2005). Network theory further suggests that relational ties are not mutually exclusive. In other words an actor's position in one set of relations may be connected with positions in other networks.

Unlike transaction cost economics theory that conceptualizes collaboration as a purely economic function, network theory relies on social norms, trust and obligations to explicate collaborative networks (Lackey et al., 2002; Thurmaier \& Wood, 2002). Frederickson (1999) has observed in the public sector that compared to elected officials, administrators tend to work collectively owing to the fact that they share common norms, values, rules, and practices. Brown and Potoski $(2003,2005)$ have further observed that past interactions help build trust and credibility which in turn reduce the risk of opportunistic behavior.

\section{Theorizing Interlocal Collaboration}

The model of interlocal collaboration adopted in this study draws from Feoick's $(2004,2005,2013)$ institutional collective action (ICA) framework. The ICA framework combines Olson's (1965) logic of collective action with Williamson's (1991) transaction cost economics to explicate the circumstances under which local governments and private institutions work together in a voluntary manner to solve shared problems. The ICA 
framework explores transaction risk reduction strategies and examines mechanisms for incentivizing and sanctioning voluntary collaboration across jurisdictions and organizations (Andrew et al., 2015; Feiock, 2013; Feiock \& Scholz, 2010).

Similar to the ICA framework, the model of collaboration in this study is premised on the assumption that local governments are interested in maximizing their utility from interlocal exchanges. It further assumes that all other things being equal, rational and self-interested local governments are willing to solve mutual problems by assessing for themselves the costs and benefits of participating in voluntary exchanges compared to private markets or hierarchical exchange mechanisms. Where the benefits of interlocal cooperation outweigh the costs, rational and self-interested local governments assess the different modes of voluntary interlocal agreements that produce the largest utility gains. In a nutshell, local governments will only act collectively if they are "...persuaded that their jurisdiction will enjoy benefits in excess of the costs" (Leroux, 2006, p. 9).

The ICA framework reveals that collaborating jurisdictions are prone to both exante and ex-post transaction costs in interlocal exchanges (Andrew, 2008b; Andrew \& Hawkins, 2012; Feiock, 2013; Hawkins, 2009). Ex-ante transaction costs occur prior to the implementation of an agreement. They include costs associated with the lack of (asymmetry) information, negotiations, and writing of agreements. Ex-post transaction costs occur after the implementation of an agreement. They include costs associated with the monitoring and enforcement of agreements against any future conflicts. When transaction costs are low, the prospects for institutional collective action are enhanced and vice versa. The magnitude of transaction costs is however dependent on the 
specificity and measurability of the service in question. Services that have low asset specificity and at the same time easily measurable have low transaction costs. Such services provide opportunities for collaboration (Feiock, 2005).

Additionally, conditions within the exchange environment such as differences in attributes of transacting parties, changes in the exchange conditions as well as behavioral and environmental uncertainties can also increase the transaction costs and make interlocal exchange riskier (Shrestha, 2008). Safeguarding agreements against such potential influences may increase the enforcement costs for participating municipalities. Indeed, these transaction risks not only influence the decisions of local governments to adopt collaboration but also the extent, direction and pattern of collaboration. The sections that follow explain in detail how transaction costs and exchange embeddedeness help mitigate the transaction risks in interlocal exchange.

\section{Microanalytics of Transaction Costs in Collaborative Governance}

Governance, according to the "commons" theory (E. Ostrom, 1990), is a means to mitigate conflict, infuse order, and thereby realize mutual gains from voluntary exchange. Examining the microanalytics of transactions put forward by Williamson (2002) and the thesis on alternative paths to new regionalism by Savitch and Vogel (2000) provides a theoretical lens for understanding why municipalities engage in different exchange mechanisms.

From the perspective of Savitch and Vogel (2000) collaboration is a reflection of the regional path on which a local government is treading. Local governments in the US are situated in five regional structures - consolidated regions, multitierd regions, linked 
functions regions, complex network regions and public choice (polycentric) regions. Consolidated and public choice regions are akin to Williamson's (2002) hierarchy and markets respectively while multi-tiered, linked functions and complex network regions are akin to hybrids. The Multi-tiered approach suggests a two-tier governmental structure - metropolitan level system maintenance service structure and city level lifestyle service structure. The first tier of government represents a single metro wide government for "system maintenance" services such as water, sewers and mass transport. Whilst the second represents municipal-level management of lifestyle services such as parks and recreation, elementary and secondary school education. Linked functions also known as functional consolidation is an approach that sustains a pattern of functional relations between a city and its county. Relations could be pay-for-service agreements, joint service agreements or mutual aid agreements. Complex networks is an approach that encourages several independent local government of similar cohort to engage in voluntary collaboration through "multiple, overlapping webs of interlocal agreements" for their mutual benefit (Savitch and Vogel 2000, 164). From a transaction cost perspective the rudiments of identifying these alternative modes of regional governance are the attributes of the service being transacted - including asset specificity and service measurability.

\section{Asset Specificity}

Asset specificity is the ease with which an asset used for transaction 'A' can also be used for transaction 'B'. Where a party makes an investment in assets that cannot be easily redeployed to other locations for different users and uses, such an investment is 
asset specific. The specificity of assets can lead to 'hold-up' problems in transactions. The more specific a collaborative agreement is, the more dependent the producing party is and the higher the risk of opportunistic behavior. Thus transactions that require specific investments require strictly enforced contracts to protect parties against early termination or renegotiation of the terms of the agreement (Milgrom \& Roberts, 1992).

\section{Service Measurability}

Service measurability refers to the ease with which service outputs can be measured (Brown \& Potoski, 2003). It also refers to how costly, impossible or only partly possible service outputs can be measured (Milgrom \& Roberts, 1992). Ostrom et al. (1961) have observed that where performance can be easily measured, local governments are able to streamline the production or provision of a public good and hold producing agencies accountable for any inconsistencies in performance. However, where performance is difficult to measure it is hard to sanction bad behavior and incentivize good behavior. Measurement difficulty therefore creates opportunity for manipulation and free riding at others' cost. As explained by the institutional collective action framework, services with outputs that are difficult to measure may be less likely candidates for inter-local collaborations because they involve increased transaction costs. As measurement difficulty decreases, transaction costs in turn decrease and local governments are significantly more likely to collaborate with other local governments. But when service outputs become difficult to measure, local governments are significantly less likely to collaborate with other local governments. 
A number of studies on interlocal collaboration have found that transaction costs associated with the negotiation, operation and enforcement stages of an agreement are major barriers to collaboration (c.f. Andrew, 2008a; Dusin et al., 2009; Feiock \& Scholz, 2010; Kwon \& Feiock, 2010; LeRoux et al., 2010; LeRoux \& Carr, 2007; Shrestha, 2008; Wood, 2008). Studies by Brown and Potoski (2003) and Andrew (2009) and Carr et al. (2009) have further indicated that services with high asset specificity and measurement difficulty are less likely to be provided through interlocal collaboration because of the risk of opportunistic behaviors on the part of collaborating municipalities.

Some studies have found empirical support for the service measurability hypothesis but not asset specificity (e.g. Shrestha, 2008). Yet still others like Andrew (2005) have found no evidence in support of either the asset specificity or service measurability theses.

\section{Network Embeddedness - How Well Do You Know Your Partner?}

It has been established from TCE theory that information asymmetry represents one of the main sources of transaction costs. Unlike the "economic man" who acts rationally because he has complete knowledge and anticipates the consequences that will follow on each choice, the "administrative man's" knowledge of consequences in transactions is usually fragmentary. In short, the administrative man is bounded rational (Simon, 1945). In the absence of complete knowledge, municipalities are bound to make decisions on service delivery mechanisms with varying levels of uncertainty. The uncertainty associated with the behaviors and actions of collaborating parties leaves room for opportunistic behaviors (Feiock, 2013). To offset such opportunistic behaviors, 
jurisdictions may consider entering into agreements with partners who form part of their social network rather than with strangers (Lazarsfeld \& Merton, 1954).

In his seminal paper; "The Sources and Consequences of Embeddedness for the Economic Performance of Organizations: The Network Effect”, Uzzi (1996) explains that organizational networks operate in an embedded logic of exchange that promotes economic performance through resource pooling, cooperation, and coordinated adaptation. This means that to curb both ex-ante and ex-post transaction costs due to information asymmetry, municipalities can rely on relational mechanisms through repeated interaction and reciprocity to facilitate exchange (Granovetter, 1985; Uzzi, 1996; Zaheer \& Venkatraman, 1995).

This is because reciprocal and repeated interactions allow local government partners to gain first-hand experience about each other's behavior (Shrestha, 2006; Granovetter, 1985). Having access to such behavioral information can serve as a tool for controlling each other and thereby limiting any tendencies for opportunistic behavior (Shrestha, 2006; Williamson, 1996). The special relations developed from reciprocal and repeated interaction over time allows collaborating parties to develop credibility and trust (Andrew, 2009; Coleman, 1988; Frederickson et al., 2004; Wukich, 2014) which in turn reduce both ex-ante and ex-post transaction costs (Olberding, 2002; Poppo \& Zenger, 2002; Schneider et al., 2003; Uzzi, 1996). Local governments that interact frequently also have the opportunity to develop internal code of conduct and informal communications that help to streamline their actions (Milgrom \& Roberts, 1992; Ostrom et al., 1994; Parks et al., 1996; Valley et al., 1998). 
Through this process of exchange embeddedness the behavior of collaborating partners becomes more predictable for existing and subsequent exchange (Gulati \& Gargiulo, 1999) creating a basis for increased interlocal cooperation (Gerber \& Gibson, 2005).

\section{Towards A New Model of Interlocal Collaboration}

The review of literature so far has explored three grounded theories of collaboration - logic of collective action, transaction cost economics theory and the logic of network embeddedness. These theories explain how local governments can offset transaction risks in interlocal exchanges. Transaction cost theory and the logic of collective action are based on the economic assumption of rationality while the logic of network embeddedness is based on trust and credibility developed through reciprocity and repeated interactions. TCE and the logic of collective action help to explain the decision to collaborate but fail to resolve ex-post behavioral uncertainties. On the other hand the logic of network embeddedness helps to explicate ex-post behavioral uncertainties but fails to provide an economic (cost-benefit) approach to collaboration. The model of interlocal exchange adopted in this study thus incorporates elements of all three theories to explain exchange patterns and relationships in collaborative governance.

\section{Number of Collaborating Partners: Bilateral vs. Multilateral Relations}

One of the most relevant questions about collaboration regards the effect of the number of partners on collaborative behavior. In his magnum opus The Logic of Collective Action, Mancur Olson (1965) demonstrated that the number of partners in a 
group is inversely related to a group's ability to achieve collective action. In other words as the size of a group increases, the probability of the group achieving a collective action decreases (E. Ostrom, 2010, p. 157). This thesis, according to Olson, is based on two reasons - "the free rider" problem and the problem of high transaction costs. As the size of a group increases so does the difficulty of accounting for individual contributions towards the provision of a public good. Group members who perceive that their noncontributions will neither be noticed nor affect the likelihood that a good will be provided will free ride. Second, Olson suggests that as group size increases transaction costs regarding internal negotiations, writing of agreements and enforcement of agreements also increase.

Following Olson's influential work, scholars from various disciplines have sought to further investigate the effects of group size on collaborative behavior albeit with mixed results. Whilst some scholars have found evidence in support of Olson's position that the relationship is negative (c.f. Baland \& Platteau, 1999; Dawes et al., 1977; Grujić et al., 2012; Komorita \& Lapworth, 1982; Nosenzo et al., 2013; E. Ostrom, 2005; Vilone et al., 2014), others have found the relationship to be rather positive (c.f. Agrawal \& Chhatre, 2006; Haan \& Kooreman, 2002; Isaac et al., 1994; Masel, 2007; Martin McGuire, 1974; Szolnoki \& Perc, 2011). Yet still others have found that the relationship between group size and collaborative behavior is either ambiguous (c.f. Chamberlin, 1974; Esteban, 2001; Oliver \& Marwell, 1988; Pecorino \& Temimi, 2008), non-significant (c.f. Gautam, 2007; Rustagi et al., 2010; Sandler, 1992) or curvilinear (Agrawal, 2000; Agrawal \& Goyal, 2001; Chamberlin, 1974; Cinner et al., 2013; Frohlich \& Oppenheimer, 1970; Hardin, 1982; Pecorino, 1999; Poteete \& Ostrom, 2004; Yang et al., 2013). 
Indeed, the general agreement amongst scholars who support the curvilinear hypothesis is that large groups increase transaction costs while small groups usually do not possess the resources and capacity required for effective collective action. Thus, medium-size groups collaborate better than either small or large groups. Some of these scholars have also established that group size and the likelihood of collaboration are indirectly related (Chamberlin, 1974; E. Ostrom, 2001). This means that differences in group size first influences other variables like one's marginal contribution in a group, which in turn influences collaborative behavior.

E. Ostrom (2010) observed that one reason why there have been inconsistent patterns in previous literature is the failure of scholars to distinguish between what constitutes excludable (substractive) and non-excludable (nonsubstractive) public goods. In a substractive public good scenario, the use of a good by individual A reduces the benefits for individual $\mathrm{B}$. Thus increasing the number of participants increases the extent of "nonoptimality" (E. Ostrom, 2010). In a nonsubstractive public good environment, the use of a good by individual A does not impact the benefits individual B receives. Increasing the number of participants in a nonsubstractive good environment thus allows participants to enjoy a larger collective pool of additional resources. The underlying hypothesis is that when "a good has pure jointness of supply, group size has a positive effect on the probability that it will be provided" (Marwell \& Oliver, 1993, p. 45).

In interlocal exchanges, local governments are also confronted with the decision of choosing between bilateral (two local governments) or multilateral (more than two local governments) agreements. A bilateral relationship may be advantageous in certain situations because it provides a basis for a more cohesive relationship between 
transacting jurisdictions in terms of social capital, mutual solidarity, and trust (Coleman, 1988). Partners involved in bilateral relations are better positioned to gain first-hand information and experience about each other (Granovetter, 1985). The prospect of repeated dealings further strengthens mutuality between transacting jurisdictions and help reduce the prospects of supplier (producer) opportunism.

However, repeated interaction and familiarity may also serve as an incentive for opportunism. A buyer (provider) government concerned with this familiarity problem and the potential threat of a single supplier's (producer) opportunistic behavior may choose to enter into an agreement with several suppliers (producers) or several buyers (providers) of the same service. Multilateral agreements have an advantage over bilateral agreements in that they are less susceptible to interruption in service supply. In situations where one supplier government fails to provide a particular service other supplier governments may be available to fill the lag in supply. Again, in a multilateral agreement, the credibility of a supplier (producer) municipality may serve as a self-restraint against any opportunistic temptation (Poppo \& Zenger, 2002). There are however certain limitations to multilateral

agreements. Since administrative (procurement and financial) procedures, number of personnel, qualifications and training vary across jurisdictions, negotiating joint service and mutual aid agreements can be complex when multiple partners are involved (Haddow et al., 2013; Krueger \& Bernick, 2010; Scorsone, 2006).

\section{Direction of Collaboration: Vertical vs Horizontal Relations}

Besides choosing the number of potential partners, local governments are also confronted with the dilemma of deciding the direction in which to collaborate. They may 
decide to enter into horizontal agreements with other municipalities, private or nonprofit entities or alternatively, they may also be motivated to establish vertical relationships with county governments (Andrew et al., 2015). In a heuristic way, Figure 3 shows how transaction cost influence the direction of collaboration in different regional governance/government structures - markets, complex networks, linked functions, multitiered governments and consolidations (Savitch \& Vogel, 1996).

Figure 3

A Heuristic Model of Regional Governance

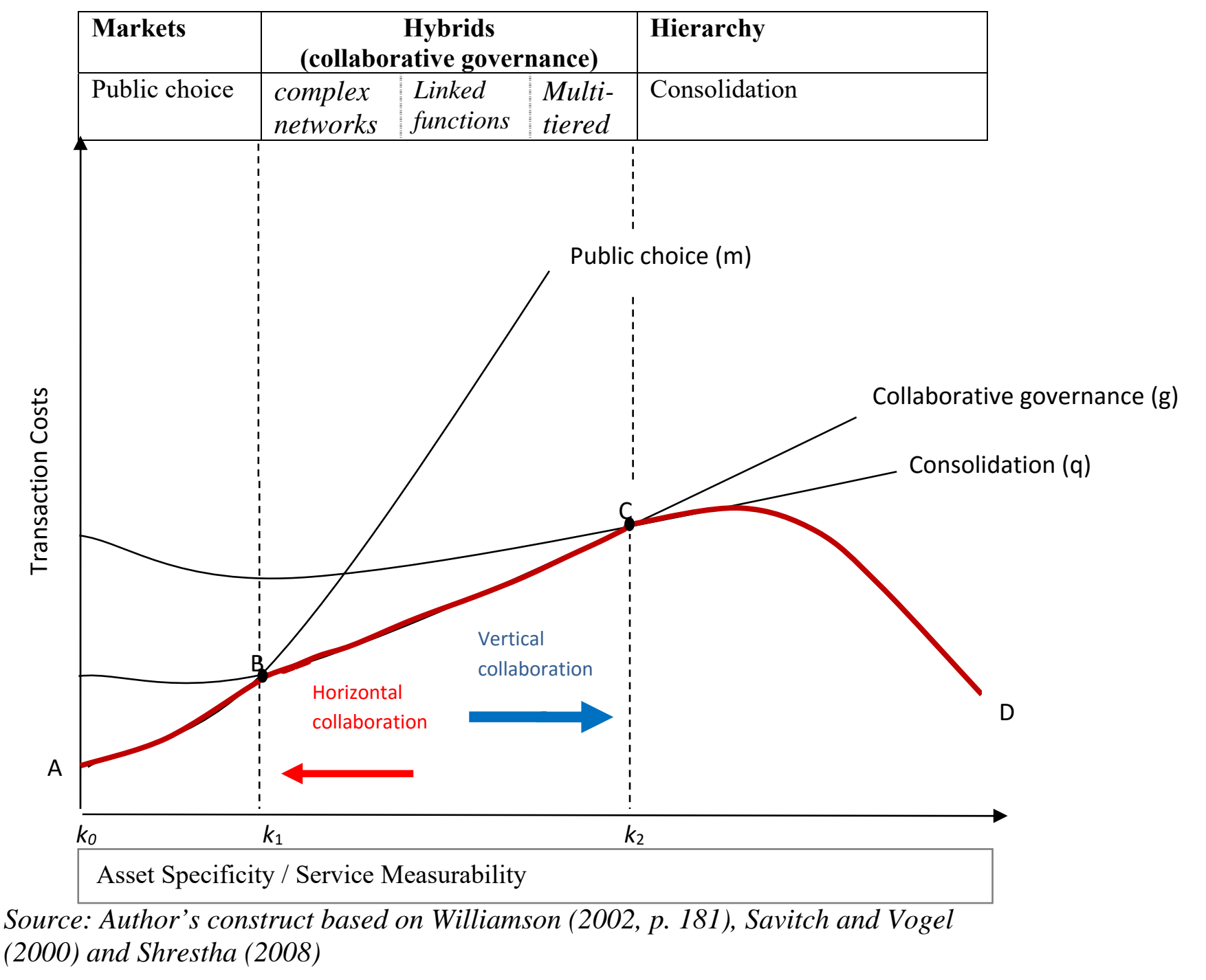


As shown in Figure 3, the burdens of bureaucracy make consolidated governments more costly at $k_{0}$. From asset specificities $k_{0}$ to $k_{1}$ public choice $\mathrm{m}(k)$ is more cost effective than collaborative governance $\mathrm{g}(k)$ and consolidation $\mathrm{q}(k)$ by reason of its flexibility and adaptability. Beyond asset specificity $k_{1}$, collaborative governance $\mathrm{g}(k)$ becomes more cost effective than public choice $\mathrm{m}(k)$ and consolidation $\mathrm{q}(k)$. Local governments are therefore better off with collaborative governance, $\mathrm{g}(k)$ at this stage. Collaborative governance mechanisms could either be complex networks, linked functions or multi-tiered. Within these three strata of collaborative governance, complex networks are the closest to public choice and so attract lower asset specificities. Multitiered governments are associated with higher asset specificities because they are closest to consolidation. Beyond $k_{2}$ where asset specificity is at an optimum level, local jurisdictions are likely to adopt consolidation $\mathrm{q}(k)$ as it becomes less costly than public choice $\mathrm{m}(k)$ and collaborative governance $\mathrm{g}(k)$. In other words $\mathrm{m}(k)>\mathrm{g}(k)>\mathrm{q}(k)$ because consolidated governments have successfully coordinated and adapted to the transaction process at this stage. This illustration indicates that collaborative governance is most advantageous at intermediate range of asset specificity $\left(k_{1}<k_{2}\right)$. It also indicates that within collaborative governance $\mathrm{g}(k)$, jurisdictions have a choice of interacting horizontally - with local governments of comparable powers - or interacting vertically with local governments of different powers (Kenyon \& Kincaid, 1991). From Figure 3, it can be inferred that at lower levels of asset specificity cities are better off engaging in horizontal collaborations. As asset specificities increase, jurisdictions may turn towards vertical collaboration (with a county for example) for efficiency gains. 
This rudimentary setup can also be extended to explicate the impact of service measurability on collaborative behavior. The basic argument propounded here is that vertical collaboration is preferred to horizontal collaboration as a public service becomes highly asset specific and difficult to measure, ceteris paribus. Prior studies have found that when municipalities rely on vertical collaboration they gain from higher levels of regulatory enforcement and a minimal cost of monitoring potential defectors (Andrew, 2009; Feiock, 2007, 2009; Scholz \& Wang, 2006).

\section{Determinants of Interlocal Collaboration: Empirical Background}

Over the past two decades there have been a series of attempts to find empirical explanations to the factors that determine interlocal collaboration. Despite these attempts scholars are yet to agree on a general theory or model of collaboration. Some of the variables that have been examined in prior research include asset specificity, service measurability, labor/capital intensity, reciprocity and recurrence of exchange. Other demand-side factors such as local fiscal capacity, changes in a local government's population, the amount of personal income, property wealth of residents, form of government, demographic characteristics and social networks have equally been empirically tested by different scholars albeit with inconclusive results (e.g. Krueger \& McGuire, 2005; Leroux, 2006; Post, 2002; Rawlings, 2003; Shrestha, 2008; Wood, 2006; Zeemering, 2007). Granted that results from prior studies are inconclusive, it is worth finding out if the variables that have been tested elsewhere in the US are significant determinants in the case of Kentucky. 


\section{Fiscal Factors}

For a long time fiscal capacity has remained the number one cited determinant of interlocal collaboration (e.g. Advisory Council on Intergovernmental Relations, 1985; Bartle \& Swayze, 1997; Krueger \& McGuire, 2005; Leroux, 2006; MacManus \& Caruson, 2008; Morgan \& Hirlinger, 1991; Sonenblum et al., 1977; Stein, 1990). Studies highlighting fiscal capacity have often suggested that governments faced with depleting property tax base and state funding are better off engaging in interlocal collaboration rather than in-house production (Carr et al., 2007). Prior studies stressed further that by entering into collaborative agreements local governments are able to achieve cost savings and scale economies on services that are mostly capital intensive or have high start-up costs (Morgan \& Hirlinger, 1991).

Notwithstanding these supporting arguments, empirical testing of the fiscal capacity variable by different scholars has produced mixed results (e.g. Adhikari, 2015; Bartle \& Swayze, 1997; Krueger \& McGuire, 2005; Stein, 1990; Wood, 2004). Those who have found empirical support for the hypothesis include Wood (2004) and Krueger and McGuire (2005). In a study of 46 city managers in the Kansas City Metropolitan Area, Wood (2004) found that eighty (80) percent of the cities using interlocal agreements achieved cost savings whilst eighty three (83) percent achieved economies of scale. In similar study of 2,825 U.S. cities, Krueger and McGuire (2005) found that tax revenue per capita and federal grants per capita were significant in determining both the decision to collaborate and the extent of collaboration.

Other studies have demonstrated that fiscal capacity in terms of per capita taxable value does not significantly influence the decisions to collaborate even when jurisdictional differences in population, land area, and demographic characteristics are 
considered (e.g. Carr et al., 2007; Morgan \& Hirlinger, 1991; Thurmaier, 2005; Thurmaier \& Wood, 2002). Yet still, others have shown that cities participate in collaborative arrangements irrespective of fiscal capacity. In a study of 1,290 local governments in Iowa Thurmaier (2005) for instance found that local governments do not necessarily engage in collaborative exchanges because they want to cut production costs. Rather, local governments collaborate because they want to ensure efficiency and effectiveness (managerial values) in service delivery.

Obviously, this variability of findings results from the lack of a standard measure of fiscal capacity. Prior studies have often used different measures including local property tax per capita, personal income per capita, and government spending as proxies for fiscal capacity. It is however not clear whether these proxies accurately capture the true financial situations of the municipalities they study.

\section{Labor Intensive versus Capital Intensive Services}

Findings from prior research suggest that the decision to collaborate is also largely influenced by the characteristics of the service in question. One of such characteristics is the labor intensity - capital intensity dichotomy. Labor intensive services are services that require continuous levels of staffing. Examples include police, fire corrections and health services. Because production costs for labor intensive services do not decrease as volumes increase, realizing economies of scale in labor intensive services is difficult (Leroux, 2006). Capital intensive services on the other hand are services that have high start-up costs. Examples include highway construction, housing, parks, sewage, gas and water distribution. Capital intensive equipments and materials are 
usually less expensive when purchased in large quantities thus they tend to produce economies of scale. The general argument therefore is that local governments are more likely to collaborate on services that are capital intensive, and less likely to collaborate on services that are labor intensive. In a study of 140 metropolitan areas, Post (2002) found that while both labor intensive and capital intensive service related collaborations occur in almost all geographically dense regions, collaborations in capital-intensive services occur at higher rates than labor-intensive services.

\section{System Maintenance versus Lifestyle Services}

In his book, Metropolitan Political Analysis: A Social Access Approach, Oliver Williams (1971) drew attention to what he perceived as the "lifestyle model" of metropolitan service delivery. The lifestyle model dichotomizes public services provided in metropolitan areas as either systems maintenance functions or lifestyle functions. Systems maintenance functions are services that provide the needed infrastructure essential for maintaining the health and safety of residents. These include sewer, water distribution, solid waste disposal, storm water management, and roads. Lifestyle services are services that usually influence residential location decisions (Andrew et al., 2015). They include services that provide comfort and satisfaction to a select group of residents, particularly residents of upper-middle class suburbs who enjoy affluent lifestyles. Lifestyle goods include parks and recreation.

At the regional level, this dichotomy of services suggests a two-tier governmental structure - metropolitan level system maintenance service structure and city level lifestyle service structure. The first tier of government represents a single metro wide 
government for "system maintenance" services such as water, sewers and mass transport. Services provided at this level require a vertical form of collaboration (see Figure 1) between local governments and a county or consolidated government. The second represents municipal-level management of lifestyle services such as parks and recreation, elementary and secondary school education. Lifestyle service structures require horizontal forms of collaboration between local governments, service districts, for-profits and non-profits.

A number of studies (Rawlings 2003; Wood 2004; LeRoux 2006) have employed Williams's (1971) social access model to explain interlocal collaboration based on the general hypothesis that public managers are more likely to collaborate on "system maintenance" services than they would on "lifestyle" services. The assumption here is that cities are more likely to make efficiency gains and enjoy economies of scale by delivering system maintenance services on a larger scale than lifestyle services. But here again empirical findings have been inconclusive. Some studies (e.g. Julnes \& Pindur, 1994; Rawlings, 2003; Savitch \& Vogel, 1996) found interlocal service collaboration to be much more common for systems maintenance functions than lifestyle services. Others (e.g. Wood, 2006) found no supporting evidence.

In his study of 1,848 collaborative service delivery arrangements among 46 cities and counties in the Kansas City Metropolitan area Wood (2006) found no evidence to support the notion that local governments are mostly inclined to collaborate on systems maintenance functions than lifestyle goods. He noted rather that collaboration for lifestyle goods and services occur at almost the exact same rate as cooperation for systems maintenance functions. 


\section{Form of Local Government}

To a large extent, the decision to produce or provide a service is very political. This is why the form of government - Mayor Council, Commission or Council Manager - is an important factor for explaining decisions to participate in interlocal collaboration (Ferris \& Graddy, 1986; Sonenblum et al., 1977). The council-manager form of government in particular has been identified as a very significant predictor of collaboration because of the common values and norms city managers share (Bartle \& Swayze, 1997; Krueger \& McGuire, 2005; Morgan \& Hirlinger, 1991; Thurmaier \& Wood, 2002; Wood, 2006).

In a strict sense elected public officials like mayors and councilmen are not as administrative minded as city managers. As public administrators, city managers perform the role of public entrepreneurs promoting new innovations whilst generating political support. Frederickson (1999) notes that public administrators are able to perform this entrepreneurial role because they usually have a long tenure compared to other elected city officials. They therefore hold shared professional values and norms that are geared towards development. This inner drive motivates them to cooperate with each other as long as it leads to the development of their respective municipalities. In addition to Fredrickson's position, Stein (1990) surmises that professional administrators are also motivated to collaborate in order to enhance their professional reputation.

Other findings indicate that although influential, the council-manager form of government is only significant in cases of private contracting but not for interlocal service agreements (Brown \& Potoski, 2003). 


\section{State Rules}

Prior studies have noted that the "the decision calculus of local leaders" is often influenced by the legal environment within which their municipalities exist (Krueger \& Bernick, 2010, p. 714). Thus state legal environments can either support or inhibit collaborative efforts. Local governments that exist in home rule states for example have the autonomy to decide which possible combinations of service delivery methods are beneficial to its citizens. Additionally, the presence of an Interlocal Cooperation Act provides the legal backing required to reduce the potential risks of opportunism in interlocal collaborations. Municipalities that have this legal backing are more confident to engage in interlocal agreements.

Prior studies that examine the limiting aspects of state laws have however surmised that instruments like state mandates and conditional grants-in-aid tend to promote competition and conflict rather than collaboration among autonomous jurisdictions (McEntire \& Dawson, 2007; Volden, 2007).

\section{Resident Income Levels}

Previous research has also examined the influence of residents' income levels on collaborating patterns (c.f. Leroux, 2006; Morgan \& Hirlinger, 1991; Shrestha, 2008). The notion that low income levels are a general indication of poverty and fiscal stress is the basis for the resident income hypothesis. Just like the fiscal capacity hypothesis, the prevailing argument here is that communities with majority low income residents are more likely to collaborate rather than produce services in-house. The reverse is also true 
for communities with high median incomes. Communities that are wealthy are more likely to produce services in-house because they can afford them.

Yet again, empirical evidence shows that the conventional median income hypothesis is inconclusive. In a study of public safety services for example Andrew (2010) found that high median household incomes are linked to less reliance on interlocal collaboration. Other studies by Morgan and Hirlinger (1991), LeRoux and Carr (2007) and Leroux (2006) have shown that the relationship between per capita income and interlocal collaboration is nonlinear. This means that both wealthy and poor communities are equally likely to use interlocal contracting arrangements. In the case of wealthy communities collaboration occurs because they can afford to experiment with alternative service delivery arrangements (Leroux, 2006).

\section{Density of Local Governments}

The density of local governments is another factor that has been identified in previous studies as a determinant of interlocal collaboration. Post (2004) has noted that the higher the density of local governments in an area the higher the potential for policy spillovers. Interlocal collaboration serves as a control mechanism against free-riding in such instances. The density of local governments also impacts the transaction costs (negotiation, operation, enforcement) of collaboration. Where local government densities

are low, proximity to collaborating partners is limited which may increase the cost of negotiations, operations and enforcement of agreements. The reverse is also true when local governments are highly dense. 


\section{Social Networks}

Local government decision-makers interact and share information on a daily basis at the professional and social levels. Memberships of associations like the International City and County Management Association (ICMA), Council of Governors (COG), Area Development Districts (ADDs), League of Cities and a host of other regional organizations enable municipalities to share common norms, values, rules, and practices. These relationships help build trust which is critical for interlocal collaboration (Kettl, 2013; Roberts, 2008). Thurmaier and Wood (2002) have shown empirically, that social relations among city managers positively influence interlocal collaboration. Similarly, Brown and Potoski (2003) and Lackey et al. (2002) have shown that where administrators belong to similar professional associations they tend to collaborate.

Based on the theory of network homophily (Lazarfeld and Merton, 1954), also known as "like-me" hypothesis, other researchers have hypothesized that municipalities are more likely to interact with those whom they have more in common. Empirical evidence on this logic is however been mixed. Similar to previous findings by Dye, Leibman, Williams and Herman (1963) five decades ago, Foster (1998) has found that central cities and suburbs that share common social and economic characteristics are more likely to collaborate in a number of services than are central cities and suburbs with dissimilar attributes. More recent studies have shown that having similar social and economic characteristics only influences collaboration under less restrictive contractual arrangements (Andrew, 2009). In a study of interlocal public safety agreements in Florida, Andrew and Hawkins (2012) found that communities that have similar levels of median income are more likely to collaborate under mutual aid agreements. He also 
found that contrary to the ICA proposition, racial heterogeneity rather than homogeneity encourages collaboration. In his analysis he found that communities with a higher percentage of white population were more likely to enter into agreements that have localities with a lower percentage of white residents.

\section{Research Gaps}

Given the fact that contemporary public management theory has accepted the principle that managers must operate across organizations (Agranoff \& McGuire, 2003) and that solving seemingly complex social problems of today require mechanisms that are more inclusive and more adaptable (Alter \& Hage, 1993), an in-depth study on the exchange relationships and patterns in collaborative governance is a worthy exercise.

Similar to Andrew's (2009) previous observation there are currently three dominant research approaches to understanding the dynamics of voluntary interlocal collaboration. The first approach addresses interlocal collaboration as one of the many alternatives of service delivery, including in-house production, provision by private enterprises, provision by county, and provision by other municipalities (Brown \& Potoski, 2003; Chen \& Thurmaier, 2009; LeRoux \& Carr, 2007). The likelihood of a municipality choosing to collaborate or otherwise is treated as a variable which is dependent on other social, economic and political explanatory variables. Scholars who adopt this approach often theorize with Williamson's (1971) transaction cost economics or Feoick's $(2005,2009,2013)$ institutional collective action framework. A second approach draws on network values such as credibility, trust and reciprocity to explain how different interlocal networks foster and support collaboration (Andrew, 2009; 
Shrestha, 2010; Thurmaier \& Wood, 2002). The third approach relies on more qualitative case studies and interviews to explore the internal dynamics of collaboration (Taylor \& Bassett, 2007; Zeemering, 2008a).

A review of literature on the three dominant research approaches has revealed inconclusive evidence on why local governments and institutions choose to collaborate. Specifically, the review of literature has shown that prior studies are limited in the following ways:

1) A limited number of researches exist that analyze the determinants of collaboration for different public services (e.g., public safety, economic development, infrastructure etc).

2) A limited number of researches exist that examine the determinants of collaboration based on the number of collaborating partners (e.g., bilateral versus multilateral relations)

3) A limited number of researches exist that examine the determinants of collaboration based on direction (vertical versus horizontal relations). Although in recent times research.

This dissertation will address these gaps by analyzing the patterns of collaboration on a number of services in the state of Kentucky. 


\section{Conclusion}

Collaborative governance has gained popularity over the past two decades. There have been a series of attempts to find empirical explanations to the question of what factors determine interlocal collaboration. Whilst some progress has been made by scholars in answering this question there is yet to be consensus on a general methodology and theory of collaboration. Beside asset specificity, service measurability, reciprocity and recurrence of exchange, other factors including fiscal capacity, labor/capital intensity, form of government, demographic characteristics and social networks have been empirically tested by different scholars albeit with inconclusive results. Although results from these studies are inconclusive, it is worth finding out if these factors are significant determinants in the case of Kentucky. The next section outlines the research questions, hypotheses and methodology for the study 


\section{CHAPTER III \\ RESEARCH QUESTIONS, HYPOTHESES AND METHODOLOGY}

\section{Introduction}

This chapter begins with an outline of the research questions for the study. Based on the extant theoretical and empirical research, six hypotheses are derived to answer these research questions. The final part of the chapter outlines a study design and methodology for operationalizing the research hypotheses.

\section{Research Questions}

The objective of this research is to address some of the gaps identified in the theoretical and empirical research. Following the literature review in chapter II, the following research questions have been identified for further enquiry:

\section{Direction of Collaboration}

o On what services do cities mostly collaborate vertically?

o On what services do cities mostly collaborate horizontally?

o Which network factors have the strongest influence on a city's decision to collaborate with other cities (horizontal collaboration)?

o Which network factors have the strongest influence on a city's decision to collaborate with a county (vertical collaboration)? 


\section{Number of collaborating partners}

o On what services do cities mostly collaborate bilaterally?

o On what services do cities mostly collaborate multilaterally?

o Which network factors have the strongest influence on a city's decision to collaborate with only one partner - city, county, special district, non profit or for-profit (bilateral collaboration)?

o Which network factors have the strongest influence on a city's decision to collaborate with two or more partners (multilateral collaboration)?

\section{Hypotheses}

Consistent with prior research that utilizes the transaction cost (Andrew, 2009; Andrew \& Hawkins, 2012; Carr et al., 2009; Feiock \& Scholz, 2010; Hawkins, 2009) and network embededdness (Leroux, 2006; Shrestha, 2005) theory my central argument in this study is that a municipality's direction of collaboration and the number of collaborating partners are largely influenced by (a) the characteristics of the services and (b) the embeddedness of its network.

Six (6) research hypotheses have been developed from this general argument to address the questions raised in the previous section. A list of these hypotheses and their theoretical and empirical justifications are provided in the sections that follow.

\section{Hypotheses Examining the Direction of Collaboration}

The literature review in chapter II established that municipalities are confronted with the challenge of deciding what direction they want to collaborate. Savitch \& Vogel's 
(1996) three typologies of regional governance suggest that jurisdictions have a choice of interacting horizontally - with local governments of comparable powers - or interacting vertically - with local governments of different powers. Furthermore, the literature has established that the decision to collaborate or not also depends on the characteristics of the service in question such as asset specificity and service measurability (Brown \& Potoski, 2003, 2005; Carr et al., 2009; Feiock, 2007; Ferris \& Graddy, 1986; Shrestha, 2010; Williamson, 1985, 2010). When an investment made in a particular locality is difficult to redeploy to another location or reusable for another purpose such an investment is considered to have high asset specificity. To offset any opportunistic behaviors on the part of partners, local governments may be better off collaborating vertically on asset specific services.

Service measurability refers to the difficulty associated with measuring and monitoring the outcomes of services delivered (Brown \& Potoski, 2003). Service outcomes that are relatively difficult to measure carry greater uncertainty. Thus at higher levels of service measurability cities are better off engaging in vertical collaborations. As services become easy to measure, jurisdictions may turn towards horizontal collaboration. Based on these arguments I hypothesize that:

Hypothesis 1: Cities are more likely to collaborate vertically on services that have high levels of asset specificity and measurement difficulty.

Hypothesis 2: Cities are more likely to collaborate horizontally on services that have lower levels of asset specificity and measurement difficulty. 


\section{Hypotheses Examining the Number of Collaborating Partners}

Review of both theoretical (Coase, 1937; Feiock, 2005, 2008, 2013; Williamson, 1991) and empirical (Brown \& Potoski, 2003; Leroux, 2006; Shrestha, 2008) literature has demonstrated that transaction costs associated with information search, negotiations, and enforcement of negotiations are hindrances to collaboration. The literature has further indicated that the magnitude of these transaction costs is dependent on the specificity or measurability of the service in question. Where assets are specific in transactions, redeployment is difficult and the likelihood of opportunistic behavior is high. In the same vein, where services outputs are difficult to measure, costly, impossible or only partly possible to measure (Milgrom \& Roberts, 1992), it is hard to provide effective incentives or sanctions. The resultant effect is opportunistic behavior.

The extant literature on collective action has also demonstrated that the number of partners in a collaborative arrangement has an indirect relation with collaborative behavior (Chamberlin, 1974; E. Ostrom, 2001). The number of partners in a collaborative arrangement first influences latent factors like asset specificity and service measurability, which in turn influence collaborative behavior. Where services have high levels of asset specificity and measurement difficulty cities are better off with multilateral agreements. In a large group any costs associated with opportunistic behavior are distributed amongst all members. The final cost burden carried by a participating city therefore becomes low. Based on these arguments I hypothesize that:

Hypothesis 3: Cities are more likely to collaborate multilaterally on services that have higher levels of asset specificity and measurement difficulty. 
Hypothesis 4: Cities are more likely to collaborate bilaterally on services that have lower levels of asset specificity and measurement difficulty.

\section{Hypotheses Examining Network Embededness}

The theory of network embededdness in public administration suggests that the primary impulse of cities to collaborate is not purely based on economic reasons but rather the innate tendency to establish norms of reciprocity (Lackey et al., 2002; Thurmaier \& Wood, 2002). This argument is consistent with Frederickson's (1999) administrative conjunction thesis that surmises that administrators tend to work collectively owing to the fact that they share common norms, values, rules, and practices. Empirical evidence from recent studies also point to the fact that social relations among city managers and specialists such as being part of the same council of governments tend to support the use of interlocal agreements (Brown \& Potoski, 2003; Lackey et al., 2002; Thurmaier \& Wood, 2002). According to Brown and Potoski (2003, 2005), previous interactions build trust and credibility which ultimately reduce the risk of opportunistic behavior. This is especially relevant in agreements where services are asset specific, and difficult to measure.

Social network theory also suggests that a local government's position in one set of relations can further reinforces positions in other sets of relationships. That is to say that past collaborations within a network can breed future collaborations due to trust and credibility. In line with these arguments I hypothesize that:

Hypothesis 5: Repeated interaction in the past between transacting jurisdictions increases the likelihood of collaboration. 
Hypothesis 6: Collaboration in other service areas has a positive effect on the likelihood of collaborating on the service in question.

Table 3.1 provides a summary of the transaction characteristics of services included in this study. It also shows the expected patterns of collaboration.

Table 3.1

Characteristics of Services and Expected Pattern of Collaboration

\begin{tabular}{|c|c|c|c|}
\hline Service & $\begin{array}{l}\text { Asset specificity/ } \\
\text { measurability }\end{array}$ & $\begin{array}{l}\text { Vertical/ } \\
\text { Horizontal }\end{array}$ & $\begin{array}{l}\text { Bilateral/ } \\
\text { Multilateral }\end{array}$ \\
\hline \multicolumn{4}{|l|}{ Public Safety } \\
\hline Emergency 911 Radio Communications & HA_EM & Vertical & Multilateral \\
\hline Emergency Medical Response (EMS) & LA_DM & Vertical & Multilateral \\
\hline Fire Protection \& Response & HA_DM & Vertical & Multilateral \\
\hline Police Protection/ Law Enforcement & HA_DM & Vertical & Multilateral \\
\hline Emergency Disaster Planning & HA_DM & Vertical & Multilateral \\
\hline \multicolumn{4}{|l|}{ Economic Development } \\
\hline $\begin{array}{l}\text { Planning, Zoning, Building Inspection } \\
\text { \&Code Enforcement }\end{array}$ & HA_DM & Vertical & Multilateral \\
\hline Financing/Economic Development & LA_EM & Horizontal & Bilateral \\
\hline $\begin{array}{l}\text { Enterprise Zone \& Industrial } \\
\text { Development }\end{array}$ & \multicolumn{2}{|c|}{ Development } & Multilateral \\
\hline Tax Collection \& revenue sharing & HA EM & Vertical & Multilateral \\
\hline Parks and Recreation/ Tourism & LA_DM & Vertical & Multilateral \\
\hline Equipment Sharing & LA_EM & Horizontal & Bilateral \\
\hline $\begin{array}{l}\text { Information sharing/ Human Resources } \\
\text { Sharing }\end{array}$ & LA_EM & Horizontal & Bilateral \\
\hline \multicolumn{4}{|l|}{ Infrastructure } \\
\hline Housing \& energy & HA EM & Vertical & Multilateral \\
\hline Cable \& internet & HA_EM & Vertical & Multilateral \\
\hline Sewer System & HA_EM & Vertical & Multilateral \\
\hline Telecommunications & HA_EM & Vertical & Multilateral \\
\hline Water & $\mathrm{HA}{ }^{-} \mathrm{EM}$ & Vertical & Multilateral \\
\hline $\begin{array}{l}\text { HA_DM: High Asset Specificity, Difficult to } \\
\text { LA_DM: Low Asset Specificity, Difficult to }\end{array}$ & $\begin{array}{ll}\text { ure } & \text { HA_EM: Hig } \\
\text { ure } & \text { LA_EM: Low }\end{array}$ & set Specificit & $\begin{array}{l}\text { Easy to Measure } \\
\text { asy to Measure }\end{array}$ \\
\hline
\end{tabular}




\section{Methodology}

The study is mostly quantitative. Hypotheses 1 to 4 are analyzed using descriptive statistics whilst hypotheses 5 to 6 are analyzed using binary logistic regressions.

\section{Units of Analysis}

The analyses cover all 'home rule' cities in Kentucky with populations above 230 people. It excludes larger jurisdictions like Louisville Jefferson County Metro and Lexington Fayette Urban County governments. These two governments were left out of the study because their population sizes and government structure could potentially affect the variability in the data. Additionally, the service provision relationships between the consolidated Louisville Metro government and independent municipal governments within the consolidated entity are legally determined rather than the product of voluntary collaborative behavior. Cities of population below 230 were also left out of the analysis because sparsely populated municipalities are generally known to rely heavily on their counties for services, thereby limiting their potential for collaboration. Thus out of the three hundred and thirty four (334) incorporated cities in Kentucky, two hundred and ninety nine (299) representing 90 percent of municipalities were included in the final analyses.

\section{Data}

In this study, collaborative governance is examined under three service functions namely; public safety, economic development and Infrastructure. Public safety in particular is important to study because it is one of the major components of local 
government budgets (Carr \& LeRoux, 2005). Economic development and infrastructure were included in the study because they represent the core service agreements in Kentucky beside public safety. Other relevant local governments services like public works (road maintenance, snow plowing, street sweeping) and waste management (solid waste disposal and recycling) were excluded from this research because evidence suggests that most municipalities including the ones in Kentucky usually outsource these services to private contractors.

Interlocal service agreement data on public safety, economic development and infrastructure were sourced from the Kentucky Department of Local Government (KDLG) online database. Pursuant to KRS $65.210-65.300$ (the Interlocal Cooperation Act), all interlocal cooperation agreements entered into between cities, counties, charter counties, urban-county governments, and sheriffs (and any combination thereof) are submitted to the Department of Local Government for approval. The KDLG data provides specific information on the nature and content of all collaborative agreements including:

(1) The name of the service to be performed;

(2) Collaborating parties involved;

(3) The location of the service to be performed;

(4) The means of payment of the cost of the service

Of the six hundred and forty eight (648) interlocal agreements reported by the Kentucky Department of Local Government between years 2000 and 2013, three hundred and sixty two (362) representing 55.9 percent were selected and used in the analyses. The 
remaining two hundred and eighty six (286) agreements that were left out of the analyses were either inter-county agreements, grant based agreements or agreements between any of the 119 cities excluded from the study.

Data pertaining to median income and population were sourced from the US Census Bureau. Data on local government fiscal capacity was sourced from the annual financial reports from the cities submitted to the Department of Local Government and retained and distributed by the Kentucky League of Cities.

\section{Research Design}

The hypotheses in this study were tested as two separate but reinforcing parts. Hypotheses 1 to 4 address general transaction characteristics (asset specificity and service measurability) while hypotheses 5 and 6 address network embeddedness. Consistent with Brown and Potoski $(2001,2003,2005)$ and Andrew \& Hawkins (2012) the services were examined under four transaction characteristics: (1) low asset specificity and low service measurability, (2) high asset specificity and high service measurability, (3) low asset specificity but high service measurability, and (4) high asset specificity but low service measurability. Appendix 1 provides details of services under each category.

Descriptive statistics were used to measure the degree to which the four transaction characteristics fall under vertical, horizontal, bilateral and multilateral collaborations. Similar methodological approaches have been utilized by Dustin, Jones and Levine (2009) in their extensive study of local government collaboration in Ohio as well as Caruson and MacManus (2010) in their study of interlocal emergency management collaboration in Florida. Hypotheses 5 and 6 were examined using a binary 
logistic model. The sections that follow explain the variables and statistical tests used in analyzing hypotheses 5 and 6 .

\section{Variables}

Four variables, each addressing the mode of collaboration (vertical, horizontal, bilateral, multilateral), serve as dependent variables in the analyses. Not participating in any mode of service delivery serves as the reference category in all models. The dependent variables were examined under three service categories: (1) public safety (2) economic development and (3) infrastructure development. Table 3.1 provides details of the services included in each service category.

Service agreements amongst cities are not mutually exclusive; this means that a city may collaborate with another city in law enforcement whilst collaborating with another city on fire service. Where a city maintains two or more agreements in a service category, one service was randomly selected and used in the analyses. In public safety, thirty (30) samples were selected under bilateral collaboration; twenty four (24) samples were selected under multilateral collaborations; forty eight (48) samples were selected under vertical collaborations while six (6) samples were selected under horizontal collaborations. In economic development thirteen (13) samples were selected under multilateral collaborations; twelve (12) samples were selected under bilateral collaborations; eleven (11) samples were selected under vertical collaborations while three (3) samples were selected under horizontal collaborations. Finally, in infrastructure, seven (7) samples were selected under multilateral collaborations; sixteen (16) samples were selected under bilateral collaborations; twenty five (25) samples were selected 
under vertical collaboration while one (1) sample was selected under horizontal collaboration.

Two (2) predictor variables were included in the model to explain the dependent variables in each of the three (3) service categories. These predictor variables are collaborations in other services and repeated interaction. Control variables in the model are variables that appeared as predictors of interlocal collaboration in previous studies (Carr et al., 2007; Leroux, 2006; Morgan \& Hirlinger, 1991; Post, 2002, 2004; Shrestha, 2008). They are fiscal capacity, county density, city population, median household income, county seat and form of government. Table 3.2 provides a summary of all variables included in the study. 
Table 3.2

Summary of Variables

Variables

Dependent Variables

Direction of service delivery

(vertical / horizontal)

No. of Collaborating partners

(bilateral / multilateral)

Predictor Variables

Collaboration in other services

Repeated interaction

\section{Controls}

Fiscal Capacity

Density of municipalities

City population

Median household income

County seat

Form of government

Source: Author's construct, 2016

\section{Variable Construction}

A dichotomous variable scored 1 when a city uses a particular mode of delivery, 0 otherwise

Number of other services a city is collaborating in. The number of years a city has been collaborating

Cities' own source revenue measured in dollars per capita (Kentucky League of Cities, 2015) The number of municipalities in a City's county per square 100 square miles

A city's population in thousands transformed into natural log (American Community Survey 5 Year Data, 2009 - 2013)

Natural log of median household income in dollars (American Community Survey 5 Year Data, 2009 2013)

A city that also serves as seat of county government (Kentucky League of Cities)

A dichotomous measure indicating whether a city has council mayor (1) or otherwise (0).

\section{Measures of the Variables}

Dependent Variables

Two variables addressing interlocal collaboration in terms of number of partners (bilateral and multilateral) and two variables addressing interlocal collaboration in terms 
of direction (vertical and horizontal) were used as dependent variables. A bilateral agreement in this study is one that has only two partners of which one is a municipality. It could either be an agreement between two municipalities, between a municipality and a county or between a special district and a municipality. A multilateral agreement is one that has three or more partners of which at least one is a municipality. A vertical agreement is one that has at least one city and one county partner. A horizontal agreement is one that has at least two local governments. Available data on interlocal agreements from the Kentucky Department of Local Government website provided indication of which agreements are bilateral, multilateral, vertical or horizontal.

\section{Predictor Variables}

Two (2) predictor variables derived from the theoretical and empirical literature on exchange relations are included in the model. These variables are other collaborations and repeated interaction.

A review of the literature on social network theory suggested that a local government's position in one set of relations could further reinforce positions in other sets of relationships (Leroux, 2006; Shrestha, 2005). This means that if city A collaborates with city B on law enforcement, city A is likely to collaborate with city B or any other local government (city or county) on emergency services. Put in simple terms, collaboration breeds further collaborations. Other collaborations in this study was operationalized as the total number of other collaborative agreements a city has signed beside the one under consideration. 
It was further established in the literature review section that by engaging in repeated exchanges jurisdictions are able to develop trust, credibility and commitment in their transactions (Andrew, 2009; Coleman, 1988; Frederickson et al., 2004; Wukich, 2014). Parties involved in a long, close relationship with frequent interactions have opportunities to develop understandings and routines that reduce the need for explicit planning to coordinate their actions (Milgrom \& Roberts, 1992). Such interpersonal relations arising out of exchange relationships help mitigate transaction risks and facilitate further interlocal exchange (Olberding, 2002; Poppo \& Zenger, 2002; Schneider et al., 2003; Uzzi, 1996). Through this process of exchange embeddedness the behavior of collaborating partners becomes more predictable for existing and subsequent exchanges (Gulati \& Gargiulo, 1999) creating a basis for increased interlocal cooperation (Gerber \& Gibson, 2005). In this study, repeated interaction was operationalized as the period of time a city has maintained an agreement within a particular service category. Ultimately, the longest running agreement was the focal point in each service category.

\section{Control Variables}

The control variables employed in this study are variables that were used as predictors of interlocal collaboration in prior studies but ended up producing competing results (e.g. Carr et al., 2007; Leroux, 2006; Morgan \& Hirlinger, 1991; Post, 2002, 2004; Shrestha, 2008). They are fiscal capacity, county density, city population, median household income, county seat and form of government.

Previous research has often hypothesized that the state of a city's fiscal health can influence its decision to either collaborate or not. Where cities are fiscally stressed due to low internal revenue mobilization or limited federal and state revenue inflows tended to 
engage in collaborative arrangements with other local jurisdictions in order to manage fiscal hardships (Agranoff \& McGuire 2003; Stein, 1990). In this study fiscal capacity was operationalized as a city's own source revenue measured in dollars per capita. Federal and state funds were left out of the model for some reasons. First, federal and state funds are generally outside the control of cities. Since cities do not necessarily control what these funds are used for, this study does not regard them as good proxies for examining the internal financial capacity of cities. Additionally, the provision of federal and state funds is usually tied to specific statutory mandated collaborative arrangements. Since this study is focused solely on voluntary collaborations, federal and state funds were left out of the model. The own source revenue variable was transformed into revenue per capita by dividing every city's revenue over its total population. This transformation was to done in order to normalize the distribution and avoid biases in the model.

The density of municipalities in a city's county was also included in the analyses to control for regional fragmentation (Andrew \& Hawkins, 2012). The study assumes that cities that belong to a common county have a shared value system and responsibility towards development. Where more cities exist per 100 square miles of a county, there is a high likelihood for close collaboration and vice versa. This assumption is supported by Post's (2002) observation of increased local cooperation in higher density regions. In this study the density of local governments was determined by dividing the number of general-purpose local governments in a County by its land and transforming the result into a natural log. 
Previous research has established that the size of a city's population provides a general indication of its potential for achieving economies of scale (Joassart-Marcelli \& Musso, 2005; Nelson, 1997). City size was operationalized as the total population of the city in year 2013. The city size variable was transformed by natural log to normalize its distribution.

A city's median household income provides a general indication of its residents' effective demand for services. Evidence suggests that both high income and low income municipalities engage in interlocal collaboration for a variety of reasons (Morgan \& Hirlinger, 1991). Because municipalities with lower household incomes tend to lack lifestyle services like recreational parks, golf courses, and country clubs they are more likely to be motivated for collaboration in order to gain access to lifestyle services. Rich communities, on the other hand, may engage in increased cooperation for higher quantity or quality of services because of their ability to pay. A natural $\log$ of the median household income derived from the 2009-2013 American Community Survey 5-year estimates was utilized in the analysis.

County seat status reflects the vertical collaborative capacity of a city. Where a city serves as county seat, it is more likely to have a high concentration of county administrative offices. The proximity of county officials to city officials may in turn increase the likelihood of collaboration. This implies that a city that serves as county seat may have less need for collaboration with other cities outside the county. The county seat variable was operationalised as a dichotomous variable coded 1 where a city is a county seat and 0 where it is not. 
The form of government characterizes the political and administrative conditions of a city. Frederickson's (1999) administrative conjunctions theory suggests that professional administrators are more likely to support interlocal collaboration because of their long tenure and shared public service ethics. A council-manager form of government is often considered efficiency oriented (Ruhil et al., 1999) and entrepreneurial (Teske, Schneider, and Mintrom, 1995) compared to a mayor-council government. Interlocal cooperation is expected to be more likely in municipalities with a council-manager government than in cities with a mayor-council or commission form of government. In this study, form of government was modeled as a dummy variable with council-manager form of government serving as reference category.

\section{Statistical Analysis}

Variables in the data were analyzed using both descriptive statistics and binary logistic regression models. A number of statistical diagnostics were carried out to ensure results of the logistic regression models are more robust. To ensure that predictor variables are independent of each other collinearity statistics were sought and examined using tolerance and variance inflation factors (VIFs). Any values of the tolerance statistic less than 0.1 and any values of the VIF statistic over 10 was regarded as a problematic variable. Collinearity in the final model was low; variance inflation factors (VIFs) ranged from 1.029 to 2.168 (any value below 10 was deemed acceptable). There were no outliers or influential cases in the models.

Linearity of association between the dependent variables and the interval/ratio predictors was examined using scatterplots of studentized residuals and a loess fit line. 
Curved patterns indicated a non-linear effect of the variable. All scatterplots in the final models indicated there were only linear relationships between the independent variables and studentized residuals.

In the initial analyses, the standard error for city manager form of government under horizontal collaboration in economic development appeared inflated due to the small number of respondents with a city manager form of government. The decision was made based on size to combine commission and city manager forms of government into a single category under economic development. After doing so, there were no longer any inflated standard errors.

Goodness of fit statistics (Cox and Snell $r^{2}$, Nagelkerke $r^{2}$ and p-value) were reported for each model. Both full and parsimonious models were sought, with the parsimonious model being produced via backwards selection ( $p>.10$ to exit). In order to improve the interpretability of the intercept in the models, all interval/ratio and dummy independent variables were mean-centered prior to completing the analyses. The model used in the analyses was of the form:

$$
\ln \left(\frac{p}{1-p}\right)=\beta_{0}+\sum \beta_{i} X_{i}+\varepsilon
$$

\section{Conclusion}

Research on collaborative governance has doubtlessly flourished over the past three decades. Notwithstanding its increasing popularity there are still certain gaps in literature that merit further investigation. Based on the review of existing theoretical and empirical literature the study focused attention on two of these research gaps - direction 
of collaboration and number of collaborating partners. A number of research questions have been raised and six (6) hypotheses developed to address these research gaps. Consistent with previous studies, the analyses in this research are done using both descriptive statistics (for hypothesis $1-4$ ) and binary logistic regression (for hypotheses $5-6)$. The next chapter tests the research hypotheses. 


\section{CHAPTER IV}

\section{PATTERNS OF INTERLOCAL COLLABORATION: ANALYSES OF DATA}

\section{Introduction}

This chapter shows the results of the data analyzed in the study. It begins with a brief overview of interlocal governance and interlocal collaboration in the Commonwealth of Kentucky. This is followed by descriptive statistics of the dependent variables. The final part of this chapter describes the full and parsimonious models of the binary logistic regressions.

\section{Overview of Local Governance in Kentucky}

Kentucky has 418 general purpose local governments (Kentucky League of Cities, 2012, p. 4). Prior to the enactment of the Municipal Reclassification Reform Act, House Bill 331 (KRS 81.005), Kentucky had six classes of cities. This included one first class city, 13 second class cities, 18 third class cities, 117 fourth class cities, 111 fifth class cities and 158 sixth class cities. Effective January 1, 2015, pursuant to Kentucky House Bill 331, the arbitrary classification system with six classifications changed to two classes - first class and home rule cities. The city of Louisville remained the only first class city by virtue of being a consolidated local government. Lexington became a home rule city although it still maintains all responsibilities and privileges under its urban-county statutes. 
Kentucky cities operate under one of four forms of government - mayor alderman, mayor council, commission or city manager. Only the Louisville Metro government operates under the mayor-alderman form of government due to its first class status. Fifty three (53) percent of cities operate under mayor-council, forty two (42) percent operate under commission form of government while five (5) percent operate under the city manager form (Kentucky League of Cities, 2012, p. 9).

\section{General Overview of Interlocal Agreements in Kentucky}

"If the cities of Kentucky had a slogan, it would probably be 'doing more with less ..."” Sarah Razor, (2011, p. 26)

Interlocal collaboration is a widely recognized mode of service delivery in the Commonwealth of Kentucky. Its application spans from public safety, infrastructure development, watershed management to equipment and revenue sharing. Part of the reasons for this popularity is the fact that governments at all levels recognize they could do “...more with less..." for their citizens through joint efforts (Razor, 2011, p. 26). Most importantly, the laws governing local governance in Kentucky provide legitimacy to interlocal activities. The Kentucky Interlocal Cooperation Act (KRS 65.210-65.300) is a law that has, since its creation in 1962, authorized cities to engage in collaborative agreements for the purposes of performing a function or delivering public services. As a guide, the Act requires all interlocal agreements to specify the duration of an agreement; the composition and powers of participants; how a joint activity will be financed as well as the proper procedures for termination and disposal of properties. For an agreement to 
be legally binding, it must be approved by the Kentucky Department for Local Government.

Between 2000 and 2013, Kentucky recorded a total of 648 interlocal service agreements. Out of this figure, 627 were voluntary agreements while the remaining 21 were agreements that were tied to state grants. Of the 627 voluntary agreements 68 were inter-county agreements while the rest (559) were interlocal service agreements that had at least one city as a participant. Mutual aid agreements constituted 3.8 percent of the 559 interlocal service agreements. The remaining 96.2 percent were either pay-for-service or joint service agreements.

\section{Results}

\section{Descriptive Statistics for Dependent Variables}

Descriptive statistics for the dependent variables are reported in Tables 4.1 and 4.2. Out of the 648 interlocal service agreements recorded between years 2000 and 2013 by the Department of Local Government, 362 agreements representing 55.9 percent were included in the survey. The 362 agreements used in this study include collaborative agreements between cities selected for the study and cities excluded from the study. The 286 agreements that were excluded from the study comprises inter-county agreements, grant based agreements and agreements signed between any of the 119 cities that were left out of the study. According to Table 4.1, of the three service categories examined in this study, public safety services rank the highest (41.1 percent) in terms of interlocal collaboration. This is followed by economic development (35.4 percent) and infrastructure services (23.5 percent) in that order. 
With respect to the direction of collaboration, Table 4.1 indicates that economic development exhibits a greater association (93.8 percent) with vertical collaboration whilst public safety exhibits a greater association (18.8 percent) with horizontal collaboration. Moreover, in terms of the number of partners in an agreement, infrastructure exhibits a greater association (85.9 percent) with bilateral collaboration whilst public safety exhibits a greater association (27.5 percent) with vertical collaboration.

Table 4.1

Descriptive Statistics for Dependent Variables

\begin{tabular}{|c|c|c|c|c|c|}
\hline \multirow[t]{2}{*}{ Service category } & \multirow[t]{2}{*}{$\%$ of $N$} & \multicolumn{2}{|c|}{ Direction } & \multicolumn{2}{|c|}{ No. of Partners } \\
\hline & & Vertical & Horizontal & Multilateral & Bilateral \\
\hline $\begin{array}{l}\text { Public Safety } \\
\text { (149) }\end{array}$ & $(41.1 \%)$ & $81.2 \%$ & $18.8 \%$ & $27.5 \%$ & $72.5 \%$ \\
\hline $\begin{array}{l}\text { Economic } \\
\text { Development } \\
\text { (128) }\end{array}$ & $(35.4 \%)$ & $93.8 \%$ & $6.2 \%$ & $14.8 \%$ & $85.2 \%$ \\
\hline $\begin{array}{l}\text { Infrastructure } \\
(85)\end{array}$ & $(23.5 \%)$ & $89.4 \%$ & $10.6 \%$ & $14.1 \%$ & $85.9 \%$ \\
\hline $\mathrm{N}=362$ & & & & & \\
\hline
\end{tabular}

Consistent with Brown \& Potoski (2001, 2003, 2005) and Andrew \& Hawkins (2012) Table 4.2 examines the dependent variables under four transaction characteristics: (1) high asset specificity and difficult to measure, (2) high asset specificity but easy to measure (3) low asset specificity and easy to measure (4) low asset specificity but difficult to measure. The results displayed in Table 4.2 indicate that of the four transaction categories examined in this study, services that are highly asset specific but easily measurable rank the highest (41.4 percent) in terms of interlocal collaboration. Services that are highly asset specific and at the same time difficult to measure rank 
second (40.1 percent) followed by services that have low asset specificity but are difficult to measure (11.1 percent) and services that have low asset specificity but are easy to measure (7.4 percent) in that order.

Table 4.2

Descriptive Statistics for Dependent Variables based on Transaction Characteristics

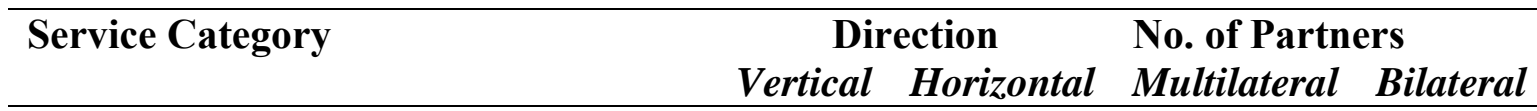

high asset specificity and difficult to measure

Fire Protection \& Response

Police Protection/ Law Enforcement

Emergency Disaster Planning

Planning and Zoning Building

Inspection \&Code Enforcement

$34 \% \quad 6.1 \% \quad 11 \% \quad 29.1 \%$

Enterprise Zone \& Industrial

Development

high asset specificity but easy to measure

Emergency 911 Radio Communications

Tax Collection \& revenue sharing

Housing \& energy

$\begin{array}{llll}38.4 \% & 3 \% & 8.8 \% & 32.6 \%\end{array}$

Cable \& internet

Sewer System

Telecommunications

Water

low asset specificity and easy to measure

Financing/Economic Development

$\begin{array}{lllll}\text { Equipment Sharing } & 10 \% & 1.1 \% & 1.1 \% & 10 \%\end{array}$

Information sharing/ Human Resources

Sharing

low asset specificity but difficult to measure

$\begin{array}{lllll}\text { Emergency Medical Response (EMS) } & 5.2 \% & 2.2 \% & 0.9 \% & 6.5 \%\end{array}$

Parks and Recreation/ Tourism

\begin{tabular}{lllll}
\hline $\mathrm{N}=362$ & $\mathbf{8 7 . 6 \%}$ & $13.4 \%$ & $19.9 \%$ & $\mathbf{8 0 . 1 \%}$ \\
\hline
\end{tabular}

Source: Author's Construct (2016) based on Brown and Potoski (2001. Pg. 31; 2003) 
With respect to the direction of collaboration, table 4.2 shows that services that are highly asset specific but easy to measure exhibit a greater association (38.4 percent) with vertical collaborations while services that are highly asset specific but difficult to measure exhibit a greater association (6.1 percent) towards horizontal collaborations. Additionally, with respect to the number of collaborating partners, services that are highly asset specific but easy to measure exhibit a greater association (32.6 percent) with bilateral collaborations while services that are highly asset specific but difficult to measure (11 percent) exhibit a greater association with multilateral collaborations.

\section{Descriptive Statistics for Predictor and Control Variables}

Descriptive statistics on the predictor and control variables are reported in Table 4.3. On the average a municipality has collaborated repeatedly for 7.5 years on 2.5 services. Additionally the results indicate that the average municipality generates $\$ 93.27$ as revenue from sources other than the county or state. This revenue figure was unusually low because of missing data on revenue. The uniform financial report provided by the Kentucky League of Cities did not provide revenue information for all the cities included in the study.

Table 4.3 indicates that on the average 1.9 cities exist per 100 square miles of a county. The average number of people in a city is 4,502 whilst the median municipal household income is $\$ 37,118.70$. Amongst the 299 cities included in the study, 37.8 percent serve as county seats. With respect to form of government, 29.4 percent of cities operate a commission form of government, 64.2 percent operate a mayor-council form of government while 6.4 percent operate a city manager form of government. 
Table 4.3

Descriptive Statistics for Predictor Variables

\begin{tabular}{lrrrr}
\hline \multicolumn{1}{c}{ Variable } & Min. & Max. & Mean & Std. Dev. \\
Predictors & & & & \\
Collaboration in other services & 0 & 26 & 2.50 & 3.52 \\
Repeated interaction & 0 & 14 & 6.89 & 5.30 \\
& & & & \\
Controls & & & & \\
Fiscal Capacity & 0 & 6,804 & 93.27 & 497.94 \\
Municipal Density & 0.2 & 9.82 & 0.02 & 0.02 \\
City population & 232 & 61,488 & $4,501.81$ & $7,980.67$ \\
Median household income & 11,813 & 106,250 & $37,118.70$ & $15,046.44$ \\
County seat & 0 & 1 & 0.38 & 0.49 \\
Form of government & 0 & 2 & 0.77 & 0.55 \\
\hline N = 299 & & & & \\
${ }^{1}$ Reference group & & & & \\
\hline Source: Author Construct, 2016 & & &
\end{tabular}

Source: Author's Construct, 2016

\section{Regression Models on the Direction of Collaboration}

Tables 4.4 to 4.9 display the results of the final regression models that examine the direction of collaboration in public safety, economic development and infrastructure. Analyses are based on the parsimonious models.

\section{Public Safety}

\section{Vertical Collaboration}

As shown in Table 4.4, four variables (collaboration in other services, repeated interaction, county density and median income) out of the eight predictor variables are significant predictors of the likelihood of vertical collaboration in public safety. The parsimonious model explained approximately 35 percent of the unexplained variance of the dependent variable (i.e. Cox and Snell $R^{2}=0.354$; Nagelkerke $R^{2}=0.504$ ). 
Table 4.4

Binary Logistic Regression Models Predicting the Likelihood of Vertical Collaboration in Public Safety ${ }^{1}$

\begin{tabular}{|c|c|c|c|c|}
\hline \multirow[t]{2}{*}{ Variables } & \multicolumn{2}{|l|}{ Full model } & \multicolumn{2}{|c|}{ Parsimonious model $^{2}$} \\
\hline & Odds ratios & S.E & Odds ratios & S.E \\
\hline Collaboration in other services & $1.709 * * *$ & 0.112 & $1.724 * * *$ & 0.105 \\
\hline Repeated interaction & $1.122 * *$ & 0.042 & $1.127 * *$ & 0.041 \\
\hline Fiscal Capacity (per capita) & 1.000 & 0.000 & & \\
\hline County Density & $0.535 * * *$ & 0.137 & $0.525 * * *$ & 0.130 \\
\hline City population (ln) & 0.975 & 0.189 & & \\
\hline Median income $(\ln )$ & 0.392 & 0.620 & $0.321 *$ & 0.559 \\
\hline County seat & 1.226 & 0.424 & & \\
\hline \multicolumn{5}{|l|}{$\begin{array}{l}\text { Form of Government } \\
\text { (Commission = reference group) }\end{array}$} \\
\hline Mayor Council & 1.378 & 0.462 & & \\
\hline City Manager & 1.378 & 0.867 & & \\
\hline Constant & $0.210 * * *$ & 0.210 & $0.212 * * *$ & 0.208 \\
\hline \multicolumn{5}{|c|}{$\begin{array}{l}{ }^{1} \text { Based on } n=299 \text { municipalities; Cox and Snell } R^{2}=0.35 \text { and Nagelkerke } R^{2}=0.511 \\
\text { for the full model; Cox and Snell } R^{2}=0.354 \text { and Nagelkerke } R^{2}=0.504 \text { for the } \\
\text { parsimonious model; all independent variables are mean centered so the constant may be } \\
\text { interpreted as the odds of vertical collaboration for the average municipality } \\
{ }^{* * * p}<0.01,{ }^{*} p<0.05, * p<0.10 \\
{ }^{2} \text { Parsimonious model produced using backward selection }(p>0.10 \text { to exit) }\end{array}$} \\
\hline
\end{tabular}

Source: Author's Construct, 2016

Table 4.4, shows that each one-unit increase in the number of other service collaborations is associated with a 72.4 percent increase in the likelihood vertical collaboration in public safety. Additionally, each one-year increase in the duration of collaboration is associated with a 12.7 percent increase in the likelihood vertical collaboration in public safety. However, each one-unit increase in the number of cities per 100 square miles is associated with a 47.5 percent decrease in the likelihood of vertical collaboration in public safety. Again, each dollar increase in median income is associated with a 67.9 percent decrease in the likelihood of vertical collaboration in public safety. 


\section{Horizontal Collaboration}

The results of regression models predicting the likelihood of horizontal collaboration in public safety are displayed in Table 4.5. Five variables (collaboration in other services, repeated interaction, median income, county seat and mayor council) out of the eight predictor variables employed in the model are significant. The parsimonious model explained approximately 30 percent of the unexplained variance of the dependent variable (i.e. Cox and Snell $R^{2}=0.296$; Nagelkerke $R^{2}=0.568$ ).

Table 4.5

Binary Logistic Regression Models Predicting the Likelihood of Horizontal Collaboration in Public Safety ${ }^{1}$

\begin{tabular}{lllll}
\hline Variables & \multicolumn{2}{l}{ Full model } & & \multicolumn{2}{l}{ Parsimonious model $^{2}$} \\
& & & & \\
& Odds ratios & S.E & Odds ratios & S.E \\
\hline Collaboration in other services & $1.356^{* *}$ & 0.091 & $1.387^{* * *}$ & 0.080 \\
Repeated interaction & $1.170^{* *}$ & 0.076 & $1.176^{* *}$ & 0.077 \\
Fiscal Capacity (per capita) & 0.999 & 0.002 & & \\
County Density & 1.111 & 0.091 & & \\
City population (ln) & 0.825 & 0.274 & & \\
Median income (ln) & $5.617^{* *}$ & 0.871 & $7.433^{* *}$ & 0.751 \\
County seat & 0.454 & 0.684 & $0.293^{* *}$ & 0.595 \\
Form of Government & & & & \\
(Commission = reference group) & & & & \\
$\quad$ Mayor Council & 2.919 & 0.760 & $2.933^{*}$ & 0.569 \\
$\quad$ City Manager & 0.681 & 1.571 & & \\
Constant & $0.033^{* * *}$ & 0.467 & $0.031^{* * *}$ & 0.465
\end{tabular}

${ }^{1}$ Based on $n=299$ municipalities; Cox and Snell $R^{2}=0.301$ and Nagelkerke $R^{2}=0.579$ for the full model; Cox and Snell $R^{2}=0.296$ and Nagelkerke $R^{2}=0.568$ for the parsimonious model; all independent variables are mean centered so the constant may be interpreted as the odds of horizontal collaboration for the average municipality; $* * * \mathrm{p}<0.01, * * \mathrm{p}<0.05, * \mathrm{p}<0.10$

2 Parsimonious model produced using backward selection ( $p>0.10$ to exit)

Source: Author's Construct, 2016 
From Table 4.5, it is clear that each one-unit increase in the number of other service collaborations is associated with a 38.7 percent increase in the likelihood horizontal collaboration in public safety. Similarly, each one-year increase in the duration of collaboration is associated with a 17.6 percent increase in the likelihood horizontal collaboration in public safety. Again, each dollar increase in median income is associated with a 643.3 percent increase in the likelihood of horizontal collaboration in public safety. Also having a mayor-council form of government is associated with a county seat is associated with a 193.3 percent increase in the likelihood of horizontal collaboration in public safety. However, being a county seat is however associated with a 70.7 percent decrease in the likelihood of horizontal collaboration in public safety.

\section{Economic Development}

\section{Vertical Collaboration}

Table 4.6 provides results of regression models predicting the likelihood of vertical collaboration in economic development. Four variables (collaboration in other services, repeated interaction, county seat and city manager) out of the eight predictor variables employed in the model are significant. The parsimonious model explained approximately 21 percent of the unexplained variance of the dependent variable (i.e. Cox and Snell $R^{2}=0.209$; Nagelkerke $R^{2}=0.352$ ). 
Table 4.6

Binary Logistic Regression Models Predicting the Likelihood of Vertical Collaboration in Economic Development ${ }^{1}$

\begin{tabular}{lllll}
\hline Variables & Full model & & \multicolumn{2}{c}{ Parsimonious model $^{2}$} \\
& Odds ratios & S.E & Odds ratios & S.E \\
\hline Collaboration in other services & 1.088 & 0.061 & $1.126^{* *}$ & 0.056 \\
Repeated interaction & $1.147^{* *}$ & 0.046 & $1.153^{* *}$ & 0.045 \\
Fiscal Capacity (per capita) & 0.999 & 0.001 & & \\
County Density & 1.044 & 0.082 & & \\
City population (ln) & 1.065 & 0.197 & & \\
Median income (ln) & 1.027 & 0.674 & & 0.372 \\
County seat & $3.691 * *$ & 0.480 & $3.087 * *$ & \\
Form of Government & & & & \\
(Commission = reference group) & & & & \\
\multicolumn{1}{c}{ Mayor Council } & 1.004 & 0.542 & & \\
$\quad$ City Manager & $4.292^{*}$ & 0.851 & $4.762^{* *}$ & 0.591 \\
Constant & $0.102^{* * *}$ & 0.267 & $0.108^{* * *}$ & 0.251
\end{tabular}

${ }^{1}$ Based on $n=299$ municipalities; Cox and Snell $R^{2}=0.217$ and Nagelkerke $R^{2}=0.365$ for the full model; Cox and Snell $R^{2}=0.209$ and Nagelkerke $R^{2}=0.352$ for the parsimonious model; all independent variables are mean centered so the constant may be interpreted as the odds of vertical collaboration for the average municipality $* * * \mathrm{p}<.01, * * \mathrm{p}<.05, * \mathrm{p}<.10$

${ }^{2}$ Parsimonious model produced using backward selection $(p>.10$ to exit)

Source: Author's Construct, 2016

Table 4.6, shows that each one-unit increase in the number of other service collaborations is associated with a 12.6 percent increase in the likelihood of vertical collaboration in economic development. Each one-year increase in the duration of collaboration is associated with a 15.3 percent increase in the likelihood horizontal collaboration in economic development. Being the seat of county government and having a city manager form of government are associated with 208.7 percent and 376.2 percent increase in the likelihood of vertical collaboration in economic development respectively. 


\section{Horizontal Collaboration}

Table 4.7 provides results of regression models predicting the likelihood of horizontal collaboration in economic development. Only the collaboration in other services and city population variables were significant in this model. The parsimonious model explained approximately 7 percent of the unexplained variance of the dependent variable (i.e. Cox and Snell $R^{2}=0.074$; Nagelkerke $R^{2}=0.216$ ).

Table 4.7

Binary Logistic Regression Models Predicting the Likelihood of Horizontal Collaboration in Economic Development ${ }^{1}$

\begin{tabular}{lllll}
\hline Variables & Full model & \multicolumn{3}{c}{ Parsimonious model $^{2}$} \\
& Odds ratios & S.E & Odds ratios & S.E \\
\hline Collaboration in other services & $1.152^{* *}$ & 0.065 & $1.171^{* *}$ & 0.057 \\
Repeated interaction & 0.992 & 0.149 & & \\
Fiscal Capacity (per capita) & 1.000 & 0.001 & & \\
County Density & 1.180 & 0.105 & & 0.232 \\
City population (ln) & $1.710^{*}$ & 0.412 & $1.670^{*}$ & \\
Median income (ln) & 0.414 & 1.517 & & \\
County seat & 1.340 & 0.746 & & \\
Form of Government ${ }^{3}$ & & & & \\
(Commission/city manager $=$ & & & & \\
reference group) & & & & \\
\multicolumn{1}{c}{ Mayor Council } & 1.194 & 0.642 & & \\
Constant & $0.029 * * *$ & 0.414 & $0.033^{* * *}$ & 0.368 \\
\hline
\end{tabular}

${ }^{1}$ Based on $n=299$ municipalities; Cox and Snell $R^{2}=0.082$ and Nagelkerke $R^{2}=0.241$ for the full model; Cox and Snell $R^{2}=0.074$ and Nagelkerke $R^{2}=0.216$ for the parsimonious model; all independent variables are mean centered so the constant may be interpreted as the odds of horizontal for the average municipality

$* * * \mathrm{p}<0.01, * * \mathrm{p}<0.05,{ }^{*} \mathrm{p}<0.10$

2 Parsimonious model produced using backward selection ( $p>0.10$ to exit)

${ }^{3}$ In the regressions commission and city manager forms of government were combined as one variable in order to reduce the initial inflated standard errors.

Source: Author's Construct, 2016 
Table 4.7 shows that collaboration in other services is associated with a 17.1 percent increase in the likelihood of horizontal collaboration in economic development. Again, each one unit increase in the number of people in a city is associated with a 67 percent increase in the likelihood of horizontal collaboration in economic development.

\section{Infrastructure}

\section{Vertical Collaboration}

Table 4.8 provides results of regression models predicting the likelihood of vertical collaboration in infrastructure. One variable (repeated interaction) out of the eight predictor variables is significant. The parsimonious model explained approximately 23 percent of the unexplained variance of the dependent variable (i.e. Cox and Snell $R^{2}$ $=0.234 ;$ Nagelkerke $R^{2}=0.339$ ). 
Table 4.8

Binary Logistic Regression Models Predicting the Likelihood of Vertical Collaboration in Infrastructure ${ }^{1}$

\begin{tabular}{lllll}
\hline Variables & Full model & & \multicolumn{2}{c}{ Parsimonious model $^{2}$} \\
& & & & \\
& Odds ratios & S.E & Odds ratios & S.E \\
\hline Collaboration in other services & 1.095 & 0.057 & & \\
Repeated interaction & $1.269^{* * *}$ & 0.040 & $1.264^{* * *}$ & 0.034 \\
Fiscal Capacity (per capita) & 0.999 & 0.001 & & \\
County Density & 0.943 & 0.072 & & \\
City population (ln) & 0.814 & 0.168 & & \\
Median income (ln) & 0.801 & 0.517 & & \\
County seat & 1.281 & 0.393 & & \\
Form of Government & & & & \\
(Commission = reference group) & & & & \\
$\quad$ Mayor Council & 0.776 & 0.408 & & \\
$\quad$ City Manager & 0.462 & 0.777 & & \\
Constant & $0.224^{* * *}$ & 0.207 & $0.231^{* * *}$ & 0.200
\end{tabular}

${ }^{1}$ Based on $n=299$ municipalities; Cox and Snell $R^{2}=0.252$ and Nagelkerke $R^{2}=0.365$ for the full model; Cox and Snell $R^{2}=0.234$ and Nagelkerke $R^{2}=0.339$ for the

parsimonious model; all independent variables are mean centered so the constant may be interpreted as the odds of vertical collaboration for the average municipality $* * * \mathrm{p}<0.01, * * \mathrm{p}<0.05,{ }^{*} \mathrm{p}<0.10$

2 Parsimonious model produced using backward selection ( $p>0.10$ to exit)

Source: Author's Construct, 2016

From Table 4.8, it can be observed that each one-year increase in the duration of collaboration is associated with a 26.4 percent increase in the likelihood of vertical collaboration in infrastructure.

\section{Horizontal Collaboration}

The final regression model predicting the likelihood of horizontal collaboration in infrastructure is shown in Table 4.9. Three variables (repeated interaction, county density and median income) out of the eight predictor variables employed in the model are significant. The parsimonious model explained approximately 12 percent of the 
unexplained variance of the dependent variable (i.e. Cox and Snell $R^{2}=0.115$; Nagelkerke $R^{2}=0.407$ ).

Table 4.9

Binary Logistic Regression Models Predicting the Likelihood of Horizontal Collaboration in Infrastructure ${ }^{1}$

\begin{tabular}{lllll}
\hline Variables & Full model & \multicolumn{3}{c}{ Parsimonious model $^{2}$} \\
& & & & \\
& Odds ratios & S.E & Odds ratios & S.E \\
\hline Collaboration in other services & 1.006 & 0.089 & & \\
Repeated interaction & $1.652^{* *}$ & 0.184 & $1.522^{* *}$ & 0.153 \\
Fiscal Capacity (per capita) & 1.000 & 0.001 & & \\
County Density & $1.381^{* *}$ & 0.121 & $1.394^{* *}$ & 0.106 \\
City population (ln) & $0.533^{*}$ & 0.372 & & \\
Median income (ln) & $0.073^{* *}$ & 1.234 & $0.064^{* *}$ & 1.051 \\
County seat & 0.633 & 0.846 & & \\
Form of Government & & & & \\
(Commission = reference group) & & & & \\
$\quad$ Mayor Council & 3.849 & 1.027 & & \\
$\quad$ City Manager & $45.303^{* *}$ & 1.666 & & \\
Constant & $0.003^{* * *}$ & 1.218 & $0.006^{* * *}$ & 1.038
\end{tabular}

${ }^{1}$ Based on $n=299$ municipalities; Cox and Snell $R^{2}=0.134$ and Nagelkerke $R^{2}=0.407$ for the full model; Cox and Snell $R^{2}=0.115$ and Nagelkerke $R^{2}=0.349$ for the parsimonious model; all independent variables are mean centered so the constant may be interpreted as the odds of horizontal for the average municipality $* * * \mathrm{p}<0.01, * * \mathrm{p}<0.05,{ }^{*} \mathrm{p}<0.10$

2 Parsimonious model produced using backward selection ( $p>0.10$ to exit)

Source: Author's Construct, 2016

Reference to Table 4.9 each one-year increase in the duration of collaboration is associated with a 52.2 percent increase in the likelihood horizontal collaboration in infrastructure. Each one-unit increase in the number of cities per 100 square miles is associated with a 39.4 percent increase in the likelihood of horizontal collaboration in infrastructure. However, each dollar increase in median income is associated with a 93.6 percent decrease in the likelihood of vertical collaboration in infrastructure. 


\section{Regressions Models on the Number of Collaborators}

Tables 4.10 to 4.15 show the results of the regression models examining the number of collaborators in an agreement.

\section{Public Safety}

\section{Bilateral Collaboration}

As shown in Table 4.10, of the eight predictor variables employed in the model only collaboration in other services and repeated interaction significantly predict the likelihood of bilateral collaboration in public safety. The parsimonious model for public safety explained approximately 25 percent of the unexplained variance of the dependent variable (i.e. Cox and Snell $R^{2}=0.253$; Nagelkerke $R^{2}=0.405$ ). 
Table 4.10

Binary Logistic Regression Models Predicting the Likelihood of Bilateral Collaboration in Public Safety

\begin{tabular}{lllll}
\hline Variables & Full model & & \multicolumn{2}{c}{ Parsimonious model $^{2}$} \\
& & & & \\
& Odds ratios & S.E & Odds ratios & S.E \\
\hline Collaboration in other services & $1.322^{* * *}$ & 0.080 & $1.279^{* * *}$ & 0.063 \\
Repeated interaction & $1.175^{* *}$ & 0.051 & $1.192^{* * *}$ & 0.050 \\
Fiscal Capacity (per capita) & 1.000 & 0.000 & & \\
County Density & 0.937 & 0.082 & & \\
City population (ln) & 0.952 & 0.191 & & \\
Median income (ln) & 2.341 & 0.632 & & \\
County seat & 1.602 & 0.469 & & \\
Form of Government & & & & \\
(Commission = reference group) & & & & \\
$\quad$ Mayor Council & 1.063 & 0.499 & & \\
$\quad$ City Manager & 0.807 & 0.865 & & \\
Constant & $0.116^{* * *}$ & 0.271 & $0.119^{* * *}$ & 0.268
\end{tabular}

${ }^{1}$ Based on $n=299$ municipalities; Cox and Snell $R^{2}=0.263$ and Nagelkerke $R^{2}=0.420$ for the full model; Cox and Snell $R^{2}=0.253$ and Nagelkerke $R^{2}=0.405$ for the parsimonious model; all independent variables are mean centered so the constant may be interpreted as the odds of bilateral collaboration for the average municipality $* * * \mathrm{p}<0.01, * * \mathrm{p}<0.05,{ }^{*} \mathrm{p}<0.10$

2 Parsimonious model produced using backward selection ( $p>0.10$ to exit)

Source: Author's Construct, 2016

Table 4.10 also indicates that each one-unit increase in the number of other service collaborations is associated with a 27.9 percent increase in the likelihood of bilateral collaboration in public safety. Similarly, each one-year increase in the duration of collaboration is associated with a 19.2 percent increase in the likelihood of bilateral collaboration in public safety.

\section{Multilateral Collaboration}

Results of the binary logistic models predicting the likelihood of multilateral collaboration in public safety are shown in Table 4.11. In addition to collaboration in 
other services and repeated interaction, a city's median household income and form of government also serve as significant predictors of the likelihood of multilateral collaboration in public safety. The parsimonious model explained approximately 30 percent of the unexplained variance of the dependent variable (i.e. Cox and Snell $R^{2}$ $=0.301 ;$ Nagelkerke $R^{2}=0.450$ ).

Table 4.11

Binary Logistic Regression Models Predicting the Likelihood of Multilateral Collaboration in Public Safety ${ }^{1}$

\begin{tabular}{lllll}
\hline Variables & Full model & \multicolumn{2}{l}{ Parsimonious model $^{2}$} \\
& & & & \\
& Odds ratios & S.E & Odds ratios & S.E \\
\hline Collaboration in other services & $1.550^{* * *}$ & 0.094 & $1.520^{* * *}$ & 0.078 \\
Repeated interaction & $1.090^{* *}$ & 0.043 & $1.096^{* *}$ & 0.041 \\
Fiscal Capacity (per capita) & 1.000 & 0.000 & & \\
County Density & 0.930 & 0.088 & & \\
$\begin{array}{l}\text { City population (ln) } \\
\text { Median income (ln) }\end{array}$ & 1.092 & 0.186 & & \\
County seat & $0.278^{* *}$ & 0.626 & $0.238^{* *}$ & 0.508 \\
$\begin{array}{l}\text { Form of Government } \\
\text { (Commission = reference group) }\end{array}$ & 0.980 & 0.422 & & \\
$\quad$ Mayor Council & $2.632^{*}$ & 0.512 & $2.550^{*}$ & 0.401 \\
$\quad$ City Manager & 1.011 & 0.884 & & \\
Constant & $0.189^{* * *}$ & 0.220 & $0.192^{* * *}$ & 0.215 \\
\hline
\end{tabular}

${ }^{1}$ Based on $n=299$ municipalities; Cox and Snell $R^{2}=0.304$ and Nagelkerke $R^{2}=0.455$ for the full model; Cox and Snell $R^{2}=0.301$ and Nagelkerke $R^{2}=0.450$ for the parsimonious model; all independent variables are mean centered so the constant may be interpreted as the odds of multilateral collaboration for the average municipality ${ }^{* * *} \mathrm{p}<0.01,{ }^{* *} \mathrm{p}<0.05,{ }^{*} \mathrm{p}<0.10$

${ }^{2}$ Parsimonious model produced using backward selection $(p>0.10$ to exit) Source: Author's Construct, 2016

From Table 4.11 each one-unit increase in the number of other service collaborations is associated with a 52 percent increase in the likelihood of multilateral collaboration in public safety. Similarly, each one-year increase in the duration of 
collaboration is associated with a 9.6 percent increase in the likelihood multilateral collaboration in public safety. Also, operating as a mayor-council instead of a commission form of government is associated with a 155 percent increase in the likelihood of multilateral collaboration in public safety. However, each dollar increase in median income is associated with a 76.2 percent decrease in the likelihood of multilateral collaboration in public safety.

\section{Economic Development}

\section{Bilateral Collaboration}

Table 4.12 shows regression models for the likelihood of bilateral collaboration in economic development. Out of the eight predictor variables used in the model four (collaboration in other services, repeated interaction, county seat and city manager) significantly predict the likelihood of bilateral collaboration in economic development. The parsimonious model explained approximately 25 percent of the unexplained variance of the dependent variable (i.e. Cox and Snell $R^{2}=0.246$; Nagelkerke $R^{2}=0.386$ ). 
Table 4.12

Binary Logistic Regression Models Predicting the Likelihood of Bilateral Collaboration in Economic Development ${ }^{1}$

\begin{tabular}{lllll}
\hline Variables & Full model & & \multicolumn{2}{l}{ Parsimonious Model $^{2}$} \\
& & & & \\
& Odds ratios & S.E & Odds ratios & S.E \\
\hline Collaboration in other services & $1.162^{* *}$ & 0.067 & $1.201^{* *}$ & 0.060 \\
Repeated interaction & $1.143^{* *}$ & 0.042 & $1.138^{* *}$ & 0.042 \\
Fiscal Capacity (per capita) & 0.999 & 0.001 & & \\
County Density & & & & \\
City population (ln) & 1.056 & 0.080 & & \\
Median income (ln) & 0.874 & 0.189 & & \\
County seat & 1.757 & 0.627 & & \\
Form of Government & $5.008^{* *}$ & 0.464 & $3.417^{* *}$ & 0.354 \\
(Commission = reference group) & & & & \\
$\quad$ Mayor Council & 1.202 & 0.505 & & \\
$\quad$ City Manager & $4.227^{*}$ & 0.838 & $3.037^{*}$ & 0.560 \\
Constant & $0.134^{* * *}$ & 0.243 & $0.091^{* * *}$ & 0.228 \\
& & & & \\
\hline
\end{tabular}

${ }^{1}$ Based on $n=299$ municipalities; Cox and Snell $R^{2}=0.255$ and Nagelkerke $R^{2}=0.401$ for the full model; Cox and Snell $R^{2}=0.246$ and Nagelkerke $R^{2}=0.386$ for the parsimonious model; all independent variables are mean centered so the constant may be interpreted as the odds of bilateral collaboration for the average municipality $* * * \mathrm{p}<0.01, * * \mathrm{p}<0.05,{ }^{*} \mathrm{p}<0.10$

2 Parsimonious model produced using backward selection ( $p>.10$ to exit)

Source: Author's Construct, 2016

From Table 4.12 , it can be observed that collaboration in other services is associated with a 20.1 percent increase in the likelihood of bilateral collaboration in economic development. Additionally, each one-year increase in the duration of collaboration is associated with a 13.8 percent increase in the likelihood of bilateral collaboration in economic development. Again, being a county seat is associated with a 241.7 percent increase in the likelihood of bilateral collaboration in economic development. Additionally, being a city manager is associated with a 203.7 percent increase in the likelihood of bilateral collaboration in economic development. 


\section{Multilateral Collaboration}

The results of logistic regressions predicting the likelihood of multilateral collaboration in economic development are shown in Table 4.13. In all, four variables (collaboration in other services, repeated interaction, county density and county seat) out of the eight predictor variables are significant. The parsimonious model explained approximately 31 percent of the unexplained variance of the dependent variable (i.e. Cox and Snell $R^{2}=0.308 ;$ Nagelkerke $\left.R^{2}=0.498\right)$.

Table 4.13

Binary Logistic Regression Models Predicting the Likelihood of Multilateral Collaboration in Economic Development ${ }^{1}$

\begin{tabular}{|c|c|c|c|c|}
\hline \multirow[t]{2}{*}{ Variables } & \multicolumn{2}{|l|}{ Full model } & \multicolumn{2}{|c|}{ Parsimonious model $^{2}$} \\
\hline & Odds ratios & S.E & Odds ratios & S.E \\
\hline Collaboration in other services & $1.245 * *$ & 0.077 & $1.271 * *$ & 0.076 \\
\hline Repeated interaction & $1.101 * *$ & 0.046 & $1.100 * *$ & 0.045 \\
\hline Fiscal Capacity (per capita) & 1.000 & 0.000 & & \\
\hline County Density & $1.419 * * *$ & 0.099 & $1.373 * * *$ & 0.086 \\
\hline City population (ln) & 1.127 & 0.214 & & \\
\hline Median income $(\ln )$ & 0.660 & 0.682 & & \\
\hline County seat & $0.267 * *$ & 0.528 & $0.371 * *$ & 0.457 \\
\hline \multicolumn{5}{|l|}{$\begin{array}{l}\text { Form of Government } \\
\text { (Commission = reference group) }\end{array}$} \\
\hline Mayor Council & 1.420 & 0.534 & & \\
\hline City Manager & 1.829 & 0.975 & & \\
\hline Constant & $0.132 * * *$ & 0.239 & $0.135 * * *$ & 0.234 \\
\hline \multicolumn{5}{|c|}{$\begin{array}{l}{ }^{1} \text { Based on } n=299 \text { municipalities; Cox and Snell } R^{2}=0.313 \text { and Nagelkerke } R^{2}=0.506 \\
\text { for the full model; Cox and Snell } R^{2}=0.308 \text { and Nagelkerke } R^{2}=0.498 \text { for the } \\
\text { parsimonious model, all independent variables are mean centered so the constant may be } \\
\text { interpreted as the odds of multilateral collaboration for the average municipality } \\
{ }^{* * * p}<0.01,{ }^{*} p<0.05,{ }^{*} p<0.10 \\
{ }^{2} \text { Parsimonious model produced using backward selection }(p>0.10 \text { to exit })\end{array}$} \\
\hline
\end{tabular}

Source: Author's Construct, 2016 
Reference to table 4.13 , each one-unit increase in the number of other service collaborations is associated with a 27.1 percent increase in the likelihood of multilateral collaboration in economic development. Additionally, each one-year increase in the duration of collaboration is associated with a 10 percent increase in the likelihood multilateral collaboration in economic development. Moreover, each one-unit increase in the number of cities per square mile is associated with a 37.3 percent increase in the likelihood of multilateral collaboration in economic development. However, being a county seat is associated with a 62.9 percent decrease in the likelihood of multilateral collaboration in economic development.

\section{Infrastructure}

\section{Bilateral Collaboration}

Table 4.14 below provides results of regressions models predicting the likelihood of bilateral collaboration in infrastructure. Three (repeated interaction, county density and city population) out of the eight predictor variables used in the model are significant. The parsimonious model explained approximately 16 percent of the unexplained variance of the dependent variable (i.e. Cox and Snell $R^{2}=0.155$; Nagelkerke $R^{2}=0.259$ ). 
Table 4.14

Binary Logistic Regression Models Predicting the Likelihood of Bilateral Collaboration in Infrastructure ${ }^{1}$

\begin{tabular}{lllll}
\hline Variables & Full model & \multicolumn{3}{c}{ Parsimonious model $^{2}$} \\
& Odds ratios & S.E & Odds ratios & S.E \\
\hline Collaboration in other services & 0.974 & 0.061 & & \\
Repeated interaction & $1.261^{* * *}$ & 0.042 & $1.255^{* * *}$ & 0.040 \\
Fiscal Capacity (per capita) & 1.000 & 0.000 & & \\
County Density & 0.758 & 0.116 & $0.763^{* *}$ & 0.098 \\
City population (ln) & $0.557^{* *}$ & 0.196 & $0.648^{* *}$ & 0.142 \\
Median income (ln) & 1.767 & 0.578 & & \\
County seat & $1.729^{*}$ & 0.444 & & \\
Form of Government & & & & \\
(Commission = reference group) & & & & \\
\multicolumn{1}{c}{ Mayor Council } & 1.011 & 0.445 & & \\
$\quad$ City Manager & 1.813 & 0.863 & & \\
Constant & $0.121^{* * *}$ & 0.232 & $0.125^{* * *}$ & 0.228
\end{tabular}

${ }^{1}$ Based on $n=299$ municipalities; Cox and Snell $R^{2}=0.166$ and Nagelkerke $R^{2}=0.277$ for the full model; Cox and Snell $R^{2}=0.155$ and Nagelkerke $R^{2}=0.259$ for the parsimonious model; all independent variables are mean centered so the constant may be interpreted as the odds of bilateral collaboration for the average municipality $* * * \mathrm{p}<0.01, * * \mathrm{p}<0.05,{ }^{*} \mathrm{p}<0.10$

2 Parsimonious model produced using backward selection $(p>.10$ to exit)

Source: Author's Construct, 2016

From Table 4.14, each one-year increase in the duration of collaboration is associated with a 25.5 percent increase in the likelihood bilateral collaboration in infrastructure. However, each one-unit increase in the number of cities per 100 square miles is associated with a 23.7 percent decrease in the likelihood bilateral collaboration in infrastructure. Also, each one-unit increase in the number of people in a city is associated with a 35.2 percent decrease in the likelihood of bilateral collaboration in infrastructure. 


\section{Multilateral Collaboration}

Table 4.15 provides results of regressions models predicting the likelihood of multilateral collaboration in infrastructure. Only two variables (collaboration in other services and repeated interaction) out of the eight predictor variables employed in the model are significant. The parsimonious model explained approximately 19 percent of the unexplained variance of the dependent variable (i.e. Cox and Snell $R^{2}=0.19 .1$; Nagelkerke $\left.R^{2}=0.30\right)$.

Table 4.15

Binary Logistic Regression Models Predicting the Likelihood of Multilateral Collaboration in Infrastructure ${ }^{1}$

\begin{tabular}{lllll}
\hline Variables & Full model & & \multicolumn{2}{c}{ Parsimonious model $^{2}$} \\
& & & & \\
& Odds ratios & S.E & Odds ratios & S.E \\
\hline Collaboration in other services & $1.105^{*}$ & 0.056 & $1.127^{* *}$ & 0.051 \\
Repeated interaction & $1.253^{* * *}$ & 0.054 & $1.236^{* * *}$ & 0.053 \\
Fiscal Capacity (per capita) & 1.000 & 0.001 & & \\
County Density & $1.139^{*}$ & 0.075 & & \\
City population (ln) & 0.984 & 0.195 & & \\
Median income (ln) & 0.393 & 0.639 & & \\
County seat & 0.840 & 0.467 & & \\
Form of Government & & & & \\
(Commission = reference group) & & & & \\
$\quad$ Mayor Council & 0.633 & 0.483 & & 0.289 \\
\multicolumn{1}{c}{ City Manager } & 0.895 & 0.854 & & \\
Constant & $0.092^{* * *}$ & 0.295 & $0.097^{* * *}$ & \\
\hline
\end{tabular}

${ }^{1}$ Based on $n=299$ municipalities; Cox and Snell $R^{2}=0.207$ and Nagelkerke $R^{2}=0.348$ for the full model; Cox and Snell $R^{2}=0.191$ and Nagelkerke $R^{2}=0.320$ for the parsimonious model; all independent variables are mean centered so the constant may be interpreted as the odds of multilateral collaboration for the average municipality $* * * \mathrm{p}<0.01, * * \mathrm{p}<0.05,{ }^{*} \mathrm{p}<0.10$

2 Parsimonious model produced using backward selection $(p>0.10$ to exit)

Source: Author's Construct, 2016

From Table 4.15, each one-unit increase in the number of other service collaborations is associated with a 12.7 percent increase in the likelihood multilateral 
collaboration in infrastructure. Additionally, each one-year increase in the duration of collaboration is associated with a 23.6 percent increase in the likelihood multilateral collaboration in infrastructure. 


\section{CHAPTER V}

\section{DISCUSSION OF RESULTS}

\section{Introduction}

A general discussion of results and major findings from the data analyzed in chapter IV are presented in this chapter. Through the lens of existing theoretical and empirical literature, the chapter also tests the hypotheses introduced in chapter III.

\section{Characteristics of Services and the Pattern of Collaboration}

In the previous chapter, four dependent variables measuring the direction (horizontal / vertical) and number of partners (bilateral / multilateral) in a collaborative agreement were examined using data on interlocal service agreements from the Kentucky Department of Local Government. The dependent variables were examined for three service categories: (1) public safety (2) economic development and (3) infrastructure development. Consistent with Brown \& Potoski (2001, 2003, 2005) and Andrew \& Hawkins (2012) these three service categories were further examined under four transaction characteristics: (1) low asset specificity and low service measurability, (2) high asset specificity and high service measurability, (3) low asset specificity but high service measurability, and (4) high asset specificity but low service measurability. Hypotheses 1- 4 were tested based on these four transaction characteristics. 
Descriptive statistics in chapter IV indicated that compared to economic development (35.4 percent) and infrastructure services (23.5 percent), public safety services rank highest (41.1 percent) in terms of number of registered interlocal agreements. The finding on public safety goes contrary to Post's (2004) assertion that public safety functions attract less inter-local collaboration because they are mainly labor intensive. It is however consistent with Carr et al. (2007) and Leroux's (2006) empirical findings on interlocal collaboration in Detroit. Given the fact that public safety remains the largest systems maintenance function on municipal budgets, this finding is unsurprising.

Descriptive statistics on the direction of collaboration indicated that compared to other public services, economic development services have a greater association (93.8 percent) with vertical collaboration whilst public safety services have a greater association (18.8percent) with horizontal collaboration. In terms of the number of partners in an agreement, infrastructure ( 85.9 percent) has the greatest association with bilateral collaboration whilst public safety has the greatest association (27.5 percent) with multilateral collaboration.

Prior research based on transaction cost theory suggests that transaction characteristics such as asset specificity and service measurability play important roles in local governments' decisions to collaborate (e.g. Andrew, 2009; Andrew \& Hawkins, 2012; Brown \& Potoski, 2001 2003, 2005; Carr et al., 2009; Feiock \& Scholz, 2010; Hawkins, 2009). From the analyses it became clear that compared to other transaction characteristics, services that are highly asset specific but easily measurable (911 radio communications, tax collection \& revenue sharing, housing \& energy, cable \& internet, 
sewer system, telecommunications, water) attract the highest percentage of interlocal agreements (41.4 percent). Services that are highly asset specific but difficult to measure (fire protection \& response, police protection/ law enforcement, emergency disaster planning, planning and zoning, building inspection \&code enforcement, enterprise zone \& industrial development) rank second (40.1 percent) followed by services that have low asset specificity but are difficult to measure (11.1 percent) and services that have low asset specificity but are easy to measure ( 7.4 percent). These findings support previous research that all things considered, the specificity of an investment is a major determinant of interlocal collaboration.

With respect to the direction of collaboration, the analyses indicated that compared to other transaction characteristics services that are highly asset specific but easy to measure exhibit a greater association (38.4 percent) with vertical collaboration. On the other hand services that are highly asset specific but difficult to measure have a greater association (6.1 percent) with horizontal collaboration. These findings are inconsistent with hypotheses 1 and 2 that: (1) cities are more likely to collaborate vertically on services that have high levels of asset specificity and measurement difficulty and (2) cities are more likely to collaborate horizontally on services that have lower levels of asset specificity and measurement difficulty.

In terms of the number of partners in an agreement, the analyses indicated that compared to other transaction characteristics services that are highly asset specific but easy to measure exhibit a greater association (32.8 percent) with bilateral collaboration. Services that are highly asset specific but difficult to measure have a greater association (11 percent) with multilateral collaboration. These findings do not support research 
hypotheses 3 that: (3) cities are more likely to collaborate bilaterally on services that have lower levels of asset specificity and measurement difficulty. They are however consistent with hypothesis 4 that: (4) cities are more likely to collaborate multilaterally on services that have higher levels of asset specificity and measurement difficulty.

\section{Network Embeddedness and the Pattern of Collaboration}

Simon (1945) noted that the "administrative man" unlike the "economic man", has fragmentary knowledge about the consequences of economic transactions. Limited information thus leaves municipalities prone to opportunistic behavior from partners. To offset this, jurisdictions may rely on relational mechanisms to facilitate exchange (Granovetter, 1985; Uzzi, 1996; Zaheer \& Venkatraman, 1995). Previous studies have suggested that by engaging in repeated exchanges jurisdictions are able to develop trust, credibility and commitment that help mitigate transaction risks and facilitate further interlocal exchange (Leroux, 2006; Shrestha, 2005). Others have suggested that a city's collaboration in one set of service agreements can reinforce collaborations in other sets of agreements (Leroux, 2006; Shrestha, 2005).

In this study, collaborations in other services and repeated interaction were included in the model to explain how network embededdness influences the direction and number of partners in a collaborative agreement. The results of the analyses reveal that with respect to direction, collaborations in other services and repeated interaction best predict the likelihood of vertical collaboration in public safety, explaining 35 percent of the unexplained variance. This is followed by horizontal collaboration in public safety (30 percent), vertical collaboration in economic development (27 percent), vertical 
collaboration in infrastructure (23 percent), horizontal collaboration in infrastructure (17 percent) and horizontal collaboration in economic development (7 percent).

In terms of number of partners, collaborations in other services and repeated interaction best predict the likelihood of multilateral collaboration in economic development, explaining 31 percent of the unexplained variance. This is followed by multilateral collaboration in public safety (30 percent), bilateral collaboration in public safety (25 percent), multilateral collaboration in infrastructure (19 percent), bilateral collaboration in economic development (25 percent) and bilateral collaboration in infrastructure (16 percent) in that order.

\section{Collaboration in other services and the Pattern of Collaboration}

Out of twelve (12) regression models, the collaboration in other services variable was significant in nine (9). The variable was not significant in predicting the likelihood of vertical collaboration in infrastructure, horizontal collaborations in infrastructure and bilateral collaboration in infrastructure. The highest percentage increase in the likelihood of collaboration was recorded for multilateral collaboration in public safety (52 percent increase) while the lowest percentage increase in the likelihood of collaboration was recorded for multilateral collaboration in economic development (12.5 percent increase). The relation between the collaboration in other services variable and the likelihood of collaboration was positive in all nine (9) models.

By significantly predicting nine out of twelve models, one is justified to concur with Leroux (2006) and Shrestha (2005) that a city's collaboration in one set of agreements reinforces collaborations in other sets of agreements. The research hypothesis 
that collaboration in other service areas has a positive effect on the likelihood of collaborating on the service in question is therefore supported.

\section{Repeated Interaction and the Pattern of Collaboration}

The results of the analyses indicate that repeated interaction is a significant predictor of the likelihood of collaboration in eleven (11) out of twelve regression models. The variable was not significant in predicting the likelihood of horizontal collaboration in economic development. Coefficients in all eleven (11) models show positive relations between the repeated interaction variable and the likelihood of collaboration. The highest percentage increase in the likelihood of collaboration was recorded for horizontal collaboration in infrastructure (52.2 percent increase) while the lowest percentage increase in the likelihood of collaboration was recorded for multilateral collaboration in public safety ( 9.6 percent increase). Given the fact that infrastructure is an asset specific service with high start-up costs, it is not surprising that it takes a large amount of trust and credibility developed through repeated interaction to influence horizontal collaboration on this particular service.

Two factors help explain the low percentage increase recorded for multilateral collaboration on public safety. In this study almost all the multilateral public safety agreements recorded had at least one county partner. Since counties hold administrative and regulatory rights, their involvement in an agreement reduces potential any risks of opportunistic behaviors. Trust and credibility developed through repeated interactions will therefore have limited influence in such circumstances.

Notwithstanding these observations the study concurs with the findings of Leroux (2006) and Shrestha (2005) that where municipalities repeatedly interact they develop 
trust and social capital necessary for forging further cooperative endeavors. The research hypothesis that repeated interaction in the past between transacting jurisdictions increases the likelihood of collaboration is thus supported by the above findings.

\section{Fiscal Capacity and the Pattern of Collaboration}

Previous studies have often suggested that fiscal stress due to low internal revenue

mobilization or limited federal and state revenue inflows encourage interlocal collaboration (e.g. Adhikari, 2015; Advisory Council on Intergovernmental Relations, 1985; Agranoff \& McGuire, 2003; Bartle \& Swayze, 1997; Krueger \& McGuire, 2005; MacManus \& Caruson, 2008; Morgan \& Hirlinger, 1991; Sonenblum et al., 1977; Stein, 1990; Wood, 2004). In this study fiscal capacity was a significant predictor in one model - the likelihood of vertical collaboration in infrastructure. The relation between fiscal capacity and vertical collaboration was negative indicating that each dollar increase in a city's own revenue per capita was associated with 0.1 percent decrease in the likelihood of vertical collaboration in infrastructure. Given the fact that infrastructure is an asset specific service with high start-up cost, it stands to reason that cities may collaborate with counties only when their capacity to fund these services themselves is low. It is therefore not surprising that the likelihood of collaborating with counties decrease as cities' internally generated revenues increase.

Since fiscal capacity was a significant predictor in only one (1) out of twelve (12) models, one may concur with previous findings by Carr et al., (2007); Leroux, (2006); Shrestha, (2005); Thurmaier, (2005); Thurmaier and Wood (2002) that a local government's fiscal capacity does little to predict interlocal collaboration. 


\section{County Density and the Pattern of Collaboration}

According to Axelrod (1984) when jurisdictions are in close proximity they tend to interact more. This research assumes that cities located within a common county have a shared value system and responsibility towards the development of their jurisdictions. Where more cities exist per 100 square miles of county, there is a high likelihood for close collaboration and vice versa.

In this study the local government density variable was significant in predicting the likelihood of collaboration in four (4) regression models - vertical collaboration in public safety, multilateral collaboration in economic development, bilateral collaboration in infrastructure and horizontal collaboration in infrastructure. The highest percentage increase in the likelihood of collaboration was recorded for horizontal collaboration in infrastructure (39.4 percent increase). The relation between the local government density variable and the likelihood of collaboration was negative in two (2) models - vertical collaboration in public safety (47.5 percent decrease) and bilateral collaboration in infrastructure (23.7 decrease).

Infrastructure services usually have high start-up costs. For efficiency gains, municipalities in high density areas are better off developing infrastructure services together and sharing these start-up costs. It is not surprising that as the number of cities per 100 square miles increases, the likelihood of horizontal collaboration in infrastructure increases. This finding is consistent with the observations of Axelrod (1984), Post (2002), Leroux (2006), Shrestha (2005) and Adhikari (2015) that density of municipalities has a positive influence on the likelihood of interlocal cooperation. 
Aside having high start-up costs, infrastructure services are also highly asset specific and therefore more prone to opportunism. To avoid opportunistic behavior municipalities in high density areas may prefer to have less bilateral collaborations on infrastructure services. This explains why as the number of cities per 100 square miles increases, the likelihood of bilateral collaboration in infrastructure decreases. Public safety services on the other hand have spillover effects (positive externalities). It is easy for a neighboring jurisdiction B to benefit from jurisdiction A's law enforcement services without participating in any agreements. Where several municipalities exist per 100 square miles, the motivation to collaborate with a county on public safety may be low since municipalities have increased incentive to free-ride and enjoy public safety services from their neighbors. The finding that as the density of local governments increases the likelihood of vertical collaboration in public safety decreases is therefore not surprising.

\section{City Population and the Pattern of Collaboration}

Some prior studies, a city's population indicates its potential for achieving economies of scale (cf. Adhikari, 2015; Joassart-Marcelli \& Musso, 2005; LeRoux et al., 2010; Nelson, 1997). Thus population size is regarded as a good predictor of interlocal collaboration. Two opposing views exist regarding the direction of the population size hypothesis. There are those that hypothesize that smaller jurisdictions are more likely to support interlocal collaboration because operating independently they may not be able to provide public services in a cost efficient manner. By pooling resources together small cities can improve the efficiency of service delivery (Andrew, 2008a; Mohr et al., 2010). Conversely, others hypothesize that larger jurisdiction are more likely to collaborate 
because they tend to have lower cost of obtaining information, negotiating agreements and enforcing agreements (Kwon \& Feiock, 2010). Caruson and MacManus (2006a) have observed for instance that in emergency management preparedness that because larger jurisdictions are prone to more vulnerabilities, they tend to have extensive emergency preparedness networks.

In this study population size was a significant predictor in two out of twelve regression models - the likelihood of horizontal collaboration in economic development and the likelihood of bilateral collaboration in infrastructure. The relation between population size and the likelihood of horizontal collaboration was positive. However, the relation between population size and the likelihood of bilateral collaboration in infrastructure was negative. Each one-unit increase in the size of a city's population was associated with a 35.2 percent decrease in the likelihood of bilateral collaboration in infrastructure. As explained earlier, because infrastructure services are capital intensive and asset specific they are more prone to opportunism. Rational and self interested cities may prefer to look for alternatives that are less likely to attract opportunistic behavior as population increases and demand for infrastructure surges. Additionally, cities with large populations are more likely to have large tax resources to fund infrastructure investment and may not need to collaborate. These explain why as population increases the likelihood of bilateral collaboration in infrastructure decreases.

\section{Median Household Income and the Direction of Collaboration}

A city's median household income is a general proxy for its aggregate effective demand for services (Leroux, 2006; Shrestha, 2005). It may also be considered as an 
indicator of a city's fiscal capacity (Adhikari, 2015). Similar to the population size hypothesis, there are conflicting views as to the direction of the median income hypothesis. There are those that hypothesize that cities with lower median incomes are more likely to support interlocal collaboration because it enables them to take advantage of the financial resources available to other cities (c.f Leroux and Carr, 2007). Adhikari (2015) surmises that residents of cities with lower median household incomes rely heavily on public infrastructure and other social-benefit programs. It stands to reason therefore that the likelihood of lower median income cities collaborating with other local governments will be high.

Yet still, there are others who suggest the direction of the median income hypothesis is curvilinear. Morgan and Hirlinger (1991) posit that both poor and rich communities enter into interlocal agreements based on different financial motivations. Communities with low median incomes collaborate in order to cut down administrative and production costs while rich communities collaborate because they can enjoy more services at an affordable price.

In this study median household income was a significant predictor of the likelihood of collaboration in four (4) models - multilateral collaboration in public safety, vertical collaboration in public safety, horizontal collaboration in public safety and horizontal collaboration in infrastructure. The relation between the median household income variable and the likelihood of horizontal collaboration in public safety was positive (643.3 percent increase) and consistent with the observations of Morgan and Hirlinger (1991). However, each dollar increase in median income was associated with a 76.2 percent decrease in the likelihood of multilateral collaboration in public safety. Also, 
each dollar increase in median income was associated with a 67.9 percent decrease in the likelihood of vertical collaboration in public safety.

Having a high median income means a city can afford to provide better quality public safety services to its citizens and may be more inclined to produce them. It also means a city can maintain exclusivity by avoiding too many partners in a public safety agreement. Additionally, it means high income cities can take more risks by collaborating less with the county and more with other cities on specialized public safety services.

In the case of infrastructure services, the results indicated that each dollar increase in median income is associated with a 93.6 percent decrease in the likelihood of horizontal collaboration in infrastructure. Given the fact that infrastructure services are capital intensive and asset specific even when median incomes increase cities may still prefer to look for other modes of service delivery that are less prone to opportunism.

\section{County Seat and the Direction of Collaboration}

A county seat status suggests that a city's administrative branch has close proximity to the corridors of power. Where a city serves as county seat, it is more likely to have a high concentration of county administrative offices. The proximity of county officials to city officials would invariably increase the likelihood of collaboration.

In this study the county seat variable was a significant predictor of the likelihood of collaboration in four (4) regression models - horizontal collaboration in public safety, vertical collaboration in economic development, bilateral collaboration in economic development and multilateral collaboration in economic development. The relation between county seat and the likelihood of vertical collaboration in economic 
development was positive (208.7 percent increase). Similarly, the relation between the county seat variable and the likelihood of bilateral collaboration in economic development was positive (241.7 percent increase). However, being a county seat was associated with a 62.9 percent decrease in the likelihood of collaborating multilaterally in economic development and a 70.7 percent decrease in the likelihood of collaborating horizontally in public safety.

By virtue of being administrative seats, cities that serve as county capitals have significant access to economic development services. This implies that any interlocal collaboration on economic development services may be limited to a few partners instead of multiple collaborating partners. Similarly, proximity to the corridors of power means cities that serve as county seats have ready access to county law enforcement services and other public safety services. The likelihood of these cities participating in interlocal collaboration with other cities in the county on public safety services is sure to decrease.

\section{Form of Government and the Direction of Collaboration}

The form of government characterizes the political and institutional conditions of a city. According to the administrative conjunction theory the longer tenure and commonly shared public service ethic among professional administrators makes them more development oriented compared to elected officials (Frederickson, 1999). Prior studies have therefore hypothesized based on the theory of administrative conjunctions that cities in a council-manager form of government are more likely to participate in interlocal cooperation than cities with a mayor-council government (Brown \& Potoski, 2003; Ruhil et al., 1999; Schneider et al., 1995) 
In this study, form of government was significant in three regression models bilateral collaboration in economic development, horizontal collaboration in public safety and vertical collaboration in economic development. The relation between the form of government variable and the likelihood of collaboration in all three models was positive. Having a city manager form of government was associated with a 473.2 percent increase in the likelihood of bilateral collaboration in economic development and a 461.1 percent increase in the likelihood of vertical collaboration in economic development. Having a mayor-council form of government was associated with a 193.3 percent increase in the likelihood of horizontal collaboration in public safety. Giving the fact that the city manager form of government is seen to be more development oriented than its councilmayor counterpart, it is not surprising to find in this study that having a manager form of government is associated with bilateral and vertical collaboration in economic development. These findings are consistent with the observations of Leroux (2006), Shrestha (2005) and Adhikari (2015) that form of government has an influence on the likelihood of interlocal cooperation.

Table 5.1 provides a summary of variables that were significant in the study whilst table 5.2 provides a summary of test results for the research hypotheses. 
Table 5.1

Summary of Significant Variables

\begin{tabular}{|c|c|c|c|c|c|c|c|c|c|c|c|c|}
\hline \multirow[t]{2}{*}{ Variables } & \multicolumn{4}{|c|}{ Public Safety } & \multicolumn{4}{|c|}{$\begin{array}{c}\text { Economic } \\
\text { development }\end{array}$} & \multicolumn{4}{|c|}{ Infrastructure } \\
\hline & $V$. & $H$. & $M$. & $B$. & $V$. & $H$. & $M$ & $B$. & $V$. & $H$. & M. & $B$. \\
\hline $\begin{array}{l}\text { Collaboration in } \\
\text { other services }\end{array}$ & yes & yes & yes & yes & yes & yes & yes & yes & - & - & yes & - \\
\hline $\begin{array}{l}\text { Repeated } \\
\text { interaction }\end{array}$ & yes & yes & yes & yes & yes & - & yes & yes & yes & yes & yes & yes \\
\hline Fiscal Capacity & - & - & - & - & - & - & - & - & *yes & - & - & - \\
\hline County Density & *yes & - & - & - & - & - & yes & - & - & yes & - & *yes \\
\hline City population & - & - & - & - & - & yes & - & - & - & - & - & *yes \\
\hline Median income & *yes & yes & *yes & - & - & - & - & - & - & *yes & - & - \\
\hline County seat & - & *yes & - & - & yes & - & *yes & yes & - & - & - & - \\
\hline Mayor Council & - & yes & - & - & - & - & - & - & - & - & - & - \\
\hline City Manager & - & - & - & - & yes & - & - & yes & - & - & - & - \\
\hline
\end{tabular}

V. vertical

H. horizontal

M. multilateral

B. bilateral

*variable is significant but inconsistent with expected direction

Spaces marked (-) indicates variable is not significant in the model.

Source: Author's Construct, 2016 
Table 5.2

Results of Test of Hypotheses

Hypotheses
Hypothesis 1:
Cities are more likely to collaborate vertically on services
that have high levels of asset specificity and measurement
difficulty.

Results

Not supported

Services that have high

levels of asset specificity

and measurement

difficulty have a greater

association with

horizontal collaboration

Hypothesis 2:

Cities are more likely to collaborate horizontally on services that have lower levels of asset specificity and measurement difficulty.

Hypothesis 3:

Cities are more likely to collaborate multilaterally on services that have higher levels of asset specificity and measurement difficulty.

Hypothesis 4:

Not supported

Cities are more likely to collaborate bilaterally on services that have lower levels of asset specificity and measurement difficulty

\section{Hypothesis 5:}

Repeated interaction in the past between transacting jurisdictions increases the likelihood of collaboration.

Hypothesis 6:

Collaboration in other service areas has a positive effect on the likelihood of collaborating on the service in question.

Source: Author's Construct, 2016 


\section{CHAPTER VI}

\section{CONCLUSION}

Collaborative governance has gained traction in recent years. From environmental resource management to public safety, collaborative governance continues to play a vital role in regional problem solving. Proponents have attributed the increasing popularity of the concept to the changing dynamics and complexity of $21^{\text {st }}$ century problems which require collaborative efforts beyond the fragmented state.

Indeed, for a long time America's fragmented political system has been an enduring subject of debate attracting both support and criticisms. Proponents, particularly those from the public choice school, have often viewed fragmentation as an opportunity competition and efficiency in public service delivery. On the other hand, some critics have repudiated the system for its duplicative and wasteful tendencies (Frederickson, 1999). Other critics have cited problems of inner city decline, widening of the income gap between central cities and suburbs and environmental degradation as some of the problems of America's fragmented local government system. As a solution to these negative impacts some scholars have proposed political consolidation. Yet evidence suggests consolidation by itself also creates principal-agent problems which lead to further inefficiencies in the supply of public services.

To avoid loss of jurisdictional autonomy from political consolidation and the occasional lack of private market for certain public services from public choice, many 
local governments have embraced the idea of pulling resources together with other local governments to deliver public services. The surge of interest in collaborative governance concept calls for critical enquiry into why local governments chose certain types of interlocal agreements. Questions worthy of enquiry include: (1) what motivates interlocal collaboration? (2) How do interlocal agreements differ by service type? (3) What are the directions of collaboration? (4) What number of partners is appropriate for collaboration?

\section{Determinants of Vertical, Horizontal, Multilateral and Bilateral Collaboration}

This study sought to find answers to the questions listed above by examining the patterns of interlocal collaboration in the Commonwealth of Kentucky using transaction cost theory and the concept of exchange embeddedness as theoretical lenses. Based on existing interlocal agreement data from the Kentucky Department of Local Governments this study has shown that for services like public safety, economic development and infrastructure, majority of municipalities prefer to participate in agreements that have at least one county government as partner. Similarly, majority of municipalities prefer to be in agreements that have only two participating local governments.

The study has also buttressed previous findings that the transaction characteristics of services (asset specificity and service measurability) have strong influence on the likelihood of collaboration. In terms of direction, the study has confirmed that services that have high levels of asset specificity but easily measurable have a greater association with vertical collaboration whilst services that have high levels of asset specificity and measurement difficulty have a greater association with horizontal collaboration. It has also established that that services that have high levels of asset specificity but easily 
measurable have a greater association with bilateral collaboration whilst services that have high levels of asset specificity and measurement difficulty have a greater association with multilateral collaboration.

The study has further established that a municipality's collaborations in other services and repeated interaction in the past have the most influence on the likelihood of vertical collaboration in public safety and the least influence on the likelihood of horizontal collaboration in economic development. In terms of number of partners, the study has shown that collaborations in other services and repeated interaction have the most influence on the likelihood of multilateral collaboration for public safety and the least influence on the likelihood of bilateral collaboration in infrastructure. The study has thus demonstrated that repeated interactions in the past and collaborations in other related services have significant influence on interlocal collaborations.

\section{Implications of Study: Main Contributions to Scholarship}

The study has made important contributions that enhance existing knowledge on collaborative governance in the fields of public management, and urban studies. It has validated and in certain cases refuted hypotheses by its predecessors. At the conceptual level, the study complements the existing theory of collaborative governance and helps initiate further scholarly discussion on the topic. Spatially, the research contributes to the existing practice of regionalism by providing in-depth explanation to the structure and nature of exchange in collaborative governance.

Previous research has focused on the general determinants of collaboration without identifying what services are the strongest candidates for collaboration. To a 
certain extent, this study has addressed this gap by examining three important local government services - public safety, economic development and infrastructure. From the analyses, public safety ranked highest as the service that attracts most collaborative agreements.

Previous research has also failed to examine the different levels of government that mostly appear as candidates for partnerships. This study has addressed this gap by identifying and examining two directions of collaboration - vertical and horizontal. The analyses of data revealed that vertical collaboration remains the preferred mode of collaboration for municipalities.

Again, previous research has failed to examine the number of partners in collaborative arrangements. This study has addressed this gap by identifying and examining two types of partners - multilateral and bilateral. The analyses of data revealed that bilateral collaboration remains the preferred mode of collaboration for municipalities.

Finally the study has also corroborated findings from previous research that the transaction cost and relational dimensions of exchange are important determinants of local governments' choice of interlocal exchange.

\section{Limitations of This Study}

Notwithstanding its theoretical, methodological and empirical strengths, this study is limited in a number of ways. First, the robustness of the results in this study could have been improved by examining both the likelihood and magnitude of collaboration in Kentucky. Statistical analyses on the magnitude of collaboration were not performed in 
this study because of the general lack of data on intergovernmental revenues and expenditures. Where data was available from the US Census Bureau and State databases, revenue and expenditure streams between counties and cities were usually not reported. The Kentucky 'City Uniform Financial Information Report', which is the source of intergovernmental revenue and expenditure data did not provide any information on city to county revenue transfers. Thus even in cases where data on city to city revenue transfers existed, this research was still limited in the area of county to city transfers. Additionally, most of the intergovernmental transfers registered with the Department of Local Governments were joint service agreements rather than pay-for-service agreements, meaning there was more human resource and equipment transfers than fund transfers.

Second, this study was undertaken based on secondary data from only one state (Kentucky) in the entire US. Because the US is politically, economically and socially diverse, the results from this study cannot be taken in its entirety as a true reflection of the patterns of collaboration in the country. Research shows for instance that local government decisions are to a large extent influenced by state rules and regulations Krueger and Bernick 2010, 714). Since every state rule affects localities differently it stands to reason that the causal chains of collaboration at the local level in Kentucky may be different from that of Indiana for instance.

Third, the study uses data on municipalities that range from very small (230 people) to small $(61,488$ people). This selection eliminates mid-sized and large cities which are known to offer more variety of services to residents. To the extent that this 
study relies on a small sample data from only one state in the US, any generalizations from this study will have to be made with a certain degree of caution.

Finally, the study showed high percentage figures for vertical collaborations. This may be critiqued on purely methodological grounds. In my analyses every agreement that had at least one county partner was deemed vertical even if it had only one county but several cities. The study was designed based on the premise that the role of counties as administrative arms of the state gives them the upper hand in an agreement (Dustin et al., 2009). The counter argument is that in some agreements large municipalities may rather have the upper hand because of their superior management systems (Caruson \& MacManus, 2006b, 2008).

\section{Future Direction of Research}

While this study has been largely successful in explaining the patterns of interlocal collaboration, there still remains certain theoretical aspects of the concept that need further investigations and clarifications. This research can serve as a good starting point for such future investigations.

First, in terms geographic of scope, the study was restricted to one out of 50 states in the US. Moreover, the units of analyses did not include mid-sized and large cities which are known to offer more variety of services to residents. Future studies should correct this anomaly by expanding the study to include mid-size and large MSAs from other states. Enlarging the scope of the study to include cites and MSAs in all four geographic regions of the US will improve the generalizability of results. 
Second, the direction and number of partners in a collaborative arrangement should not be solely determined by a binary choice (yes or no). it is an established fact that collaborative arrangements between local governments also differ in terms of the degree of collaboration. In public safety for instance the degree of collaboration on law enforcement services between jurisdiction $\mathrm{X}$ and $\mathrm{Y}$ may be entirely different from a similar agreement between jurisdiction $\mathrm{A}$ and $\mathrm{B}$. The use of revenue and expenditure data to analyze the degree of interlocal agreement in any future research will bolster the findings of this study.

Third, the influence of transaction characteristics (asset specificity and measurement difficulty) on the pattern of collaboration was examined in this study using descriptive statistics. This method can be improved by using scalar measures of asset specificity and measurement difficulty for all services in future studies. A database of asset specificity and service measurability measures derived from a survey of local government officials across the US will improve future results.

Fourth, future research should consider exploring the spatial dynamics of vertical, horizontal, multilateral and bilateral collaboration. Although this study enhanced our understanding of the patterns of collaboration, it failed to show how such patterns self organize in space. The use of GIS to generate such interactions will improve our understanding of how collaborative governance manifests across regions.

Finally, future studies should explore the extent to which vertical, horizontal, bilateral and multilateral patterns of interlocal service delivery produce cost savings, improve service quality and enhance citizen satisfaction. Having a good understanding of 
the benefits of these four patterns of collaboration will be helpful for local government practitioners in decision making. 


\section{REFERENCES}

Adams, D. H., \& Savitch, H. (1997). Central cities and suburbs. In R. K. Vogel (Ed.), Handbook of Research on Urban Politics and Policy in the United States (pp. 170). Westport, CT: Greenwood.

Adhikari, S. (2015). Community characteristics associated with local intergovernmental cooperation. (PhD dissertation), University of Louisville, Louisville. Retrieved from http://dx.doi.org/10.18297/etd/2108 (2108)

Advisory Council on Intergovernmental Relations. (1985). Intergovernmental Service Agreements for Delivering Local Public Services: Update 1983 (A-103). Washington, DC: Government Printing Press.

Agranoff, R. (2006). Inside Collaborative Networks: Ten Lessons for Public Managers. Public Administration Review, 66(Supplement), 56-65.

Agranoff, R., \& McGuire, M. (2001). Big Questions In Public Network Management Research. Journal of Public Administration Research and Theory, 11(3), 295-326.

Agranoff, R., \& McGuire, M. (2003). Collaborative Public Management: New Strategies For Local Governments. Georgetown University Press.

Agrawal, A. ( 2000). Small Is Beautiful, But Is Larger Better? Forest Management Institutions In The Kumaon Himalaya, India. In C. Gibson, M. McKean, \& E. Ostrom (Eds.), People and Forests: Communities, Institutions, and Governance (pp. 57-86). Cambridge, MA: MIT Press. 
Agrawal, A., \& Chhatre, A. (2006). Explaining success on the commons: Community Forest Governance In The Indian Himalaya. World development, 34(1), 149-166.

Agrawal, A., \& Goyal, S. (2001). Group size and collective action third-party monitoring in common-pool resources. Comparative Political Studies, 34(1), 63-93.

Alter, C., \& Hage, J. (1993). Organizations Working Together. Newbury Park, CA: Sage Publications.

Andrew, S. A. (2005). Interlocal Agreements as an Urban Management Tool: Applicability of Network Analysis to Understanding Interlocal Cooperation. Paper presented at the Paper presented at the annual meeting of the The Midwest Political Science Association, Palmer House Hilton, Chicago, Illinois.

Andrew, S. A. (2008a). Governance by Agreements: Why do Local Governments Enter into Multilateral Agreements? Working Group on Interlocal Services $\begin{array}{llll}\text { Cooperation, } & \text { (Paper } & \text { 37). } & \text { Retrieved }\end{array}$ http://digitalcommons.wayne.edu/interlocal_coop/37 website

Andrew, S. A. (2008b). Regional Integration Through Contracting Networks: An Empirical Analysis Of Institutional Collection Action Framework. Urban Affairs Review.

Andrew, S. A. (2009). Recent Developments In The Study Of Interjurisdictional Agreements: An Overview And Assessment. State \& Local Government Review, $133-142$.

Andrew, S. A. (2010). Adaptive Versus Restrictive Contracts: Can They Resolve Different Risk Problems. In J. T. Scholz \& R. Feiock (Eds.), Self-Organizing 
Federalism: Collaborative Mechanisms to Mitigate Institutional Collective Action Dilemmas (pp. 91-113). New York: Cambridge University Press.

Andrew, S. A., \& Hawkins, C. V. (2012). Regional Cooperation And Multilateral Agreements In The Provision Of Public Safety. The American Review of Public Administration, 43(4), 460-475.

Andrew, S. A., Short, J. E., Jung, K., \& Arlikatti, S. (2015). Intergovernmental Cooperation in the Provision of Public Safety: Monitoring Mechanisms Embedded in Interlocal Agreements. Public Administration Review, 75(3), 401410.

Axelrod, R. (1984). The Evolution of Cooperation. New York, NY.: Basic Book: Inc.

Baland, J.-M., \& Platteau, J.-P. (1999). The Ambiguous Impact of Inequality on Local Resource Management. World development, 27(5), 773-788.

Bartle, J. R., \& Swayze, R. (1997). Interlocal cooperation in Nebraska. Unpublished Report Prepared for the Nebraska Mandates Management Initiative.

Bentley, A. F. (1949). The process of government. Evanston, IL: Principia Press.

Bentrup, G. (2001). Evaluation of a Collaborative Model: A Case Study Analysis of Watershed Planning in theIntermountain West. Environmental management, 27(5), 739-748.

Blomquist, W., \& Parks, R. B. (1995). Fiscal, Service, and Political Impacts of Indianapolis-Marion County's Unigov. Publius, 37-54.

Bollens, J. C., \& Schmandt, H. J. (1965). Metropolis; Its People, Politics, And Economic Life. York: Harper \& Row. 
Borgatti, S. P., Everett, M. G., \& Johnson, J. C. (2013). Analyzing Social Networks. SAGE Publications Limited.

Brierly, A. B. (2004). Issues of Scale and Transaction Costs in City-County Consolidation. In J. Carr \& R. Feiock (Eds.), City County Consolidation and its Alternatives. Armonk, NY: M. E. Sharpe.

Brown, T. L., \& Potoski, M. (2001 ). The Influence of Transaction Costs on Municipal and County Government Choices about Alternative Modes of Service Provision. Paper presented at the 6th National Public Management Research Conference. October 2001 Bloomington, Indiana

Brown, T. L., \& Potoski, M. (2003). Transaction Costs and Institutional Explanations for Government Service Production Decisions. Journal of Public Administration Research and Theory, 13(4), 441-468.

Brown, T. L., \& Potoski, M. (2005). Measuring Service Delivery Transaction Costs. Public Performance and Management Review, 28(3), 326-351.

Bryson, J. M., Crosby, B. C., \& Stone, M. M. (2006). The Design and Implementation of Cross-Sector Collaborations: Propositions from the Literature. Public Administration Review, 66(Supplement 1), 44-55.

Camerer, C., \& Knez, M. (1996). Coordination, Organizational Boundaries and Fads in Business Practices. Industrial and Corporate Change, 5(1), 89-112. doi: $10.1093 / \mathrm{icc} / 5.1 .89$

Camerer, C., \& Knez, M. (1997). Coordination In Organizations: A Game Theoretic Perspective. In Shapira (Ed.), Organizational Decision Making, (pp. 158-188). Cambridge, UK: Cambridge University Press. 
Carr, J. B., \& Feiock, R. C. (1999). Metropolitan Government And Economic Development. Urban Affairs Review, 34(3), 476-488.

Carr, J. B., \& Feiock, R. C. (2004). City-County Consolidation And Its Alternatives: Reshaping The Local Government Landscape. ME Sharpe.

Carr, J. B., Gerber, E. R., \& Lupher, E. W. (2007). Explaining Horizontal and Vertical Cooperation on Public Services in Michigan: The Role of Local Fiscal Capacity. Working Group on Interlocal Services Cooperation, Paper 34.

Carr, J. B., LeRoux, K., \& Shrestha, M. (2009). Institutional Ties, Transaction Costs, And External Service Production. Urban Affairs Review, 44(3), 403-427.

Carrington, P. J., Scott, J., \& Wasserman, S. (2005). Models And Methods In Social Network Analysis (Vol. 28). Cambridge University Press.

Caruson, K., \& MacManus, S. A. (2006a). Funding Homeland Security And Hurricane Preparedness: Florida's Local Governments Face Formidable Fiscal Pressures. Municipal Finance Journal, 27 (2), 75-93.

Caruson, K., \& MacManus, S. A. (2006b). Mandates And Management Challenges In The Trenches: An Intergovernmental Perspective On Homeland Security. Public Administration Review, 66(4), 522-536.

Caruson, K., \& MacManus, S. A. (2008). Disaster Vulnerabilities How Strong a Push Toward Regionalism and Intergovernmental Cooperation? The American Review of Public Administration, 38(3), 286-306.

Chamberlin, J. (1974). Provision Of Collective Goods As A Function Of Group Size. American Political Science Review, 68(02), 707-716. 
Chen, Y.-C., \& Thurmaier, K. (2009). Interlocal Agreements as Collaborations An Empirical Investigation of Impetuses, Norms, and Success. The American Review of Public Administration, 39(5), 536-552.

Chubb, J. E. (1985). The Political Economy Of Federalism. American Political Science Review, 79(04), 994-1015.

Cinner, J. E., MacNeil, M. A., Basurto, X., \& Gelcich, S. (2013). Looking Beyond The Fisheries Crisis: Cumulative Learning From Small-Scale Fisheries Through Diagnostic Approaches. Global Environmental Change, 23(6), 1359-1365.

Cisneros, H. (1993). Interwoven Destinies: Cities And The Nation. WW Norton \& Company.

Coase, R. H. (1937). The Nature of the Firm. Economica, 4(16), 386-405.

Coleman, J. S. (1988). Social Capital in the Creation of Human Capital. American Journal of Sociology, 94, 95-120.

Collins, S. (2006). Interlocal Service-Sharing Agreements: International City/County Management Association.

Cooper, T. L., Bryer, T. A., \& Meek, J. W. (2006). Citizen-Centered Collaborative Public Management. Public Administration Review, 66(s1), 76-88.

Dawes, R. M. (1973). The Commons Dilemma Game: An N-Person Mixed-Motive Game With A Dominating Strategy For Defection. ORI Research Bulletin, 13(2), 1-12.

Dawes, R. M., McTavish, J., \& Shaklee, H. (1977). Behavior, Communication, And Assumptions About Other People's Behavior In A Commons Dilemma Situation. Journal of personality and social psychology, 35(1), 1. 
De Nooy, W., Mrvar, A., \& Batagelj, V. (2011). Exploratory Social Network Analysis With Pajek (Vol. 27): Cambridge University Press.

Donahue, J. D., \& Zeckhauser, R. (2011). Collaborative Governance : Private Roles For Public Goals In Turbulent Times. Princeton, N.J.: Princeton University Press.

Downs, A. (1994). New Visions For Metropolitan America. Washington, D.C.; Cambridge, Mass.: Brookings Institution ; Lincoln Institute of Land Policy.

Dustin, J., Jones, D., \& Levine, M. (2009). Collaborative Local Government In The State Of Ohio. Dayton, OH: Wright State University.

Dye, T. R., Leibman, C. S., Williams, O. P., \& Herman, H. (1963). Differentiation And Cooperation In A Metropolitan Area. Midwest Journal Of Political Science, 145155.

Esteban, J. (2001). Collective Action And The Group Size Paradox. Paper presented at the American Political Science Association.

Feiock, R. C. (2004). Metropolitan Governance: Conflict, Competition, And Cooperation. Georgetown University Press.

Feiock, R. C. (2005). Institutional Collective Action and Local Goverance. Working Group on Interlocal Services Cooperation, 5.

Feiock, R. C. (2007). Rational Choice and Regional Governance. Journal of Urban Affairs, 29(1), 47-63.

Feiock, R. C. (2008). Institutional Collective Action And Local Government Collaboration. In L. B. Bingham and R. O'Leary (Eds), Big Ideas In Collaborative Public Management, 195-210. Amonk, NY: M. E Sharpe. 
Feiock, R. C. (2009). Metropolitan Governance and Institutional Collective Action. Urban Affairs Review, 44(3), 356-377.

Feiock, R. C. (2013). The Institutional Collective Action Framework. Policy Studies Journal, 41(3), 397-425.

Feiock, R. C., Carr, J. B., \& Johnson, L. S. (2006). Structuring The Debate On Consolidation: A Response To Leland And Thurmaier. Public Administration Review, 274-278.

Feiock, R. C., \& Scholz, J. T. (2010). Self-Organizing Federalism: Collaborative Mechanisms To Mitigate Institutional Collective Action Dilemmas: Cambridge University Press.

Feiock, R. C., Tao, J., \& Johnson, L. (2004). Institutional Collective Action: Social Capital And The Formation Of Regional Partnerships. In R. C. Feiock (Ed.), Metropolitan governance: Conflict, competition, and cooperation (pp. 147-158). Washington, D.C: Georgetown University Press.

Ferris, J., \& Graddy, E. (1986). Contracting Out: For What? With Whom? Public Administration Review, 332-344.

Foss, N. J. (2001). Leadership, Beliefs and Coordination: An Explorative Discussion. Industrial and Corporate Change, 10(2), 357-388. doi: 10.1093/icc/10.2.357

Foster, K. A. (1998). Municipal Cooperative Agreements In Western New York: Survey Finding. Institute for Local Governance and Regional Growth, University at Buffalo, State University of New York.

Frederickson, H. G. (1999). The repositioning of American Public Administration. Political Science \& Politics, 32(04), 701-712. 
Frederickson, H. G., Johnson, G. A., \& Wood, C. H. (2004). The Adapted City: Institutional Dynamics And Structural Change. ME Sharpe.

Friesema, H. P. (1971). Metropolitan Political Structure: Intergovernmental Relations And Political Integration In The Quad-Cities. University of Iowa Press.

Frohlich, N., \& Oppenheimer, J. A. (1970). I Get By With A Little Help From My Friends. World Politics, 23(01), 104-120.

Frug, G. E. (2002). Beyond Regional Government. Harvard Law Review, 1763-1836.

Gautam, A. P. (2007). Group Size, Heterogeneity And Collective Action Outcomes: Evidence From Community Forestry In Nepal. International Journal of Sustainable Development \& World Ecology, 14(6), 574-583.

Gerber, E. R., \& Gibson, C. C. (2005). Cooperative Municipal Service Provision: A Political-Economy Framework for Understanding Intergovernmental Cooperation. Working Group on Interlocal Services Cooperation(11).

Gerlak, A. K., \& Heikkila, T. (2006). Comparing Collaborative Mechanisms In LargeScale Ecosystem Governance. Natural Resources Journal, 46, 657.

Gerlak, A. K., Lubell, M., \& Heikkila, T. (2013). The Promise And Performance Of Collaborative Governance. In S. Kamieniecki \& M. E. Kraft (Eds.), The Oxford Handbook of US Environmental Policy (pp. 413). New York: Oxford University Press.

Geyskens, I., Steenkamp, J.-B. E., \& Kumar, N. (2006). Make, Buy, Or Ally: A Transaction Cost Theory Meta-Analysis. Academy of Management Journal, 49(3), 519-543.

Gillette, C. P. (2001). Regionalization and interlocal bargains. NYUL rev., 76, 190. 
Gillette, C. P. (2005). Conditions of Interlocal Cooperation, The. JL \& Pol., 21, 365.

Goldsmith, S., \& Eggers, W. D. (2004). Governing by network: The new shape of the public sector: Brookings Institution Press.

Granovetter, M. (1985). Economic Action and Social Structure: The Problem of Embeddedness. American Journal of Sociology, 91(3).

Grujić, J., Eke, B., Cabrales, A., Cuesta, J. A., \& Sánchez, A. (2012). Three Is A Crowd In Iterated Prisoner's Dilemmas: Experimental Evidence On Reciprocal Behavior. Scientific Reports, 2.

Gulati, R., \& Gargiulo, M. (1999). Where do Interorganizational Networks Come From? American Journal of Sociology, 104(5).

Gulati, R., Lawrence, P. R., \& Puranam, P. (2005). Adaptation In Vertical Relationships: Beyond Incentive Conflict. Strategic Management Journal, 26(5), 415-440. doi: $10.1002 / \mathrm{smj} .458$

Haan, M., \& Kooreman, P. (2002). Free Riding And The Provision Of Candy Bars. Journal Of Public Economics, 83(2), 277-291.

Haddow, G., Bullock, J., \& Coppola, D. P. (2013). Introduction To Emergency Management (3rd ed.). Boston: Butterworth-Heinemann.

Hanneman, R. A. \& Riddle M. (2005). Introduction to Social Network Methods. Riverside, CA: University of California, Riverside.

Hardin, R. (1982). Collective Action Johns Hopkins University Press. Baltimore, MD.

Hawkins, C. V. (2009). Prospects For And Barriers To Local Government Joint Ventures. State \& Local Government Review, 108-119. 
Hawkins, C. V., \& Andrew, S. A. (2011). Understanding Horizontal And Vertical Relations In The Context Of Economic Development Joint Venture Agreements. Urban Affairs Review, 1078087410396300.

Healey, P. (2003). Collaborative Planning In Perspective. Planning theory, 2(2), 101-123.

Heath, C., \& Staudenmayer, N. (2000). Coordination Neglect: How Lay Theories Of Organizing Complicate Coordination In Organizations. In N. Staudenmayer (Ed.), Research in Organizational Behavior

(Vol. 22, pp. 153-191). Greenwich, CT: JAI Press.

Heikkila, T., \& Gerlak, A. K. (2005). The Formation of Large-scale Collaborative Resource Management Institutions: Clarifying the Roles of Stakeholders, Science, and Institutions. Policy Studies Journal, 33(4), 583-612.

Hill, E. W., Wolman, H. L., \& Ford, C. C. (1995). Can Suburbs Survive Without Their Central Cities? Examining The Suburban Dependence Hypothesis. Urban Affairs Review, 31(2), 147-174.

Howell-Moroney, M. (2008). The Tiebout hypothesis 50 years later: Lessons And Lingering Challenges For Metropolitan Governance In The 21st Century. Public Administration Review, 68(1), 97-109.

ICMA. (1997). Local Intergovernmental Agreements: Strategies for Cooperation. Management Information Service, 29(7), 1-11.

Innes, J. E., \& Booher, D. E. (1999). Consensus Building And Complex Adaptive Systems: A Framework For Evaluating Collaborative Planning. Journal Of The American Planning Association, 65(4), 412-423. 
Isaac, R. M., Walker, J. M., \& Williams, A. W. (1994). Group Size And The Voluntary Provision Of Public Goods: Experimental Evidence Utilizing Large Groups. Journal Of Public Economics, 54(1), 1-36.

Joassart-Marcelli, P., \& Musso, J. (2005). Municipal Service Provision Choices Within A Metropolitan Area. Urban Affairs Review, 40(4), 492-519.

Julnes, G., \& Pindur, W. (1994). Determinants of Local Governmental Support for Alternative Forms of Regional Coordination. The American Review of Public Administration, 24(4), 411-428.

Kadushin, C. (2012). Understanding Social Networks: Theories, Concepts, And Findings. Oxford University Press.

Kelly, J. M., \& Adhikari, S. (2013). Indicators of Financial Condition in Pre-And Post-Merger Louisville. Journal of Urban Affairs, 35(5), 553-567.

Kentucky League of Cities. (2012). The Basics of Kentucky Cities. Lexington, KY: Kentucky League of Cities.

Kenyon, D. A., \& Kincaid, J. (1991). Competition among States and Local Governments. Efficiency and Equity in American Federalism Washington DC: The Urban Institute Press.

Kettl, D. F. (2000). The Global Public Management Revolution: A Report on the Transformation of Governance Washington, DC: Brookings Institution.

Kettl, D. F. (2013). System under stress: Homeland Security and American politics (3rd ed.). Washington, DC: CQ Press. 
Komorita, S. S., \& Lapworth, C. W. (1982). Cooperative Choice Among Individuals Versus Groups In An N-Person Dilemma Situation. Journal Of Personality And Social Psychology, 42(3), 487.

Krueger, S., \& Bernick, E. M. (2010). State Rules And Local Governance Choices. Publius: The Journal of Federalism, 40(4), 697-718.

Krueger, S., \& McGuire, M. (2005). A Transaction Costs Explanation Of Interlocal Government Collaboration. Working Group on Interlocal Services Cooperation, 21.

Kwon, S.-W., \& Feiock, R. C. (2010). Overcoming the Barriers to Cooperation: Intergovernmental Service Agreements. Public Administration Review, 70(6), 876-884.

Lackey, S. B., Freshwater, D., \& Rupasingha, A. (2002). Factors Influencing Local Government Cooperation In Rural Areas: Evidence from the Tennessee Valley. Economic Development Quarterly, 16(2), 138-154.

Lazarsfeld, P. F., \& Merton, R. K. (1954). Friendship As A Social Process: A Substantive And Methodological Analysis. In M. Berger, T. F. Abel, \& C. H. Page (Eds.), Freedom And Control In Modern Society. New York: Van Nostrand.

Leach, W. D. (2006). Collaborative Public Management And Democracy: Evidence From Western Watershed Partnerships. Public Administration Review, 66(s1), 100-110.

Ledebur, L. C., \& Barnes, W. R. (1992). Metropolitan Disparities and Economic Growth: City Distress and the Need for a Federal Growth Package. Washington, DC: National League of Cities. 
Ledebur, L. C., \& Barnes, W. R. (1993). All In It Together: Cities, Suburbs And Local Economic Regions. Washington, DC: National League of Cities.

Leroux, K. (2006). The Role Of Structure, Function, And Networks In Explaining Interlocal Service Delivery: A Study Of Institutional Cooperation In Michigan. Wayne State University, Detroit, Michigan.

LeRoux, K., Brandenburger, P. W., \& Pandey, S. K. (2010). Interlocal Service Cooperation in U.S. Cities: A Social Network Explanation. Public Administration Review, 70(2), 268-278.

LeRoux, K., \& Carr, J. B. (2007). Explaining Local Government Cooperation On Public Works Evidence From Michigan. Public Works Management \& Policy, 12(1), 344-358.

Liesbet, H., \& Gary, M. (2003). Unraveling The Central State, But How? Types Of Multi-Level Governance. American Political Science Review, 97(02), 233-243.

Lowery, D. (2000). A Transactions Costs Model Of Metropolitan Governance: Allocation Versus Redistribution In Urban America. Journal of Public Administration Research and Theory, 10(1), 49-78.

Lynn, P. (2005). Mutual Aid: Multijurisdictional Partnerships For Meeting Regional Threats. US Department of Justice, Office of Justice Programs, Bureau of Justice Assistance Washington, DC.

MacManus, S. A., \& Caruson, K. (2008). Financing Homeland Security and Emergency Preparedness: Use of Interlocal Cost-Sharing. Public Budgeting \& Finance, 28(2), $48-68$. 
Mandell, M., \& Keast, R. (2007). Evaluating Network Arrangements: Toward Revised Performance Measures. Public Performance \& Management Review, 30(4), 574597.

Marwell, G., \& Oliver, P. (1993). The Critical Mass In Collective Action. Cambridge University Press.

Masel, J. (2007). A Bayesian Model Of Quasi-Magical Thinking Can Explain Observed Cooperation In The Public Good Game. Journal of Economic Behavior \& Organization, 64(2), 216-231.

Maxey, C. C. (1922). The Political Integration of Metropolitan Communities. National Municipal Review, 11(8), 229-254.

McEntire, D. A., \& Dawson, G. (2007). The Intergovernmental Context. In W. L. Waugh Jr \& K. Tierney (Eds.), In Emergency Management: Principles And Practice For Local Government (2nd ed., pp. 57-70). Washington, DC: ICMA Press.

McGinnis, M. D., \& Ostrom, E. (2012). Reflections on Vincent Ostrom, Public Administration, And Polycentricity. Public Administration Review, 72(1), 15-25.

McGuire, M. (1974). Group Size, Group Homo-Geneity, And The Aggregate Provision Of A Pure Public Good Under Cournot Behavior. Public Choice, 18(1), 107-126.

McGuire, M. (2006). Collaborative Public Management: Assessing What We Know And How We Know It. Public Administration Review, 66(s1), 33-43.

Milgrom, P., \& Roberts, J. (1992). Economics, Organization And Management. Englewood Cliffs Prentice Hall. 
Mohr, R., Deller, S. C., \& Halstead, J. M. (2010). Alternative Methods of Service Delivery in Small and Rural Municipalities. Public Administration Review, 70(6), 894-905.

Morgan, D. R., \& Hirlinger, M. W. (1991). Intergovernmental service contracts a multivariate explanation. Urban Affairs Review, 27(1), 128-144.

Morton, L. W., Chen, Y. C., \& Morse, R. S. (2008). Small Town Civic Structure And Interlocal Collaboration For Public Services. City \& Community, 7(1), 45-60.

Nelson, M. A. (1997). Municipal Government Approaches To Service Delivery: An Analysis From A Transactions Cost Perspective. Economic Inquiry, 35, 82-96.

Newman, M. (2010). Networks: An Introduction: Oxford University Press.

Nicholson-Crotty, S. (2004). Goal Conflict And Fund Diversion In Federal Grants To The States. American Journal of Political Science, 48(1), 110-122.

Nicholson, W. C. (2007). Legal Issues In Emergency Management: Principles And Practice For Local Government. In W. Waugh \& K. Tierney (Eds.), Emergency management: Principles And Practice For Local Government (2nd ed.). Washington, DC: ICMA Press.

Nosenzo, D., Quercia, S., \& Sefton, M. (2013). Cooperation In Small Groups: The Effect Of Group Size. Experimental Economics, 18(1), 4-14.

Nunn, S., \& Rosentraub, M. S. (1997). Dimensions Of Interjurisdictional Cooperation. Journal Of The American Planning Association, 63(2), 205-219.

O'Leary, R., Gerard, C., \& Bingham, L. B. (2006). Introduction to the Symposium on Collaborative Public Management. Public Administration Review, 66, 6-9. 
O'Toole, L. J. (1997). Treating Networks Seriously: Practical And Research-Based Agendas In Public Administration. Public Administration Review, 57(1).

O’Leary, R., Gazley, B., McGuire, M., \& Bingham, L. B. (2009). Public Managers in Collaboration. In R. O'Leary \& L. Bingham (Eds.), The Collaborative Public Manager: New Ideas for the Twenty-First Century. Washington, D.C: Georgetown University Press.

Oakerson, R. J. (2004). The Study of Metropolitan Governance. In R. C. Feiock (Ed.), Metropolitan Governance: Conflict, Competition, And Cooperation. Washington, D.C: Georgetown University Press.

Olberding, J. C. (2002). Does Regionalism Beget Regionalism? The Relationship between Norms and Regional Partnerships for Economic Development. Public Administration Review, 62(4), 480-491.

Oliver, P. E., \& Marwell, G. (1988). The Paradox of Group Size in Collective Action: A Theory of the Critical Mass. II. American Sociological Review, 1-8.

Olson, M. (1965). The Logic Of Collective Action: Public Goods And The Theory Of Groups. Cambridge, MA: Harvard University Press.

Ostrom, E. (1990). Governing The Commons: The Evolution Of Institutions For Collective Action. Cambridge: Cambridge University Press.

Ostrom, E. (2001). Social Dilemmas And Human Behavior. In R. Noe, J. Van Hooff, \& P. Hammerstein (Eds.), Economics in Nature: Social Dilemmas, Mate Choice and Biological Markets. Cambridge: Cambridge University Press.

Ostrom, E. (2005). Understanding Institutional Diversity. Princeton, NJ: Princeton University Press. 
Ostrom, E. (2010). Analyzing collective action. Agricultural Economics, 41(s1), 155-166.

Ostrom, V., Tiebout, C. M., \& Warren, R. (1961). The organization of government in metropolitan areas: a theoretical inquiry. American Political Science Review, $55(04), 831-842$.

Parks, R. B., \& Oakerson, R. J. (1989). Metropolitan Organization and Governance A Local Public Economy Approach. Urban Affairs Review, 25(1), 18-29.

Parks, R. B., \& Oakerson, R. J. (2000). Regionalism, Localism, And Metropolitan Governance: Suggestions From The Research Program On Local Public Economies. State \& Local Government Review, 169-179.

Pecorino, P. (1999). The Effect Of Group Size On Public Good Provision In A Repeated Game Setting. Journal Of Public Economics, 72(1), 121-134.

Pecorino, P., \& Temimi, A. (2008). The Group Size Paradox Revisited. Journal of Public Economic Theory, 10(5), 785-799.

Peirce, N. R. (1993). Citistates: How Urban America Can Prosper In A Competitive World. Seven Locks Press.

Poppo, L., \& Zenger, T. (2002). Do Formal Contracts And Relational Governance Function As Substitutes Or Complements? Strategic Management Journal, 23(8), 707-725.

Post, S. (2002). Local Government Cooperation: The Relationship Between Metropolitan Area Government Geography And Service Provision. Paper presented at the Annual Meeting of American Political Science Association, Boston, Massachusetts. 
Post, S. (2004). Metropolitan Area Governance And Institutional Collective Action. In R. C. Feiock (Ed.), Metropolitan Governance: Conflict, Competition, And Cooperation (pp. 67-92). Washington, DC: Georgetown University Press.

Poteete, A. R., \& Ostrom, E. (2004). Heterogeneity, Group Size And Collective Action: The Role Of Institutions In Forest Management. Development And Change, 35(3), 435-461.

Provan, K. G., \& Milward, H. B. (2001). Do Networks Really Work? A Framework For Evaluating Public-Sector Organizational Networks. Public Administration Review, 61(4), 414-423.

Rawlings, L. A. (2003). The Determinants of Cooperation Among Local Governments in Metropolitan Areas. (PhD Dissertation), George Washington University.

Razor, S. (2011). Interlocal Introspection: Governments Use Collaborative Efforts To Maintain Services During Tough Times. Collaboration, 26-27. Retrieved from: http://www.klc.org/UserFiles/Interlocal_Introspection_My-Je-11.pdf

Reed, T. H. (1949). Progress in Metropolitan Integration. Public Administration Review, 9(1), 1-10. doi: 10.2307/972657

Reynolds, L. (2003). Intergovernmental Cooperation, Metropolitan Equity, And The New Regionalism. Washington Law Review, 78, 93.

Roberts, P. S. (2008). Dispersed Federalism As A New Regional Governance For Homeland Security. Publius: The Journal of Federalism, 38(3), 416-443.

Robins, G. (2015). Doing Social Network Research: Network-based Research Design for Social Scientists: Sage. 
Rosentraub, M. S. (2000). City-County Consolidation And The Rebuilding Of Image: The Fiscal Lessons From Indianapolis's Unigov Program. State \& Local Government Review, 180-191.

Rothenberg, J. (1970). Local Decentralization And The Theory Of Optimal Government. In The Analysis Of Public Output (pp. 31-68): NBER.

Ruhil, A. V., Schneider, M., Teske, P., \& Ji, B.-M. (1999). Institutions and Reform Reinventing Local Government. Urban Affairs Review, 34(3), 433-455.

Rusk, D. (2003). Cities Without Suburbs: A Census 2000 Update (3rd ed.). Washington, D.C.: Woodrow Wilson Center Press

Rusk, D. (2013). Cities Without Suburbs. Washington, D.C.: Woodrow Wilson Center Press.

Rustagi, D., Engel, S., \& Kosfeld, M. (2010). Conditional Cooperation And Costly Monitoring Explain Success In Forest Commons Management. Science, 330(6006), 961-965.

Salamon, L. M. (2002). The Tools Of Government: A Guide To The New Governance. Oxford University Press.

Sandler, T. (1992). Collective action: Theory and applications (Vol. 4). Ann Arbor, MI: University of Michigan Press.

Savitch, H. V., \& Collins, D. (1992). The Paradox Of Diversity: Social Difference Amid Common Regions. National Civic Review, 81(3), 326-334.

Savitch, H. V., Collins, D., Sanders, D., \& Markham, J. P. (1993). Ties That Bind: Central Cities, Suburbs, And The New Metropolitan Region. Economic Development Quarterly, 7(4), 341-357. 
Savitch, H. V., \& Vogel, R. K. (1996). Regional Patterns In A Postcity Age. Urban Affairs Annual Reviews, 45, 1-22.

Savitch, H. V., \& Vogel, R. K. (2000). Introduction: Paths To New Regionalism. State \& Local Government Review, 158-168.

Savitch, H. V., Vogel, R. K., \& Ye, L. (2009). Beyond The Rhetoric: Lessons From Louisville's Consolidation. The American Review of Public Administration.

Schneider, M., Scholz, J., Lubell, M., Mindruta, D., \& Edwardsen, M. (2003). Building Consensual Institutions: Networks And The National Estuary Program. American Journal of Political Science, 47(1), 143-158.

Schneider, M., Teske, P., \& Mintrom, M. (1995). Public Entrepreneurs: Agents for Change in American Government. Princeton: Princeton University Press.

Scholz, J. T., \& Wang, C. L. (2006). Cooptation Or Transformation? Local Policy Networks And Federal Regulatory Enforcement. American Journal of Political Science, 50(1), 81-97.

Scorsone, E. A. (2006). The Distributional Consequences Of Interlocal Agreement Cost Allocation Strategies. From Working Group On Interlocal Services Cooperation http://digitalcommons.wayne.edu/interlocal_coop/37

Scott, J. (2012). Social Network Analysis: SAGE Publications.

Scott, J., \& Carrington, P. J. (2011). The SAGE Handbook Of Social Network Analysis: SAGE Publications.

Selin, S., \& Chevez, D. (1995). Developing A Collaborative Model For Environmental Planning And Management. Environmental Management, 19(2), 189-195. 
Shrestha, M. (2005). Characteristics of Service, Structure of Networks, and Forms of Inter-Local Cooperation in Local Service Production: Evidence from Florida. Working Group on Interlocal Services Cooperation, 10.

Shrestha, M. (2008). Decentralized Governments, Networks And Interlocal Cooperation in Public Goods Supply. (Doctor of Philosophy Dissertation), Florida State University, Florida.

Shrestha, M. (2010). Do risk profiles of services alter contractual patterns? A comparison across multiple metropolitan services. In R. C. Feiock \& J. Scholz (Eds.), SelfOrganizing Federalism: Collaborative Mechanisms to Mitigate Institutional Collective Action Dilemmas (pp. 114-141). New York: Cambridge University Press.

Shrestha, M., \& Feiock, R. C. (2009). Governing US Metropolitan Areas Self-Organizing and Multiplex Service Networks. American Politics Research, 37(5), 801-823.

Simo, G., \& Bies, A. L. (2007). The Role Of Nonprofits In Disaster Response: An Expanded Model Of Cross-Sector Collaboration. Public Administration Review, 67(s1), 125-142.

Simon, H. A. (1945). Administrative Behavior (Vol. 3). Cambridge Univ Press.

Sonenblum, S., Kirlin, J. J., \& Ries, J. C. (1977). How Cities Provide Services: An Evaluation Of Alternative Delivery Structures. Cambridge, MA: Ballinger Publishing Company.

Stein, R. M. (1990). The Budgetary Effects Of Municipal Service Contracting: A Principal-Agent Explanation. American Journal of Political Science, 471-502. 
Stephens, G. R., \& Wikstrom, N. (2000). Metropolitan Government And Governance: Theoretical Perspectives, Empirical Analysis, And The Future: Oxford University Press on Demand.

Stoker, G. (2006). Public Value Management A New Narrative For Networked Governance? The American Review of Public Administration, 36(1), 41-57.

Swanstrom, T. (1996). Ideas Matter: Reflections On The New Regionalism. Cityscape, 521.

Szolnoki, A., \& Perc, M. (2011). Group-Size Effects On The Evolution Of Cooperation In The Spatial Public Goods Game. Physical Review E, 84(4), 047102.

Tang, S. Y., \& Mazmanian, D. A. (2010). Understanding Collaborative Governance from the Structural Choice-Politics, IAD, and Transaction Cost Perspectives (March 1, 2010). Available at SSRN: http://ssrn.com/abstract=1516851 or $10.2139 / \mathrm{ssrn} .1516851$

Taylor, G. D., \& Bassett, E. M. (2007). Exploring Boundaries In Governance: Intergovernmental Boundary Agreements. State \& Local Government Review, 119-130.

Tewdwr-Jones, M., \& Allmendinger, P. (1998). Deconstructing Communicative Rationality: A Critique Of Habermasian Collaborative Planning. Environment and planning A, 30(11), 1975-1989.

Thurmaier, K. (2005). Elements of successful interlocal agreements: An Iowa case study. Working Group on Interlocal Services Cooperation, 2. 
Thurmaier, K., \& Wood, C. (2002). Interlocal Agreements As Overlapping Social Networks: Picket-Fence Regionalism In Metropolitan Kansas City. Public Administration Review, 62(5), 585-598.

Uzzi, B. (1996). The Sources And Consequences Of Embeddedness For The Economic Performance Of Organizations: The Network Effect. American Sociological Review, 674-698.

Valente, T. W. (2010). Social Networks And Health: Models, Methods, And Applications. Oxford University Press.

Vilone, D., Giardini, F., \& Paolucci, M. (2014). Partner Selection Supports ReputationBased Cooperation In A Public Goods Game. Available at SSRN 2515292.

Voith, R. (1998). Do suburbs need cities? Journal of Regional Science, 38(3), 445-464.

Volden, C. (2007). Intergovernmental Grants: A Formal Model Of Interrelated National And Subnational Political Decisions. Publius: The Journal of Federalism, 37(2), 209-243.

Wasserman, S., \& Faust, K. (1994). Social Network Analysis: Methods And Applications (Vol. 8). Cambridge University Press.

Weber, E. P., Lovrich, N. P., \& Gaffney, M. (2005). Collaboration, Enforcement, And Endangered Species: A Framework For Assessing Collaborative Problem-Solving Capacity. Society And Natural Resources, 18(8), 677-698.

Wikstrom, N. (2002). The City In The Regional Mosaic. Paper presented at the The Future Of Local Government Administration: The Hansell symposium.

Williams, O. P. (1971). Metropolitan Political Analysis: A Social Access Approach. Free Press. 
Williamson, O. E. (1971). The Vertical Integration Of Production: Market Failure Considerations. The American Economic Review, 112-123.

Williamson, O. E. (1975). Markets And Hierarchies. New York, 26-30.

Williamson, O. E. (1985). The Economic Institutions Of Capitalism: Firms, Markets, Relational Contracting. New York: London: Free Press;Collier Macmillan.

Williamson, O. E. (1991). Comparative economic organization: The analysis of discrete structural alternatives. Administrative science quarterly, 269-296.

Williamson, O. E. (1996). The Mechanisms Of Governance. Oxford University Press.

Williamson, O. E. (2002). The Theory of the Firm as Governance Structure: From Choice to Contract. The Journal of Economic Perspectives, 16(3), 171-195. doi: $10.2307 / 3216956$

Williamson, O. E. (2010). Transaction Cost Economics: The Natural Progression. Journal of Retailing, 86(3), 215-226.

Wood, C. (2004). Metropolitan Governance in Urban America: A Study of the Kansas City Region. (Dissertation), University of Kansas.

Wood, C. (2006). Scope and Patterns of Metropolitan Governance in Urban America Probing the Complexities in the Kansas City Region. The American Review of Public Administration, 36(3), 337-353.

Wood, C. (2008). The nature of metropolitan governance in urban America: a study of cooperation and conflict in the Kansas City Region. Administration \& Society.

Wukich, C. (2014). Professional Capital: Standards of Performance That Underlie Interlocal Cooperation. Public Administration Quarterly, 38(4), 573. 
Yang, W., Liu, W., Viña, A., Tuanmu, M.-N., He, G., Dietz, T., \& Liu, J. (2013). Nonlinear Effects Of Group Size On Collective Action And Resource Outcomes. Proceedings of the National Academy of Sciences, 110(27), 10916-10921.

Zaheer, A., \& Venkatraman, N. (1995). Relational Governance As An Interorganizational Strategy: An Empirical Test Of The Role Of Trust In Economic Exchange. Strategic Management Journal, 16(5), 373-392.

Zeemering, E. S. (2007). Who Collaborates? Local Decisions about Intergovernmental Relations. (Ph.D Dissertation), Indiana University.

Zeemering, E. S. (2008a). Governing Interlocal Cooperation: City Council Interests And The Implications For Public Management. Public Administration Review, 68(4), 731-741.

Zeemering, E. S. (2008b). Negotiation And Noncooperation: Debating Michigan's Conditional Land Transfer Agreement. State \& Local Government Review, 1-11.

Zimmerman, J. F. (1973). Meeting Service Needs Through Integovernmental Agreements. In Municipal Yearbook (pp. 79-88). Washington D.C: International City Management Association. 
APPENDIX 1:

Municipal Service Classification by Asset Specificity and Service Measurability

\begin{tabular}{|c|c|c|}
\hline & Low Asset Specificity & High Asset Specificity \\
\hline $\begin{array}{l}\text { Easy } \\
\text { Metering }\end{array}$ & $\begin{array}{l}\text { Meterable Market Services } \\
\text { Residential Solid Waste } \\
\text { Commercial Solid Waste } \\
\text { Solid Waste Disposal } \\
\text { Street Repair } \\
\text { Street/Parking Lot Clearing } \\
\text { Snow Plowing/Sanding } \\
\text { Traffic Signs } \\
\text { Tree Trimming } \\
\text { Cemetery Maintenance and } \\
\text { Operation } \\
\text { Parking Lot Operation } \\
\text { Utility Meter Reading } \\
\text { Utility Meter Billing } \\
\text { Hazardous Materials Disposal } \\
\text { Vehicle Towing } \\
\text { Convention Center Operation } \\
\text { Building/Grounds Maintenance } \\
\text { Vehicle Maintenance } \\
\text { Payroll } \\
\text { Secretarial Services } \\
\text { Personnel Services } \\
\text { Daycare Facilities } \\
\text { Park Landscaping } \\
\text { Data Processing }\end{array}$ & $\begin{array}{l}\text { Meterable Monopoly Services } \\
\text { Operation of Bus System } \\
\text { Operation of Paratransit System } \\
\text { Operation of Airports } \\
\text { Water Distribution } \\
\text { Water Treatment } \\
\text { Sewage Collection and Treatment } \\
\text { Disposal of Sludge } \\
\text { Electricity } \\
\text { Gas } \\
\text { Hospital Management } \\
\text { Operation of Libraries } \\
\text { Operation of Museums } \\
\text { Heavy Equipment Maintenance } \\
\text { Emergency Vehicle Maintenance } \\
\text { Tax Collection } \\
\text { Title/Plat Maintenance } \\
\text { Parking Meter Maintenance } \\
\text { Police and Fire Communications }\end{array}$ \\
\hline $\begin{array}{l}\text { Difficult } \\
\text { Metering }\end{array}$ & $\begin{array}{l}\text { Non-Meterable Market Services } \\
\text { Child Welfare } \\
\text { Programs for the Elderly } \\
\text { Drug Treatment } \\
\text { Homeless Shelters } \\
\text { Recreation Facilities } \\
\text { Building Security } \\
\text { Insect and Rodent Control } \\
\text { Animal Control } \\
\text { Animal Shelters } \\
\text { Public Health Programs } \\
\text { Mental Health Programs } \\
\text { Legal Services } \\
\text { Public Relations } \\
\text { Tax Assessment } \\
\text { Emergency Medical Services } \\
\text { Ambulance Services }\end{array}$ & $\begin{array}{l}\text { Non-Meterable Monopolistic } \\
\text { Services } \\
\text { Crime Prevention } \\
\text { Fire Prevention } \\
\text { Traffic Control } \\
\text { Sanitary Inspection } \\
\text { Inspection and Code Enforcement } \\
\text { Prisons and Jails }\end{array}$ \\
\hline
\end{tabular}

Brown and Potoski (2001. Pg. 31; 2003) 


\title{
CURRICULUM VITA
}

\author{
Charles Wharton Kaye-Essien \\ School of Urban and Public Affairs, \\ University of Louisville \\ kayewath@gmail.com
}

\section{RESEARCH INTERESTS}

- Local governance

- Collaborative public management

- Chaos and Adaptation in Public Organizations

- Organizational Behavior

- Program Evaluation

- Community development

- Environmental \& Social Impact Assessment

\section{EDUCATION AND TRAINING}

$\mathrm{PhD}$. Urban and Public Affairs

University of Louisville, Kentucky, USA

$20013-2016$

Master of Public Administration (MPA)

University of Western Cape, Cape Town, South Africa 
$2008-2010$

Master of Arts in Development Management

Ruhr University of Bochum, Germany

$2008-2009$

Bachelor of Science Urban Planning

Kwame Nkrumah University of Science \& Technology, Kumasi, Ghana

$2001-2005$

\section{PROFESSIONAL EXPERIENCE}

- Graduate Research Assistant; University of Louisville., Louisville, Kentucky (2013 2016)

- Director of Social \& Environmental Research; Emellord Associates, Accra Ghana (2010 - J2013)

- Project Manager; Emmellord Associates, Accra, Ghana (2007 -2008)

- Teaching Assistant; Department of Planning, Kwame Nkrumah University of Science and Technology, Kumasi, Ghana (2005 -2006)

\section{PUBLICATIONS AND CONFERENCE PAPERS}

1. Kaye-Essien, Charles W. (April 2015). "Small fishes big ocean: how manufactured housing non-profits impact public policy". Paper presented at the Urban Affairs Association Conference, Miami, Florida

2. Savitch, H.V. Doddy Iskandar \& Charles Kaye-Essien. Marseille: France's great port city comes back from the brink. In Wagner, Fritz W. \& Riad G. Mahayni (eds.). 2015. Transforming Distressed Global Communities into More Healthy and Humane Places: An international perspective. London, UK: Ashgate Press.

3. Kaye-Essien, Charles W. (November 2014). Neil Kraus 2013: Majoritarian Cities: Policy Making and Inequality in Urban Politics. Ann Arbor, MI: University of 
Michigan Press. International Journal of Urban and Regional Research. Volume 38, Issue 6, Pages: 2332-2334,

4. Kaye-Essien C.W (2012). Beneficiary Participation in Community Development Projects: The Challenges and Implications for Project Management. LAP LAMBERT Academic Publishing, Germany

5. Kaye-Essien C.W (2012). The Impact of Microfinance on the Profitability of Microenterprises: Experience from Microenterprises in Ghana. LAP LAMBERT Academic Publishing, Germany

\section{ACADEMIC AWARDS AND HONORS}

- Dean's Citation, April 2016

- Graduate Teaching Academy, April 2016

- Diversity Academic Excellence Award, April 2016

- Graduate Research Assistantship, University of Louisville, 2013

- German Academic Exchange Scholar (DAAD), 2008

Language Skills: $\quad$ English, French

Other Relevant Skills: Geographic Information Systems (GIS)

Statistical Program for the Social Sciences (SPSS) 